\title{
Implementación y uso clínico de la radioterapia adaptativa. Informe del grupo de trabajo de radioterapia adaptativa de la Sociedad Española de Física Médica (SEFM)
}

\section{Implementation and clinical use of adaptive radiotherapy. Report of the working group on adaptive radiotherapy of the Spanish Society of Medical Physics (SEFM)}

\author{
Rafael García-Mollá ${ }^{1}$, Patricia Sánchez Rubio² ${ }^{2}$ Jorge Bonaque Alandî ${ }^{3}$, \\ María Auxiliadora Carrasco Herrera ${ }^{4}$, Françoise Lliso Valverde ${ }^{5}$ \\ 1 Servicio de Radiofísica y Protección Radiológica. Consorcio Hospital General Universitario de Valencia, Valencia. \\ 2 Servicio de Radiofísica y Protección Radiológica. Hospital Universitario Puerta de Hierro Majadahonda, Madrid. \\ 3 Servicio de Radiofísica y Protección Radiológica. Consorcio Hospitalario Provincial de Castellón, Castellón. \\ 4 Servicio de Radiofísica y Protección Radiológica. Complejo Hospitalario Virgen del Rocío, Sevilla. \\ 5 Unidad de Radiofísica en Radioterapia. Hospital Universitari i Politécnic La Fe, Valencia. Unidad Mixta de Investigación en \\ Radiofísica e Instrumentación Nuclear en Medicina (IRIMED). IIS Hospital La Fe - Universitat de Valencia.
}

Fecha de Recepción: 02/12/2020 - Fecha de Aceptación: 28/01/2021

La radioterapia adaptativa (Adaptive Radiation Therapy, ART) se puede definir como la modificación del plan de tratamiento administrado a un paciente durante el curso de la radioterapia para tener en cuenta los cambios en la anatomía.

La aplicación de ART supone un cambio en el proceso radioterápico que implica el uso de numerosos recursos adicionales, no estando implementada de forma general. Así, aun tratándose de una idea introducida hace más de 20 años, todavía a fecha de hoy son objeto de estudio muchos de los aspectos que definen la ART: la decisión de proceder a la nueva planificación del tratamiento, el momento óptimo para adaptar el plan, el umbral dosimétrico o anatómico que define la necesidad de adaptar y la identificación de los pacientes que realmente se beneficiarían de la adaptación del tratamiento.

Este informe del Grupo de Trabajo sobre ART de la Sociedad Española de Física Médica (SEFM) tiene como objetivo describir los principios de esta técnica, así como los elementos necesarios para su implementación.

Se exponen las dos estrategias principales atendiendo al momento de su aplicación: offline, para actuar ante los cambios progresivos que se observan durante el tratamiento, y online, para mitigar los cambios aleatorios.

Se revisa el estado actual de ART aplicado a la práctica clínica para diferentes localizaciones anatómicas.

Se describen algunos de los instrumentos clave para su implementación: los algoritmos de registro deformable (Deformable Image Registration, DIR), exponiendo las principales métricas de similitud, los métodos de optimización de la similitud, y los modelos de deformación utilizados, analizando las características de los algoritmos de los softwares más utilizados.

Además, dada la importancia que tiene conocer la incertidumbre adicional que introduce el uso de los algoritmos DIR (sobre todo cuando se utilizan para deformar la matriz de dosis absorbida) se dedica un apartado a la validación de estos algoritmos, incluyendo los resultados para los principales softwares comerciales disponibles actualmente.

Por último, se presentan unas recomendaciones a la hora de aplicar ART en la práctica clínica.

Palabras clave: ART, radioterapia adaptativa offline y online, DIR, control calidad de algoritmos de registro deformable.

\footnotetext{
*Correspondencia: garcia_rafmol@gva.es

https://doi.org/10.37004/sefm/2021.22.1.004
} 
Adaptive Radiation Radiotherapy (ART) can be defined as the radiotherapy technique where the delivered absorbed dose is monitored during the treatment for clinical acceptability and modified, if necessary.

ART application represents a change in the radiotherapy process that implies the use of numerous additional resources, and its implementation has not yet been widely incorporated. Thus, even though the idea was introduced more than 20 years ago, to this day many of the aspects that define ART are still being studied: the action levels to proceed with the new treatment planning, the optimal time to adapt the treatment plan, the anatomical or dosimetric threshold that defines the need to adapt, the identification of the patients who would really benefit from the adaptation of the treatment, etc.

This report of the ART Working Group of the Spanish Society of Medical Physics (SEFM) aims to describe the principles of this technique, as well as the necessary elements for its implementation. The two main ART strategies regarding the application timescale are presented: off-line, intended to face progressive changes observed during treatment and on-line, to mitigate random changes. The state of the art in the application of ART to clinical practice for different anatomical locations is reviewed. One of the key instruments for its implementation is described: the deformable registration algorithms (DIR), exposing the principal similarity metrics, the similarity optimization methods, and the deformation models used, analyzing the characteristics of the algorithms of main software. Furthermore, given the importance of knowing the additional uncertainty introduced by the use of DIR algorithms, especially when they are used to deform the absorbed dose matrix, a section is dedicated to the validation of these algorithms, including the results for the main commercial software programs currently available. Finally, some recommendations are presented when applying ART in clinical practice.

Key words: ART, off-line and on-line adaptive radiotherapy, DIR, QA of deformable image registration algorithms.

\section{Tabla de contenido}

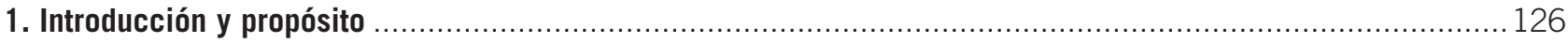

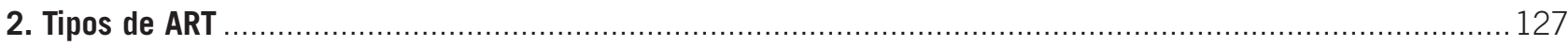

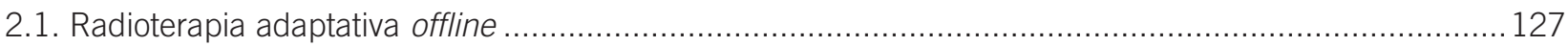

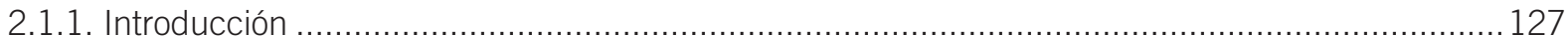

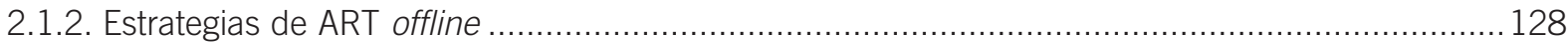

2.1.3. Radioterapia guiada por la imagen en ART offline .......................................................... 129

2.1.4. Adquisición de imágenes del nuevo tratamiento adaptado.................................................... 130

2.1.5. Optimización y evaluación del nuevo tratamiento ……..................................................... 130

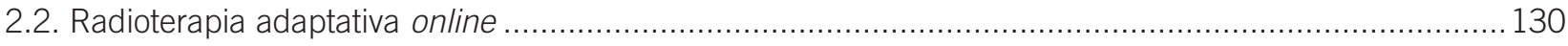

2.2.1. Radioterapia guiada por la imagen en ART online ......................................................... 131

2.2.2. Nueva delimitación de estructuras críticas mediante DIR ....................................................... 133

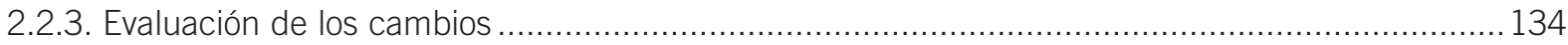

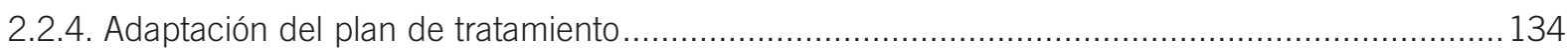

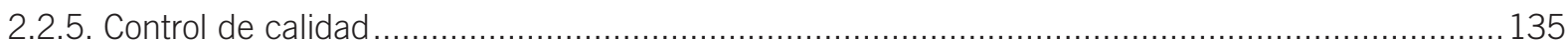

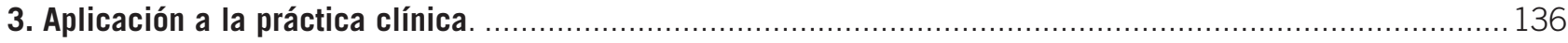

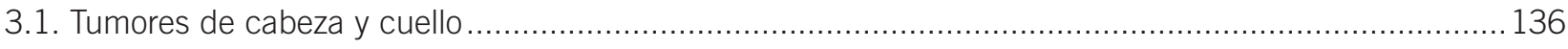

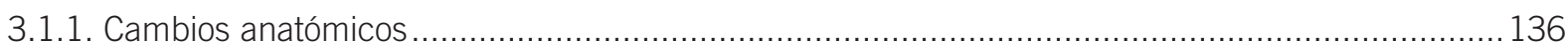

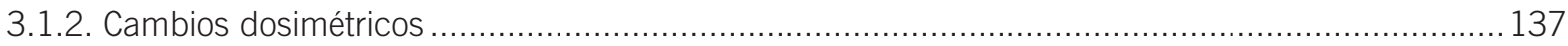

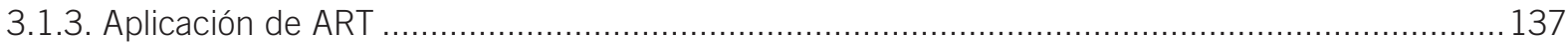

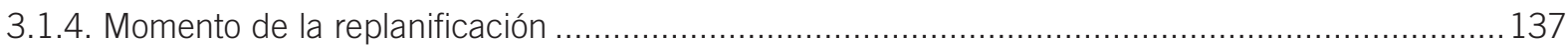

3.1.5. Criterio de selección de pacientes potencialmente beneficiarios de ART ................................... 137 


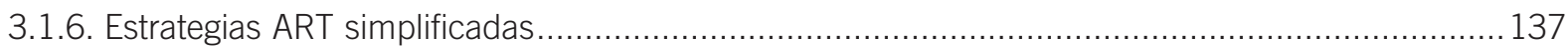

3.1.7. Beneficios dosimétricos de ART en cabeza y cuello ............................................................ 138

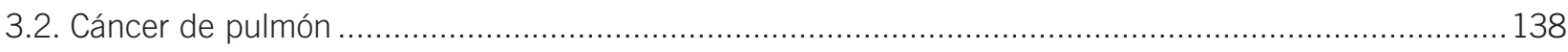

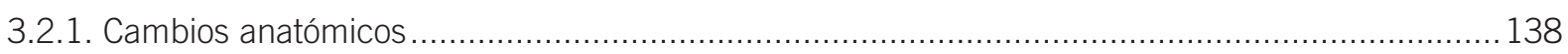

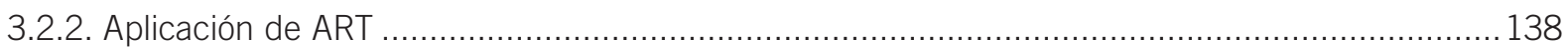

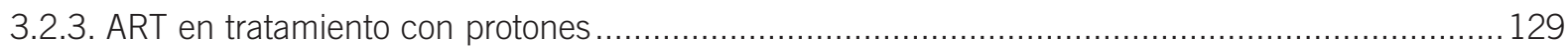

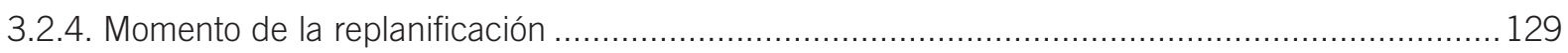

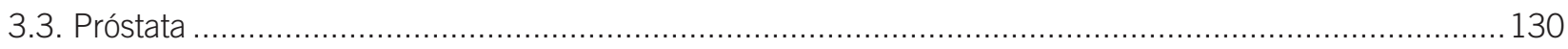

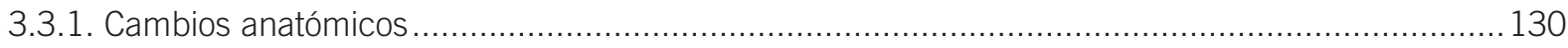

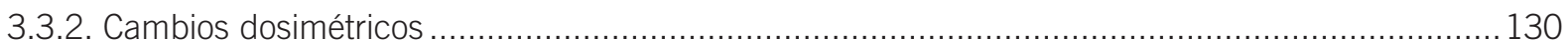

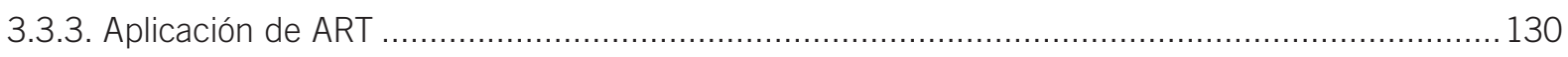

3.3.4. Beneficios dosimétricos de ART en próstata .................................................................... 130

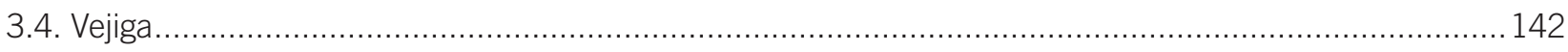

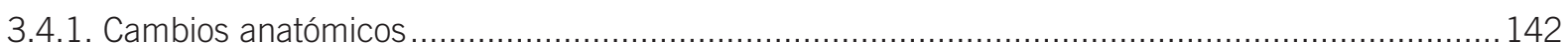

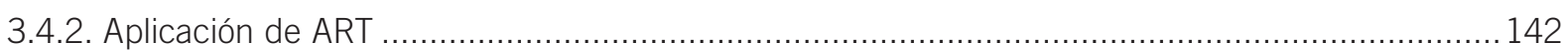

3.4.3. Beneficios dosimétricos de ART en la vejiga .................................................................. 143

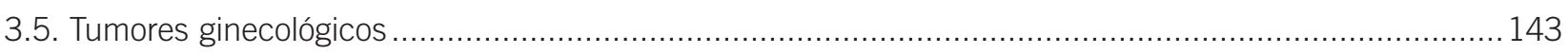

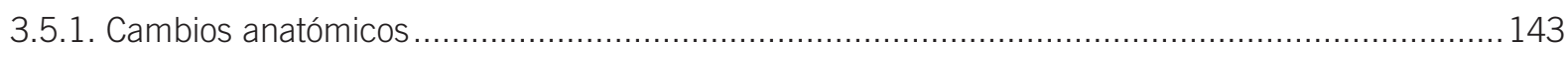

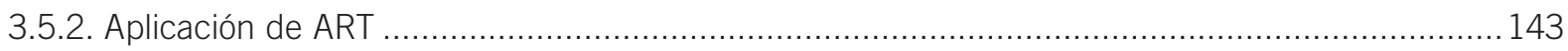

3.5.3. Beneficios dosimétricos de ART en tumores ginecológicos ................................................ 144

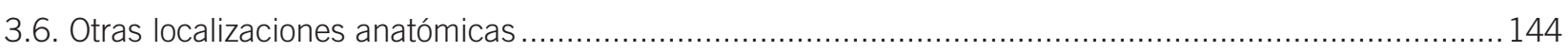

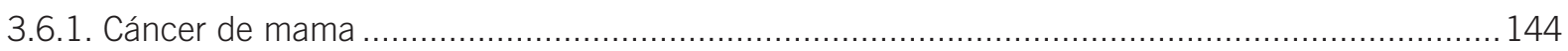

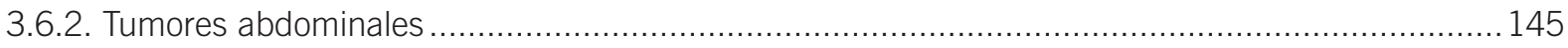

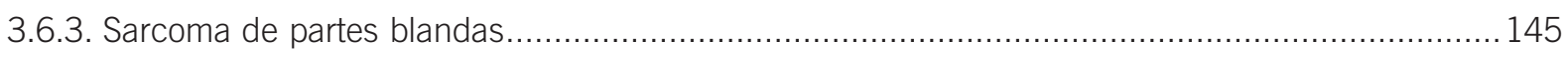

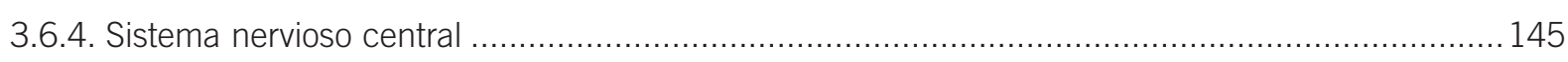

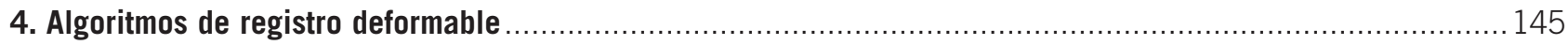

4.1. Función objetivo y regularización de la transformación ............................................................. 145

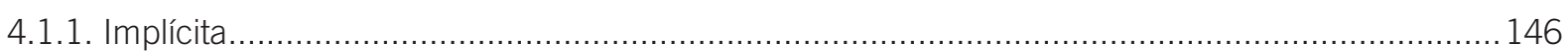

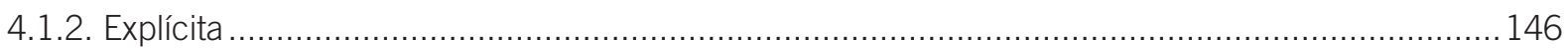

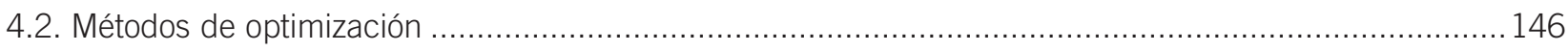

4.3. Métricas de similitud empleadas en el proceso de optimización ..................................................... 146

4.3.1. Métricas geométricas o featured-based …................................................................ 147

4.3.2. Métricas basadas en intensidad de píxel/vóxel o icónicos ................................................... 147

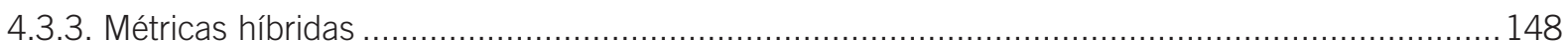

4.4. Modelos de deformación o de registro deformable .............................................................. 149

4.4.1. Transformación geométrica derivada de modelos físicos ....................................................... 149

4.4.2. Transformación geométrica derivada de la teoría de interpolación ......................................... 150

4.4.3. Transformación geométrica basada en modelos biofísicos/biomecánicos ................................. 151

4.5. Algoritmos implementados en softwares comerciales............................................................ 152 
5. Validación de los algoritmos de registro deformable de imagen......................................................... 152

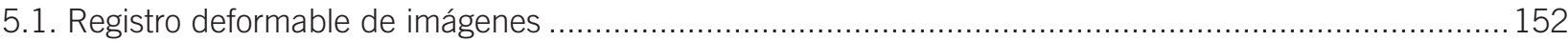

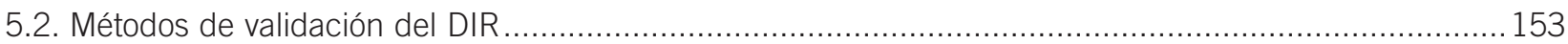

5.2.1. Validación con puntos de los algoritmos de registro deformable .......................................... 154

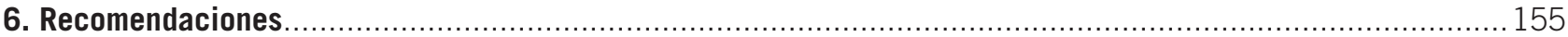

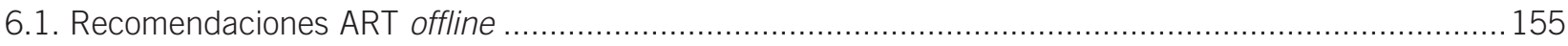

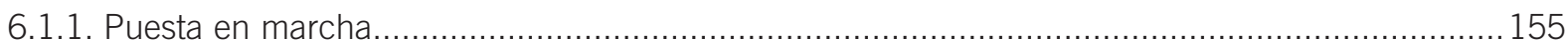

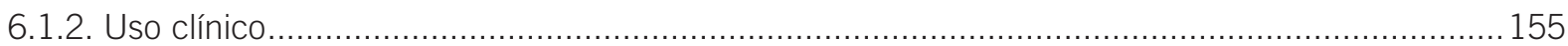

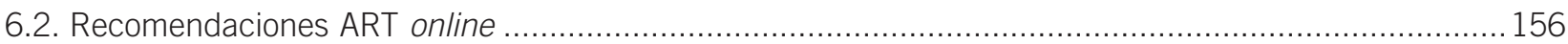

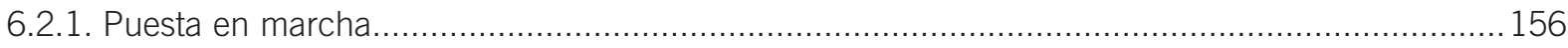

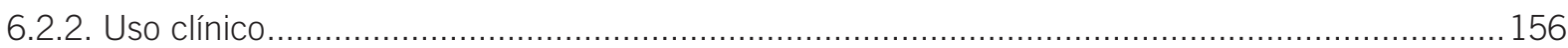

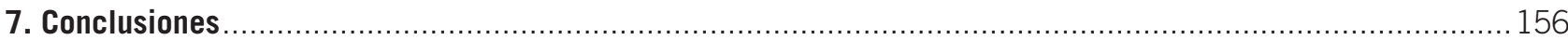

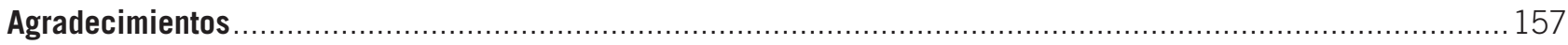

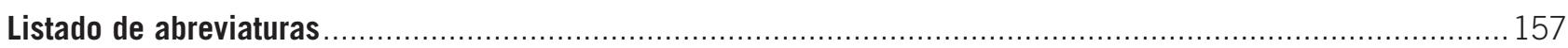

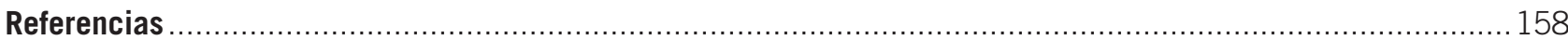

\section{Introducción y propósito}

El objetivo de la radioterapia radical es obtener la máxima probabilidad de control tumoral con el mínimo daño al tejido sano, procurando que los tejidos sanos reciban la dosis absorbida más baja posible. Tradicionalmente, se ha impartido la dosis absorbida de forma fraccionada para maximizar la diferencia entre control tumoral y daño a tejido sano. Durante del tratamiento fraccionado, existen movimientos internos fisiológicos, como, por ejemplo, la respiración, el latido cardíaco y los movimientos intestinales; por otro lado, se pueden producir variaciones de tamaño, forma y posición en los volúmenes blanco clínicos (Clinical Target Volume, CTV) a tratar, y en los órganos de riesgo (Organs At Risk, OAR); ${ }^{1}$ si para la delimitación de los volúmenes se han registrado varias series de imágenes, hay que tener en cuenta también las incertidumbres asociadas a este registro. Es por ello, que es necesario añadir a los volúmenes anteriores un margen de seguridad, denominado margen interno, que incluya todas estas variaciones, obteniendo de esta forma los volúmenes blanco internos (Internal Target Volume, ITV). Existen otras fuentes de incertidumbre, como las asociadas al posicionamiento del paciente, las incertidumbres mecánicas del acelerador y la mesa, las incertidumbres dosimétricas, etc., que se tienen en cuenta con otro margen denominado margen de configuración. De esta forma, se obtienen los volúmenes blanco de planificación (Planning Target Volume, PTV). De forma análoga, se aplican los mismos márgenes para el tejido sano, obteniendo los volúmenes de planificación (Planning organ at Risk Volume, PRV).

La aplicación de márgenes a los volúmenes a tratar aumenta la probabilidad de daño a los tejidos sanos y órganos de riesgo, por lo que, para conseguir el objetivo del tratamiento radioterápico, resulta fundamental poder conseguir reducir dichos márgenes. En los últimos años, esto ha sido posible de forma significativa gracias a los avances de los sistemas de imagen en la unidad de tratamiento y la aplicación de la radioterapia guiada por la imagen (Image-GuidedRadiation Therapy, IGRT).

Existen una gran variedad de sistemas de imagen guiada, entre los que se encuentran sistemas de imagen de tomografía computarizada (Computed Tomography, TC) de kilovoltaje alineada en un sistema de railes (TC-on-Rails), tomografía computarizada de haz cónico de kilovoltaje (Conebeam TC, CBCT), tomografía computarizada de haz cónico de megavoltaje (Megavoltaje CBCT, MVCBCT), tomografía computarizada helicoidal de haz en abanico de megavoltaje (helical Megavoltaje TC, MVCT), sistemas de radiografía o fluoroscopia planar, sistemas de imagen de ultrasonidos y, recientemente, también se han desarrollado sistemas con imagen de resonancia magnética integrada en el acelerador.

La IGRT utiliza la imagen adquirida en la unidad para corregir las variaciones entre fracciones (interfracción), o dentro de la misma fracción (intrafracción), respecto al tratamiento planificado inicialmente. Comparando estas imágenes se determinan las tras- 
laciones y, en los sistemas con mesa con seis grados de libertad, también las rotaciones necesarias para hacer coincidir la geometría del paciente obtenida en la sala de tratamiento con la geometría del paciente en la adquisición de la imagen de planificación. Para que estas geometrías coincidan la mesa lleva a cabo los movimientos necesarios. Esta técnica permite corregir las variaciones debidas a diferencias provocadas por los cambios anatómicos entre el momento de la planificación y cada una de las fracciones de tratamiento.

No obstante, la IGRT tiene algunas limitaciones. Entre ellas destaca que ésta no es capaz de tener en cuenta las deformaciones de los volúmenes, ni los movimientos independientes entre los distintos órganos. Para poder corregir estos movimientos y deformaciones, es necesario modificar el plan inicial previsto, de forma que se incluyan las diferencias encontradas. Para dar solución a esta necesidad, surge la radioterapia adaptativa (Adaptive Radiation Therapy, ART). Yan et al. ${ }^{2}$ la definen como un proceso cerrado, donde el plan inicial puede modificarse mediante una retroalimentación sistemática con la información nueva obtenida, con la intención de mejorar el tratamiento al monitorizar las variaciones e incorporarlas, para reoptimizar el plan inicial durante el curso del tratamiento. En este proceso, los márgenes y la dosis absorbida se pueden personalizar para cada paciente, para lograr una administración de tratamiento de forma segura. En un artículo posterior, Yan et al. ${ }^{3}$ proponen que para la implementación de la radioterapia adaptativa siempre deberían estar presentes cuatro elementos clave: la evaluación de la dosis absorbida real de tratamiento, la identificación/evaluación de las variaciones en el tratamiento, la decisión de modificación del tratamiento, y por último, la modificación del tratamiento. Recientemente, Green et al. ${ }^{4}$ definen la ART como la técnica de radioterapia donde la dosis absorbida administrada se monitoriza para ver su aceptabilidad clínica y se modificada, si es necesario, con el objetivo de mejorar el resultado del tratamiento.

Según el esquema temporal, la ART se puede clasificar como: offline, entre fracciones, online, inmediatamente antes de una fracción, y, por último, en tiempo real durante una fracción. ${ }^{4}$ Sea cual sea el esquema utilizado, es necesario un flujo de trabajo diseñado con las particularidades temporales indicadas, utilizando para ello las herramientas disponibles según la técnica.

La posibilidad de implementar la ART requiere un desarrollo de la tecnología y está basado en gran medida en los sistemas de imagen que hacen posible la IGRT. También son necesarias herramientas de evaluación de la dosis administrada, de forma que se pueda identificar la necesidad de cambiar el plan. Los sistemas de planificación han de permitir la adaptación a los cambios de la forma lo más rápida y automática posible y por último, se ha de disponer de herramientas de control de calidad para todo el proceso.

El presente documento se estructura en cinco capítulos en los que se pretende dar una visión global de la ART y los algoritmos de registro deformable (Deformable Image Registration, DIR), tanto en su utilización, como en sus aplicaciones y el control de calidad.

El capítulo 2 está dedicado a las dos técnicas de adaptación más utilizadas, la radioterapia adaptativa offline y la online, que se diferencian por su secuencia temporal. Se exponen las características específicas de cada una y se presenta un esquema de flujo de trabajo.

El capítulo 3 se centra en la aplicación de estas técnicas a la práctica clínica, según la localización anatómica. Existen patologías como los tumores de cabeza y cuello, en los que los cambios encontrados son graduales, por lo que es más apropiado utilizar estrategias de radioterapia adaptativa offline, mientras que otros, como los tumores pélvicos, presentan modificaciones diarias por el diferente estado de órganos como vejiga y recto, por lo que, en este caso, puede ser más adecuado el uso de ART online.

El capítulo 4 se dedica a los algoritmos de DIR, donde se exponen las principales métricas de similitud: las geométricas, las basadas en intensidad de píxeles o las híbridas, los métodos de optimización y los modelos de deformación. Por último, se analizan las características de los algoritmos de los principales softwares comerciales.

El capítulo 5 está dedicado a la validación de los algoritmos DIR. El capítulo se divide en dos secciones: una primera parte teórica, donde se detallan los diferentes métodos de validación y sus limitaciones; y una segunda parte, donde se muestran los resultados de la validación mediante puntos de los diferentes algoritmos de DIR de los principales softwares comerciales.

Por último, se presentan las recomendaciones de este Grupo de Trabajo y las conclusiones del documento.

\section{Tipos de ART}

\subsection{Radioterapia adaptativa offline}

\subsubsection{Introducción}

El procedimiento de ART offline consiste en la adaptación de un tratamiento de radioterapia a las diferentes variaciones anatómicas que se producen durante el curso de este (variación en el volumen del paciente, variación del volumen de tratamiento, cambios de forma, etc.). ${ }^{3}$ Este proceso de adaptación se realiza 
para intentar conseguir los objetivos iniciales en las fracciones restantes del tratamiento.

Es un proceso que se inicia con las imágenes de IGRT, siendo estas susceptibles de ser utilizadas para una evaluación geométrica y, en función de la tecnología utilizada, también dosimétrica (CBCT, RM, MVCBCT...), y que determinan la necesidad de iniciar un proceso de ART. La principal característica del proceso de ART es el uso del tratamiento inicial y su administración, como punto de partida para la planificación del nuevo tratamiento. Esto significa que, en la planificación del nuevo tratamiento, se hace uso de una nueva imagen de simulación mediante el análisis de la dosis absorbida administrada al paciente durante las fracciones tratadas antes de proceder a la adaptación del tratamiento. Por ello, un plan de ART conlleva los mismo pasos y procedimientos que cualquier tratamiento estándar de radioterapia, más las restricciones dosimétricas derivadas del tratamiento inicial.

En ART existen incertidumbres asociadas de tipo sistemático, que se repiten fracción a fracción, y de tipo aleatorio, las cuales varían cada día. 5,6 En un proceso de ART offline, las incertidumbres de tipo sistemático se ven reducidas, ya que todo el proceso se inicia de nuevo, pero no así las incertidumbres de tipo aleatorio, que dependen de la administración diaria del tratamiento. ${ }^{7}$ Además, un procedimiento de ART introduce nuevos procesos que tienen asociadas incertidumbres adicionales, ${ }^{8,9}$ como la del registro entre imágenes, que deben incluirse en el margen del PTV. ${ }^{10}$ Por otro lado, el procedimiento de ART offline presenta una mayor seguridad respecto a otros modelos de ART, ya que permite realizar una evaluación más detallada y con más tiempo del nuevo tratamiento adaptado; también permite una verificación en la unidad de tratamiento antes de ser administrado en el paciente para cualquier tipo de tratamiento adaptado.

Un esquema del flujo de trabajo genérico en un procedimiento de ART offline se presenta en la fig. 1. El tratamiento inicial sigue su curso habitual hasta que se observa una alerta (variación anatómica) en la imagen de IGRT (CBCT fracción 3). En este momento, se inicia un proceso de evaluación anatómico-dosimétrico con las imágenes de CBCT. Si la alerta observada no tiene efectos clínicamente relevantes (B) el tratamiento continuará con un seguimiento particular de las imágenes de IGRT. Si, por el contrario, la alerta sí que muestra variaciones dosimétricas clínicamente importantes (A) se programa una nueva simulación y se inicia un proceso de adaptación del tratamiento.

\subsubsection{Estrategias de ART offline}

Existen diferentes estrategias de ART offline que dependen de los recursos materiales y humanos del centro. En determinadas localizaciones, los cambios durante el transcurso del tratamiento son habituales

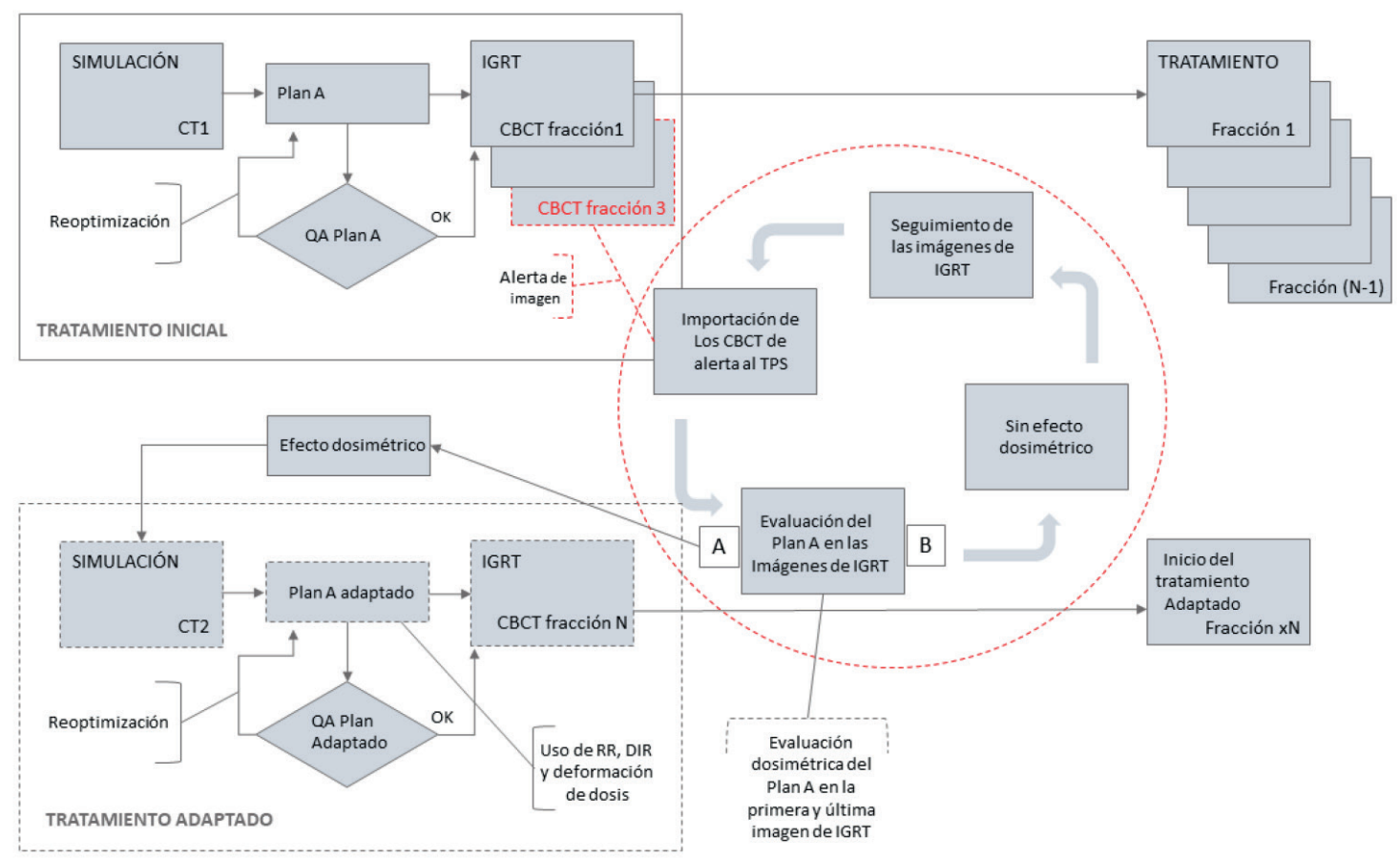

Fig. 1. Flujo de trabajo para el procedimiento de radioterapia adaptativa offline mediante el uso de las imágenes de CBCT de IGRT. 
y es necesario adaptarlos para conseguir el objetivo terapéutico planificado. En el apartado 3. Aplicación a la práctica clínica se abordará este tema.

Como plantean Sonke et al., ${ }^{11}$ se han desarrollado diferentes modos de trabajo, o de estrategias, de ART offline teniendo en cuenta la localización y los órganos comprometidos en el tratamiento o el tipo de imagen médica involucrada en la estrategia:

- Modelos anatómicos promediados: mediante un seguimiento de las imágenes de las primeras fracciones de tratamiento, se crea una estructura promedio a partir de las estructuras de cada fracción. También se utiliza un promedio de los campos vectoriales de deformación (Deformable Vector Field, DVF) ${ }^{*}$ de cada uno de los DIR realizados entre las imágenes CBCT de cada fracción con el TC de planificación. Una vez obtenido, se deforma la imagen TC para obtener una imagen promedio con la que seguir el tratamiento. ${ }^{12,13}$

- Triggered Adaptation: una variación anatómica en las imágenes de IGRT activa el protocolo de ART offline. La adaptación puede iniciarse solo con la evaluación geométrica de la imagen o con un análisis más detallado mediante un estudio dosimétrico. ${ }^{14-16}$

- Adaptación programada: en las localizaciones susceptibles de cambios anatómicos se planifica el tratamiento donde ya se considera la posible adaptación de este en determinadas fracciones, evaluando parámetros anatómicos y dosimétricos. ${ }^{17-21}$

\subsubsection{Radioterapia guiada por la imagen en ART offline}

La adquisición de imágenes de posicionamiento del paciente en la sala de tratamiento supone el punto de partida en un proceso de ART offline, ya que son las imágenes adquiridas antes de cada fracción las que nos proporcionan la información del estado anatómico del paciente y de los posibles cambios que pueda sufrir en el transcurso del tratamiento.

\subsubsection{Modalidades}

Los tipos de imágenes de IGRT que podemos utilizar para adaptar un tratamiento de radioterapia son las de carácter volumétrico, tanto con energías de kilovoltaje, ${ }^{9,22}$ como de megavoltage. ${ }^{23-25}$ Las soluciones comerciales que permiten este tipo de adquisición en los diferentes equipos de radioterapia son:

- CBCT con energía de kV mediante los sistemas X-Ray Volume Imaging ${ }^{\mathrm{TM}}$ (XVI) (Elekta $\mathrm{AB}$,

Se definirá en el capítulo 4.
Stockholm, Suecia), On-Board Imaging® (OBI), Halcyon $^{\mathrm{TM}} \mathrm{kV}$ Images y Ethos ${ }^{\mathrm{TM}} \mathrm{kV}$ Images (Varian Medical Systems, Palo Alto CA, EEUU);

- MVCBCT del sistema MVision ${ }^{\mathrm{TM}}$ (Siemens Healthineers, Erlangen, Alemania);

- MVCT, esta última, se realiza con el sistema de adquisición de tomografía del equipo de tratamiento de tomoterapia Tomo-Therapy Inc. HI-ART (Accuray, Madison WI, EEUU).

Los aspectos principales que hemos de tener en cuenta a la hora de utilizar este tipo de imágenes en un procedimiento de ART son las características tanto geométricas como de calidad de imagen. En función del uso que queramos hacer de ellas, tendremos que conocer las incertidumbres asociadas a su utilización y a la reconstrucción. Estas están fuertemente ligadas al tipo de adquisición de las imágenes y sus características físicas: localización (heterogeneidades), radiación dispersa, artefactos y limitación de la reconstrucción. 8

Si además, la utilización de la imagen incluye el cálculo de dosis absorbida para evaluar la administración del tratamiento por fracción, se añade el problema de la equivalencia entre las Unidades Hounsfield (Hounsfield Units, HU) y la densidad electrónica asociada. ${ }^{26-28}$

Otra limitación es el reducido campo de visión de la imagen, que implica que en determinados casos el contorno exterior y alguna estructura estén incompletos, de forma que complica el uso de la imagen obtenida directamente para la replanificación. ${ }^{29}$

\subsubsection{Uso para la evaluación dosimétrica}

Nos centraremos en las dos modalidades de imagen 3D de IGRT que hemos comentado anteriormente, imagen de kilovoltage y de megavoltage, y mostraremos de forma global su utilización en los diferentes sistemas comerciales que permiten realizar ART:

- RayStation (RaySearch Laboratories, Stockholm, Sweden). ${ }^{30}$ El sistema permite la importación de las imágenes CBCT y la asignación de una curva de densidad electrónica a cada imagen. Posteriormente, se realiza un registro rígido (RR) seguido de un registro deformable entre el TC de planificación (pTC) y cada uno de las imágenes de $\mathrm{CBCT}$. Estos registros permiten proyectar los contornos a las imágenes de IGRT. Finalmente, se evalúa el tratamiento inicial fracción a fracción mediante deformación y mediante la acumulación de dosis absorbida en el pTC.

- Velocity ${ }^{\top \mathrm{M}}$ (Varian Medical Systems). ${ }^{31}$ Utiliza imágenes CBCT para su posterior uso mediante DIR con el pTC. Se deforma el pTC a partir de las imágenes de IGRT. Esto permite calcular el plan de 
tratamiento sobre este nuevo conjunto de imágenes y así evaluar las discrepancias entre el tratamiento planificado y el administrado.

- Precise ART (Accuray). ${ }^{32}$ El sistema hace uso de las imágenes MVCT previamente modificadas mediante el uso de la imagen pTC y la curva de densidad electrónica del pTC obteniendo una nueva imagen modificada (mMVCT). Con esta nueva imagen, se recalcula el patrón de intensidad del tratamiento administrado (sinograma). De esta forma, se evalúa fracción a fracción el tratamiento administrado.

- MIM maestro ${ }^{2}$ (MIM Software, Inc., Cleveland, $\mathrm{OH}$, EEUU). ${ }^{33}$ Este sistema también utiliza las imágenes de CBCT. Permite tratar las imágenes mediante registro rígido y registro deformable entre pTC y CBCT. Una vez realizados los registros, se proyectan las estructuras y se calcula el tratamiento en cada CBCT. Finalmente, se evalúa el tratamiento fracción a fracción mediante deformación y acumulación de dosis absorbida.

- Pinnacle (Philips Radiation Oncology Systems, Fitchburg, WI, EEUU). ${ }^{34}$ Sistema que se basa en el uso de imágenes TC y CBCT, tanto para registro rígido como para registro deformable. Permite evaluar la dosis absorbida del plan de tratamiento en las imágenes diarias mediante CBCT y decidir si es necesario adaptar el plan de tratamiento. Para el nuevo plan adaptado, permite optimizar teniendo en cuenta la dosis absorbida administrada mediante deformación y acumulación de dosis absorbida.

Un aspecto muy importante en este proceso es el número y tipo de estructuras que utilizamos para esta evaluación dosimétrica. La capacidad para poder delimitarlas con la menor incertidumbre posible en las imágenes de IGRT dependerá de la calidad de estas. Las estructuras se pueden proyectar mediante el registro rígido o DIR entre el pTC y el CBCT, pero siempre deben ser revisadas finalmente por el especialista.

\subsubsection{Adquisición de imágenes del nuevo tratamiento adaptado}

Una vez se ha decidido iniciar la adquisición de nuevas imágenes, se han de tener en cuenta aspectos fundamentales para facilitar la adaptación del tratamiento y reducir las incertidumbres asociadas al procedimiento en general. La adquisición de un nuevo conjunto de imágenes TC se realizará de modo que se intente cumplir con ciertas condiciones:

- El posicionamiento será igual al posicionamiento inicial (posición, giro de cuello, posición de brazos, etc.). Esto implica utilizar también los mismos soportes de fijación y sistemas de inmovilización.
- Se mantendrá el mismo protocolo de adquisición asociado a la localización (uso de contraste, llenado de vejiga, características de $\mathrm{kV}$ y $\mathrm{mA}$ del tubo de RX del TC, etc.).

- Para disminuir la variabilidad en la delimitación de estructuras anatómicas, especialmente en estructuras con poco contraste, es importante volver a delimitar los mismos órganos de riesgo evaluados en el tratamiento inicial siguiendo los mismos criterios.

Estas condiciones tienen como principal objetivo mejorar al máximo la calidad del registro de imágenes, tanto del registro rígido como del DIR.

\subsubsection{Optimización y evaluación del nuevo tratamiento}

Una vez se ha decidido realizar ART, mediante herramientas de registro de imagen, y de deformación y acumulación de dosis absorbida, se evalúa el tratamiento administrado para decidir en qué momento se adapta este y las características (prescripción y límites dosimétricos de los órganos de riesgo) del nuevo tratamiento adaptado. La evaluación se realiza utilizando los algoritmos de registro deformable, ya que mediante estos podemos proyectar las dosis absorbidas calculadas en las nuevas imágenes al pTC y compararla con dosis absorbida inicialmente calculada en el pTC.

El tratamiento adaptado total se compone de la suma de la dosis absorbida administrada más la dosis absorbida del nuevo plan optimizado. Esto significa que la optimización del nuevo plan de tratamiento ha de tener en cuenta la dosis absorbida administrada previamente con el plan inicial y, por tanto, la dosis absorbida de prescripción terapéutica total. Si el volumen de tratamiento ha sufrido modificaciones considerables respecto a la anatomía del plan inicial, se puede dar el caso de encontrarnos con un plan de tratamiento adaptado que cumple las condiciones terapéuticas prescritas inicialmente a costa de tener zonas de dosis absorbida fuera del rango terapéutico por fracción.

\subsection{Radioterapia adaptativa online}

La radioterapia estándar actual, aun con la utilización de la IGRT, no es capaz de tener en cuenta las deformaciones diarias de los volúmenes, ni los movimientos independientes entre los distintos órganos. ${ }^{35,36}$ Para poder corregir estas variaciones, es necesario modificar el plan inicial de tratamiento, surge así la ART online.4,37-39 Se puede definir como la técnica que utiliza las imágenes de IGRT obtenidas inmediatamente antes de la sesión de tratamiento, adapta los cambios encontrados mediante una replanificación 


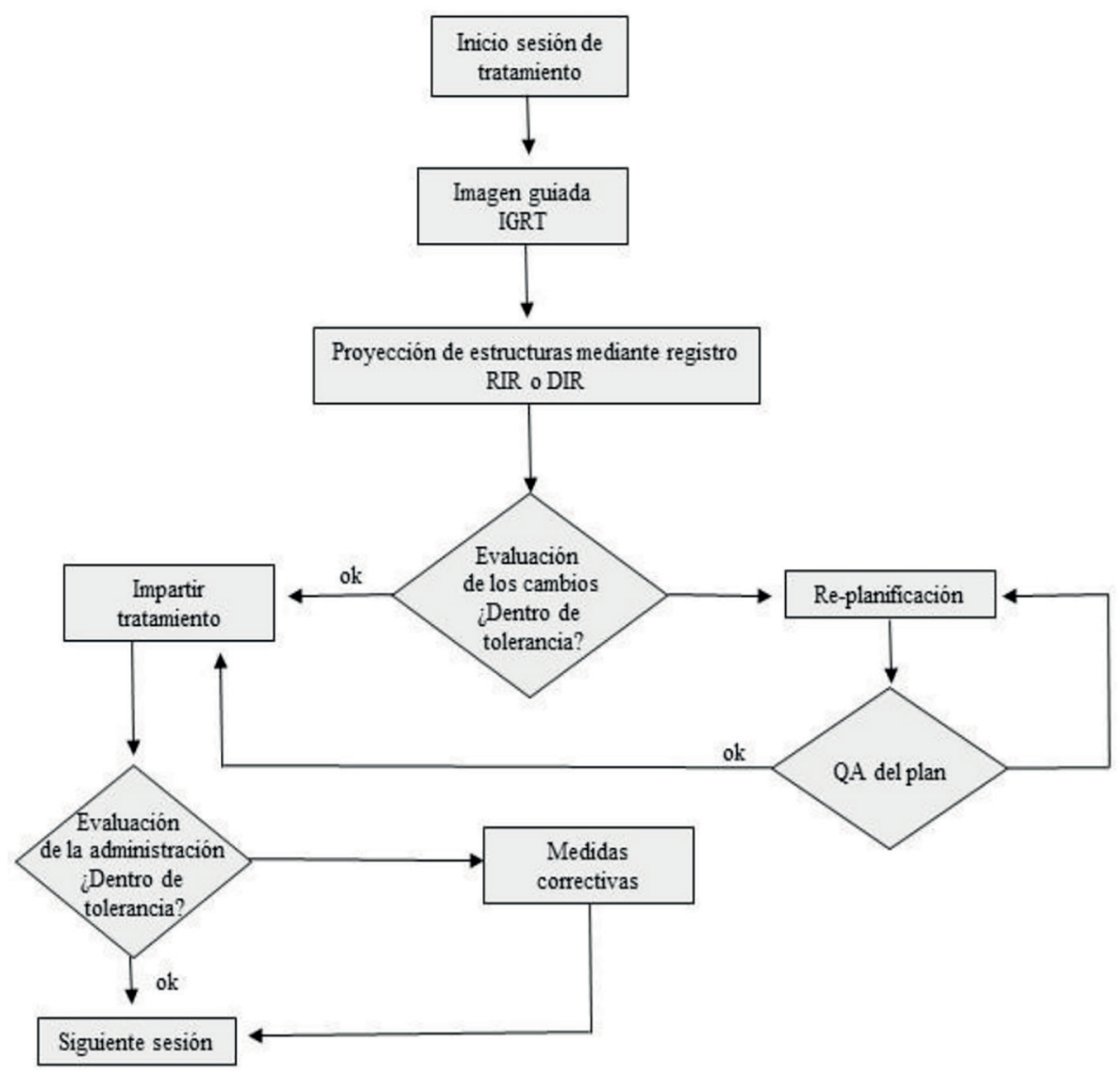

Fig. 2. Esquema de flujo de trabajo en radioterapia adaptativa online. En los subapartados de la sección 2.2 se describirán los principales elementos que lo componen.

en tiempo real, e imparte un nuevo tratamiento en el caso de ser necesario. Permite corregir tanto variaciones sistemáticas, como cambios anatómicos diarios y adaptar los márgenes para el PTV y PRV a cada sesión, de forma individualizada. Para poder llevarla a cabo, es necesario un flujo de trabajo (véase la fig. 2) con una serie de elementos con características particulares adaptadas al proceso y con el objetivo común de acortar el tiempo total: sistemas de imagen guiada, algoritmos de DIR, para la adaptación de los volúmenes iniciales y redelimitación de volúmenes; replanificación y verificación del tratamiento con el paciente en la sala; de manera que, es imprescindible que todo este proceso sea compatible con la espera del paciente inmovilizado en la unidad.

\subsubsection{Radioterapia guiada por la imagen en ART online}

Dado que se han detallado los diferentes sistemas de IGRT utilizados para la ART offline en el apartado 2.1.3.1., en esta sección se va a centrar en la imagen guiada por imagen RM que se integra en algunos modelos de aceleradores. Esta técnica tiene un excelente contraste en tejidos blandos, ${ }^{40,41}$ obteniendo buenos resultados al aplicar algoritmos de registro deformable, incluyendo deformaciones y cambios relativos de posición entre órganos. Conviene señalar que esta técnica no supone una fuente de irradiación adicional para el paciente. Además, ofrece la posibilidad de obtener secuencias de imágenes funcionales de RM mediante el uso de biomarcadores como DWI (Diffusion weighted imaging), ${ }^{42}$ lo que permite realizar una adaptación biológica que complementa a la geométrica.

Tradicionalmente, la imagen RM se ha usado corregistrada con la imagen TC, lo que introduce una incertidumbre que varía entre 0.5 y $3.5 \mathrm{~mm} .{ }^{43}$ En los últimos años, se ha planteado su uso como modalidad única, sin embargo, la imagen, al no contener información de la densidad electrónica de los tejidos, no se puede usar directamente para el cálculo de dosis absorbida en radioterapia, y es necesaria la obtención de un TC "virtual", conocido como pseudo-TC (psTC), TC-sintético o TC-sustituto (sTC). ${ }^{43}$ Para obtenerlo, se han utilizado diferentes métodos, entre ellos: método de densidad aparente (Bulk Density Method, BDM), 
método basado en atlas (Atlas Based Method, ABM) y método basado en vóxeles (Voxel Method Based, VMB).

El método de densidad aparente más sencillo consiste en asignar una sola densidad a todo el volumen, ${ }^{44,45}$ lo que puede conducir a grandes discrepancias en el cálculo de dosis absorbida respecto a un TC heterogéneo (>2\%), algunos autores sugieren que este límite (2\%) podría ser clínicamente aceptable. ${ }^{46}$ Para mejorar el método, se puede segmentar la imagen en aire, hueso y tejido blando. ${ }^{47,48}$ En resonancia convencional, es difícil distinguir el hueso cortical del aire, en sistemas en los que se dispone imagen de TC se puede delimitar automáticamente el hueso previamente y registrar ambas imágenes para transferir los contornos. Si el sistema es únicamente con resonancia, la delimitación manual es muy costosa en tiempo, y lo hace poco apropiado para la adaptación online.

El método basado en atlas utiliza normalmente una única secuencia estándar de imagen RM. ${ }^{49}$ Puede usar un único par TC-imagen RM corregistrado como atlas, o bien, un promedio de un conjunto de pares de imágenes. ${ }^{50}$ En este último caso, la imagen RM obtenida se registra con la imagen RM promedio, la deformación se aplica a la imagen TC promedio para obtener el psTC. De la misma forma se pueden proyectar los contornos de la imagen RM al psTC. Para mejorar el método se pueden aplicar técnicas de reconocimiento de patrones. ${ }^{51}$ Su limitación principal son los pacientes con una anatomía "no estándar".

El método basado en vóxel puede utilizar la imagen RM estándar, como las potenciadas en T1 o T2, secuencias especializadas, como ultra-short echo time UTE que a mayores permite visualizar hueso cortical, o bien una combinación de ambas. ${ }^{52,53}$ Dicho método, consiste en crear un psTC usando la intensidad de los vóxeles de la imagen RM, a partir de modelos obtenidos de imágenes TC-RM registradas donde se relacionan valores de intensidad de vóxel con número TC. Con este método, el psTC que se obtiene es de alta calidad, aunque si se usan secuencias especializadas, el tiempo necesario para llevarlo a cabo puede aumentar. Con este método y el anterior, se puede conseguir menos del $1 \%$ de diferencia entre el cálculo TC-psTC y de $1 \mathrm{~mm}$ en el posicionamiento con psTC.

El cálculo de dosis absorbida necesita tener en cuenta la interacción de los campos magnéticos con los electrones secundarios (fuerza de Lorenz), que hace que la trayectoria de los electrones se curve (efecto ERE: efecto de regreso de los electrones), dando lugar a la aparición de sobredosificaciones principalmente en las interfaces tejido-aire, por lo que son necesarios planificadores con algoritmos Monte Carlo. ${ }^{54}$

Los sistemas comercializados actualmente son MRIdian® y MRIdian ${ }^{\circledR}$ linac (ViewRay Technologies, Inc, Ohio, USA) y Elekta Unity (Elekta).
El sistema MRIdian® linac está formado por un equipo de resonancia magnética de $0.35 \mathrm{~T}$, integrado con un acelerador lineal de $6 \mathrm{MV}$ sin filtro aplanador con doble colimador multilámina con bancadas desplazadas la mitad de la anchura de la lámina, para reducir la transmisión del sistema MLC, mejorar y agilizar la conformación del haz sin la necesidad de mandíbulas adicionales. ${ }^{55}$ La mesa se puede desplazar en las 3 direcciones cartesianas, lo que permite corregir los errores de posicionamiento mediante desplazamiento de esta. El sistema MRIdian $₫$ es un modelo similar, pero utiliza fuentes de cobalto en lugar de un acelerador. ${ }^{56}$ Se pueden adquirir imágenes volumétricas de RM con un FOV máximo de $50 \mathrm{~cm}$ e imágenes planares sagitales en modo cine de forma continua mientras se irradia, permitiendo tratamientos de gating respiratorio. En estos casos, el haz detiene la irradiación si se exceden las tolerancias previamente fijadas para un contorno en las imágenes en tiempo real adquiridas. ${ }^{57}$ El sistema dispone de un planificador compatible con una adaptación online, con autodelimitación, cálculos Monte Carlo para 3D conformada o radioterapia de intensidad modulada (Intensity-modulated radiotherapy, IMRT), en menos de 30 segundos. Una desventaja es que el campo magnético es relativamente débil, lo que disminuye la relación señal-ruido con tiempos de relajación más cortos, aunque, por otro lado, mejora la distorsión presente en la imagen, presenta menos efectos debido al calor y se producen menos perturbaciones de la distribución de dosis absorbida, especialmente en la superficie. El tiempo total medio para la adaptación del plan para tratamientos abdominopélvicos es de 26 minutos. ${ }^{58}$

El sistema Elekta Unity consiste en una resonancia de $1.5 \mathrm{~T}$ integrada con un acelerador de $7 \mathrm{MV}$ sin filtro aplanador con sistema de colimación multilámina en un anillo. ${ }^{59,60}$ Actualmente, este diseño no permite desplazamientos de mesa una vez colocado el paciente, para compensarlo se ha desarrollado una estrategia denominada "Virtual Couch Shift", que se explica brevemente en la sección 2.2.5.2. Al igual que el sistema anterior, se pueden obtener imágenes volumétricas, también permite una monitorización en tiempo real del tratamiento mediante la adquisición de imágenes en modo cine mientras se irradia, que puede ser usada tanto para obtener la dosis absorbida acumulada total, ${ }^{61}$ como para replanificar en tiempo real. ${ }^{62}$ Dispone de un planificador GPU-Monte Carlo que permite IMRT.63 El tiempo medio para el proceso online, incluyendo adquisición de imágenes, delimitación de contornos y planificación es de unos 25 minutos. $^{64}$

Los pasos a tener en cuenta en el flujo de trabajo en el caso de RM-IGRT serían similares al esquema inicial (véase la tabla 1), teniendo en cuenta las características particulares de la técnica. ${ }^{55,64}$ En la tabla se 
Tabla 1. Flujo de trabajo para la radioterapia adaptativa online en un equipo de imagen RM integrado en un acelerador.

\begin{tabular}{|c|c|}
\hline Acción & Realizada por \\
\hline $\begin{array}{c}\text { Adquisición de las imágenes } \\
\text { de TC y RM para definición } \\
\text { de volúmenes y asignación } \\
\text { de HU }\end{array}$ & $\begin{array}{l}\text { Técnico de } \\
\text { radioterapia }\end{array}$ \\
\hline $\begin{array}{c}\text { Diseño del plan de tratamiento } \\
\text { inicial }\end{array}$ & Radiofísico \\
\hline $\begin{array}{l}\text { Control de calidad del plan } \\
\text { con maniquí y cálculo } \\
\text { independiente }\end{array}$ & Radiofísico \\
\hline $\begin{array}{l}\text { Colocación del paciente y } \\
\text { adquisición de imágenes de } \\
\text { RM en la sala de tratamiento }\end{array}$ & $\begin{array}{l}\text { Técnico de } \\
\text { radioterapia }\end{array}$ \\
\hline $\begin{array}{c}\text { Proyección de las estructuras } \\
\text { y HU del TC original a las } \\
\text { imágenes de RM mediante } \\
\text { registro deformable y } \\
\text { generación del TC "virtual" }\end{array}$ & $\begin{array}{l}\text { Técnico de } \\
\text { radioterapia }\end{array}$ \\
\hline $\begin{array}{c}\text { Evaluación de las estructuras } \\
\text { y modificación en caso de ser } \\
\text { necesario }\end{array}$ & $\begin{array}{l}\text { Oncólogo } \\
\text { radioterápico }\end{array}$ \\
\hline $\begin{array}{l}\text { Evaluación de la readaptación } \\
\text { del tratamiento }\end{array}$ & $\begin{array}{l}\text { Oncólogo } \\
\text { radioterápico }\end{array}$ \\
\hline $\begin{array}{l}\text { Reoptimización del plan de } \\
\text { tratamiento }\end{array}$ & Radiofísico \\
\hline $\begin{array}{c}\text { Evaluación de estructuras } \\
\text { críticas }\end{array}$ & $\begin{array}{l}\text { Oncólogo } \\
\text { radioterápico }\end{array}$ \\
\hline $\begin{array}{l}\text { Control de calidad del plan } \\
\text { con cálculo independiente }\end{array}$ & Radiofísico \\
\hline $\begin{array}{l}\text { Adquisición de una nueva } \\
\text { serie de imágenes de RM y } \\
\text { evaluación de los posibles } \\
\text { movimientos del paciente }\end{array}$ & $\begin{array}{l}\text { Técnico de } \\
\text { radioterapia }\end{array}$ \\
\hline Administración del tratamiento & $\begin{array}{l}\text { Técnico de } \\
\text { radioterapia }\end{array}$ \\
\hline
\end{tabular}

ha añadido en cada acción un responsable adaptando la propuesta de Lamb et al. ${ }^{65}$

En la actualidad, está disponible un nuevo acelerador especializado en radioterapia adaptativa online Ethos $^{T M}$ Therapy (Varian Medical System, Inc). Dispone de una única energía de 6 MV sin filtro aplanador, y un sistema de doble colimación multilámina. Tiene integrado un sistema de imagen de kV CBCT, denominado iCBCT, que permite adquisiciones de hasta $38.5 \mathrm{~cm}$ de longitud y utiliza un algoritmo de reconstrucción iterativo, que mejora la calidad de ima- gen y la consistencia de los números TC necesaria para el cálculo de dosis absorbida. Permite una segmentación automática de contornos, guiada por un algoritmo basado en inteligencia artificial mediante redes neuronales convolucionales estáticas, donde la entrada es la imagen de iCBCT, y la salida es la imagen segmentada. Para la creación del plan adaptado, utiliza un algoritmo de optimización denominado Intelligent Optimization Engine, que permite una automatización del proceso y que es válido para IMRT y VMAT. El control de calidad del nuevo plan se realiza con la aplicación Mobius (Mobius Medical System, Houston, TX, EEUU), incluida de forma integrada. El tiempo total de todo el proceso es de unos 15 minutos. ${ }^{66}$

\subsubsection{Nueva delimitación de estructuras críticas mediante DIR}

La imagen obtenida con el paciente en la mesa de tratamiento se registra con la imagen previa, usando algoritmos de registro deformable, obteniéndose un campo vectorial de deformación, que se aplica a los contornos de las estructuras de planificación originales para obtener nuevas estructuras "deformadas". Si los algoritmos de registro deformable no están disponibles, se pueden usar algoritmos de registro rígido, aunque sería necesario modificar manualmente algunos contornos, lo que conduce a un aumento del tiempo total del proceso. ${ }^{67}$ Es importante destacar que la delimitación de estructuras es la parte del flujo de trabajo sujeto a más incertidumbres. ${ }^{68}$

En los equipos con resonancia integrada, además de proyectar las estructuras es necesario crear un TC "virtual", como se explicó anteriormente, a partir de la densidad electrónica del TC original, si se quiere realizar el cálculo en la imagen de RM directamente. En el acelerador Elekta Unity, se definen 2 flujos de trabajo: ATP (adaptar a posición) y ATS (adaptar a forma). En el primer caso, la posición del isocentro se modifica en el TC de planificación tras un registro rígido con la imagen de RM adquirida en la sala de tratamiento; la replanificación, de esta forma, se realiza sobre el TC con las estructuras originales. Para el segundo flujo, se realiza un registro deformable entre ambas imágenes, proyectando los contornos del TC a las imágenes de RM; a cada contorno se le asigna la densidad electrónica promedio del TC, obteniendo un TC "virtual" y posteriormente, el plan es recalculado o reoptimizado sobre las imágenes de RM. ${ }^{69}$ El acelerador MRIdian ${ }^{\circledR}$ también permite un registro rígido y deformable, utilizándose éste último, de la misma forma, para proyectar contornos desde el TC original. El TC "virtual" se puede obtener asignando manualmente las densidades electrónicas o utilizando 6 densidades predefinidas para distintos tipos de tejido. ${ }^{55}$ 


\subsubsection{Evaluación de los cambios}

Los criterios para decidir si es necesaria o no, la adaptación de un plan, deben estar fijados previamente, debido tanto a la necesidad de acortar el tiempo como a la optimización de recursos humanos que intervienen en el proceso. ${ }^{4}$ Los criterios se pueden establecer para los órganos de riesgo, de esta forma se adapta el plan si se superan los límites de dosis absorbida para órganos de riesgo críticos, ${ }^{67}$ en base a una cobertura mínima a los volúmenes de tratamiento, o tener en cuenta ambos.

\subsubsection{Adaptación del plan de tratamiento}

Se pueden aplicar diferentes estrategias para la adaptación del plan de tratamiento:

\subsubsection{Librería de planes ( $L d p)$}

Esta técnica se aplica fundamentalmente cuando existen cambios anatómicos diarios de tipo aleatorio en la localización y tamaño de los volúmenes de tratamiento u órganos de riesgo (por ejemplo, llenado de vejiga y recto, cambios intestinales, etc.) como en el caso de braquiterapia y radioterapia externa de pelvis, ${ }^{70,71}$ siendo el más típico el tratamiento de vejiga. Para cada paciente están disponibles previamente varios planes, normalmente entre 3 y 6 , y cada día se elige el plan que más se asemeje a la situación actual del paciente. Esta técnica, requiere en promedio de 5 a 12 minutos adicionales para el tratamiento. ${ }^{70}$ Existen diferentes métodos para su obtención: desplazamiento de contornos; delimitación de estructuras en varias series de imágenes de planificación, que se utiliza en el caso de tener órganos con deformación, por ejemplo, vejiga llena-vacía e interpolación de situaciones intermedias. ${ }^{72}$ Como alternativa para pacientes con cáncer de vejiga, ${ }^{73}$ se pueden adquirir 3 series de imágenes tras el vaciado de la vejiga en los minutos 0,15 , 30 , realizando 3 planes alternativos. De forma similar se pueden utilizan 3 o 4 planes de tratamiento con la vejiga en distintas condiciones de llenado. ${ }^{74}$ Otra posibilidad para crear los planes es utilizar las imágenes de la primera semana de la imagen guiada, normalmente $\mathrm{CBCT}$, durante la cual el paciente se trata con un plan convencional. Posteriormente, cada día de tratamiento se elige, en base a la imagen guiada, el plan óptimo que mejor se adapte. ${ }^{75,76}$

No es una técnica que se pueda aplicar a todos los pacientes y algunas veces no hay ningún plan que se pueda considerar "óptimo" para el día de tratamiento. En estos casos se trata al paciente con el plan convencional. ${ }^{72,73,75}$

\subsubsection{Replanificación y reoptimización}

La forma más directa es volver a optimizar y calcular en los nuevos volúmenes. Para reducir los tiempos, se han diseñado algunas soluciones alternativas:

- Adaptación de aperturas (Segment Aperture Mor-phing, SAM) y pesos (Segment Weight Optimization, SWO). ${ }^{77,78} \mathrm{El}$ algoritmo SAM utiliza la relación entre los contornos de planificación y los obtenidos en la imagen guiada a través de la perspectiva del haz (Beam Eye View, BEV), para modificar la posición de las láminas para cada ángulo y segmento de planificación. SWO es una herramienta que modifica los pesos de los segmentos para alcanzar el plan óptimo, basado en los objetivos definidos por el usuario, utilizando la distribución de dosis absorbida original, por lo que la optimización es mucho más rápida, alrededor de 1 minuto, con unos tiempos totales para el procedimiento completo de unos 6-10 minutos para próstata. Presenta algunas limitaciones, debido a que la deformación 3D se proyecta a BEV bidimensionales, y además no es adecuado para grandes deformaciones ni movimientos independientes de múltiples estructuras. Estos algoritmos se usan en algunos de los métodos de optimización de los equipos RM-linac. Para el equipo Elekta Unity, están disponibles 7 modelos de optimización agrupados en 4 estrategias en función del nivel creciente de complejidad de ART: utilizar los segmentos originales, adaptar los segmentos por SAM, optimizar los pesos desde segmentos o fluencia y, por último, optimizar pesos y formas desde segmentos o fluencia. ${ }^{69}$ Para el equipo MRIdian, están disponibles a su vez distintos algoritmos de optimización: utilización de segmentos originales, optimización de pesos desde segmentos, reoptimización de fluencia usando los objetivos originales y reoptimización completa con nuevos objetivos. El cálculo se puede realizar sobre el TC de planificación o sobre las imágenes de RM.

- Desplazamiento virtual de la mesa ("Virtual Couch Shift"): ${ }^{79}$ este método consiste en trasladar y rotar la distribución de dosis absorbida original para compensar los cambios anatómicos encontrados y generar un nuevo plan de tratamiento sin mover la mesa. Esta herramienta está implementada en el acelerador con resonancia integrada Elekta Unity.

- Secuenciador adaptativo (ASEP): ${ }^{62}$ es un algoritmo de optimización iterativo para realizar la adaptación en tiempo real. Parte de una optimización inicial ideal, correspondiente a la dosis absorbida de prescripción. En cada iteración se crean segmentos según las imágenes de RM adquiridas en tiempo real en el acelerador Elekta Unity, se calcula la dosis absorbida de estos segmentos y se sustrae 


\section{FLUJO DE TRABAJO QA ART ONLINE}
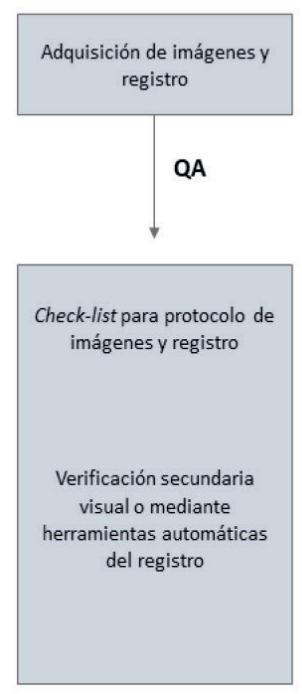
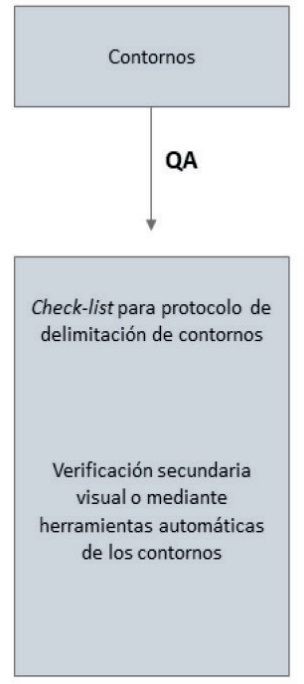
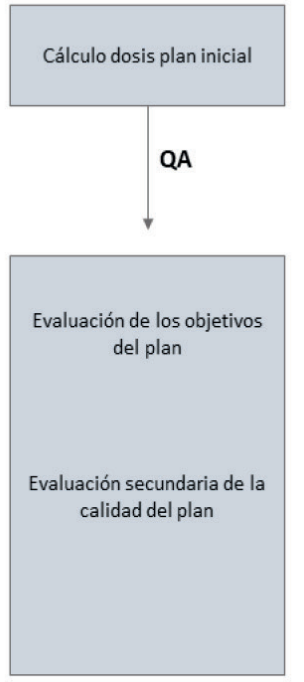
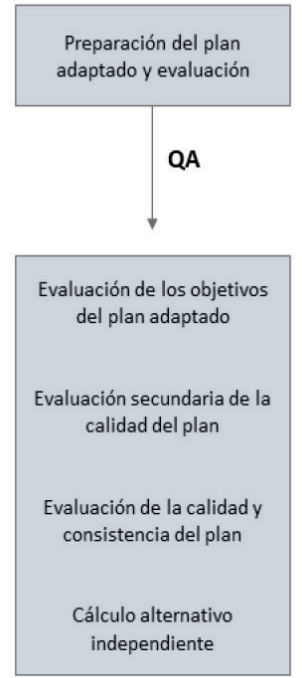
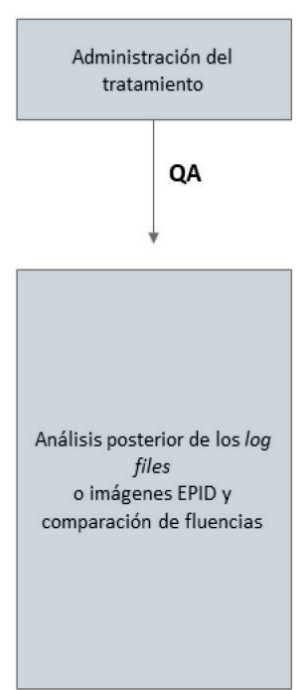

Fig. 3. Esquema general para control de calidad en radioterapia adaptativa online.

de la distribución ideal. En el siguiente paso, esta dosis absorbida actualizada sirve como punto de partida para la siguiente iteración. Este proceso se repite hasta la convergencia entre la dosis absorbida administrada y la prescrita.

- Herramientas de planes basados en el conocimiento como RapidPlan ${ }^{\text {TM }}$ (Varian Medical Systems). ${ }^{80}$ Esta herramienta utiliza una biblioteca de planes de instituciones de referencia para obtener un modelo de estimación del DVH, que aplica al plan del paciente para generar de forma automática los objetivos y los pesos del plan de forma iterativa, obteniendo un plan "óptimo".

- Herramientas que permiten el diseño y optimización de forma automática como Auto-planning de Pinnacle. ${ }^{81}$ Dicha herramienta parte de un plan que únicamente necesita las incidencias de los haces, la dosis para los volúmenes de prescripción y los objetivos para los órganos de riesgo. El optimizador automáticamente crea estructuras auxiliares con sus propios objetivos y pesos para conseguir lo requerido en volúmenes de prescripción y la mínima dosis a los órganos de riesgo. El planificador también permite combinar esta herramienta con la creación de protocolos por patologías, de forma que el diseño y optimización son totalmente automáticos. Li et al. ${ }^{82}$ utilizan un método completamente automático para hacer la adaptación online, utilizando Pinnacle mediante un código integrado en el planificador.
En radioterapia adaptativa online la técnica usada, el uso de técnicas IMRT o VMAT, está condicionada por los tiempos de cálculo y tratamiento. El plan original se toma como referencia o punto de partida, conservando el isocentro, los ángulos y los objetivos para la optimización. ${ }^{83}$

El tiempo de cálculo para el nuevo plan de tratamiento puede ser elevado, pero se puede acelerar el cálculo utilizando una arquitectura en paralelo, con un cluster de unidades de procesamiento central (CPU), soluciones basadas en la nube ${ }^{84}$ o la optimización y cálculo en la unidad de procesamiento grafico (GPU). Men et al. ${ }^{85-87}$ utilizan un algoritmo DAO (Direct Aperture Optimization) en la GPU, obteniendo planes con técnica IMRT en menos de 3 segundos.

\subsubsection{Control de calidad}

En el caso de radioterapia adaptativa online, las características asociadas a esta técnica hacen que el control de calidad deba ser aún más riguroso que en la radioterapia estándar en cada uno de los pasos. Un esquema general de un posible flujo de trabajo, tomando como base el trabajo de Cai et al. ${ }^{88}$ se indica en la fig. 3.

Peng et al.89 han desarrollado un procedimiento de control de calidad para la replanificación en radioterapia adaptativa online que consta de 4 pasos: (1) Verificación del tratamiento original mediante medidas 
experimentales con maniquí, este paso se realiza previamente en otro momento en la unidad; (2) Cálculo alternativo independiente del plan calculado para el tratamiento adaptado obtenido; (3) Verificación de la transferencia del plan usando un software propio que compara los parámetros del plan en el planificador con los transferidos a la máquina y (4) validación de los parámetros impartidos del tratamiento utilizando un software propio y los log files del acelerador. Únicamente los pasos 2 y 3 se realizan de forma online, los pasos 1 y 4 se realizan de forma offline al procedimiento.

En la adaptación online, el control de calidad independiente para el plan específico del paciente se realiza con el paciente en la mesa de tratamiento de la unidad, por lo que los sistemas convencionales de verificación con maniquí no son válidos. Además, hay que considerar el factor tiempo, necesitando sistemas mucho más rápidos que en radioterapia convencional. 88 No existe todavía consenso en la comunidad científica, ni recomendaciones acerca de cómo debe ser la verificación pre-tratamiento, algunas opciones aceptadas son:

- Sistemas de verificación mediante un segundo cálculo alternativo: Mobius3D (Mobius Medical System).

El sistema recibe como entrada los archivos DICOM provenientes del planificador (plan, dosis absorbida, estructuras, imágenes) y realiza un cálculo independiente utilizando un algoritmo collapsed-cone convolución-superposición con tiempo de cálculo acelerado por GPU. ${ }^{90}$ El sistema Mobius FX permite analizar los ficheros con la información del posicionamiento del colimador multilámina, denominados log files, provenientes del acelerador, para realizar un segundo cálculo independiente por cada sesión de tratamiento del paciente. ${ }^{91}$

- Otros sistemas de cálculo independiente son: DIAMONDR (PTW Freiburg GmbH), que realiza un segundo cálculo alternativo, que puede tener en cuenta heterogeneidades; ${ }^{92}$ ImSure $Q A^{\text {TM }}$ (Standard Imaging Inc., Middleton, WI, EEUU), dispone de un algoritmo de cálculo basado en el método de las 3 fuentes virtuales de fluencia; 93 MUCheck (Oncology Data Systems Inc, Oklahoma, EEUU) y RadCalc® (Lifeline Software Inc., Tyler, TX, EEUU). ${ }^{94}$

- Sistemas que utilizan una cámara de ionización de transmisión que analizan la salida del haz en tiempo real, como el sistema Dolphin \& COMPASS (IBA, Bélgica), permitiendo realizar un cálculo independiente utilizando un algoritmo de convolución-superposición, con dos opciones: sin medidas a partir de la fluencia importada del sistema de planificación, o experimental con la fluencia medida con la cámara. ${ }^{95}$
- Otra opción para QA online son los sistemas de verificación in-vivo como PerFRACTIONTM (Sun Nuclear Corporation, Melbourne, FL, EEUU) o ADAPTIVO ${ }^{\mathrm{TM}}$ (Standard Imaging, Middleton, WI, EEUU). PerFRACTIONTM96 permite realizar verificaciones offline pretratamiento y verificaciones online en cada sesión de tratamiento, tanto 2D como 3D, utilizando las imágenes obtenidas con el sistema portal y/o los log files del acelerador. Permite calcular tanto en la imagen de planificación como en la imagen de CBCT adquirida en la unidad. Dispone de un algoritmo collapsed-cone convolución-superposición con tiempo de cálculo acelerado por GPU para el cálculo independiente de dosis absorbida. ADAPTIVO ${ }^{\mathrm{TM}}$ permite realizar verificaciones pretratamiento y verificación in-vivo mediante el uso de las imágenes obtenidas con el sistema portal. Realiza el cálculo diario de dosis a partir de las imágenes CBCT adquiridas en la unidad, utilizando algoritmos de registro deformable para propagación de contornos; también permite la obtención de la dosis acumulada.

\section{Aplicación a la práctica clínica}

En este apartado se hace una revisión de la aplicación clínica de ART para diferentes localizaciones anatómicas. En él se exponen las causas de las discrepancias entre la dosis absorbida planificada y la dosis absorbida real recibida, las posibles soluciones que la ART aporta y las ventajas dosimétricas que supone su aplicación.

\subsection{Tumores de cabeza y cuello}

\subsubsection{Cambios anatómicos}

En los pacientes con tumores de cabeza y cuello los cambios anatómicos más frecuentes que se producen a lo largo del tratamiento son la pérdida de masa corporal, la regresión y deformación del volumen de tratamiento y la reducción de volumen y el desplazamiento medial de las parótidas. ${ }^{97}$

En cuanto a la pérdida de peso, se describen variaciones importantes: del $8-10 \%$ en promedio, oscilando entre el 3\% y el 15\%. ${ }^{98-100}$ Para los volúmenes de tumor macroscópico (GTV) existe una gran disparidad entre los resultados publicados: desde disminuciones muy pequeñas del GTV al final del tratamiento hasta reducciones del $60-70 \%$, en promedio el 30\%. ${ }^{97,101-103}$ Respecto a las parótidas, se reporta una pérdida considerable de volumen: en Castadot et al. ${ }^{101}$ se describe una reducción aproximada del 1\% 
por día de tratamiento; Brouwer et al. ${ }^{98}$ hallaron una disminución entre el 14\% y el 42\% (promedio: $26 \pm$ $11 \%$ ) y Veresezan et al. ${ }^{102}$ entre el $26 \%$ y el $30 \%$. También se describe un desplazamiento lateral medial del orden de 1-3 mm. ${ }^{99}$ Otros OAR como la médula espinal o el tronco cerebral no varían de volumen, pero si puede modificar, en presencia de pérdidas de peso importantes, su posición relativa al contorno externo.

Existe controversia en cuanto al momento en que se producen los mayores cambios. Veresezan et al. ${ }^{102}$ recogieron en su revisión publicaciones que sitúan las variaciones del CTV en la parte inicial del tratamiento y las de los OAR en la final, mientras que otros autores hallan resultados opuestos.

\subsubsection{Cambios dosimétricos}

En cuanto al detrimento en la dosis absorbida recibida por los volúmenes de tratamiento, se describen desde variaciones pequeñas (menores del 1-2\%) en el valor de $D_{2 \%}$ y $D_{95} \%$ del PTV, hasta reducciones del orden de 2 Gy en el $D_{95 \%}$ del GTV. ${ }^{97}$ La mayoría de publicaciones refieren un incremento de dosis absorbida en las parótidas mayor que en el resto de OAR siendo la dosis absorbida administrada superior a la planificada en aproximadamente $2-3 \mathrm{~Gy},{ }^{97,98}$ pero existen grandes variaciones entre los estudios, siendo el máximo de los valores reportados del orden de 10 Gy. ${ }^{104}$ Respecto a la médula espinal, las variaciones referidas son pequeñas: Castelli et al. ${ }^{97}$ encontraron incrementos de dosis absorbida menores de 2 Gy; Noble et al. ${ }^{100}$ obtuvieron una diferencia media absoluta entre el valor de $D_{2} \%$ planificado y administrado de 0.9 Gy (0.76-1.04), incluso ante variaciones anatómicas importantes (pérdida de peso: 6.8 kg; disminución del diámetro lateral de $13 \mathrm{~mm}$ ).

\subsubsection{Aplicación de ART}

Dado que los cambios que se producen durante el tratamiento en cabeza y cuello ocurren de forma gradual, es esperable que las estrategias de adaptación sean offline.

\subsubsection{Momento de la replanificación}

El número de replanificaciones van desde 1 hasta 6 (para el $74 \%$ y $10 \%$ de los autores respectivamente), Ilevadas a cabo mayoritariamente en la semana $304 .{ }^{97}$ Huang et al., 20 adquiriendo TC semanales, hallaron que 2 replanificaciones en las semanas 1 y 3 son adecuadas, en relación a cambios dosimétricos significativos tanto en volúmenes de tratamiento como OAR. En un estudio prospectivo con 110 pacientes, Brown et al. ${ }^{105}$ encontraron que los pacientes con cáncer de nasofaringe y orofaringe se benefician de una nueva planificación a principios de la semana 3 y 4, respectivamente. Zhang et al. ${ }^{106}$ reportaron que con 3 replanificaciones en las semanas 1, 2 y 5, la dosis absorbida a las parótidas disminuye en 3.1 Gy (siendo el beneficio mayor de 5 Gy para el $31 \%$ de los pacientes), e incrementa ligeramente la cobertura al CTV. Hvid et al., ${ }^{107}$ en un análisis retrospectivo para 153 pacientes, de los cuales a 93 de ellos se les realizó un TC a mitad del tratamiento y para los 60 restantes se adquirió un CBCT diario, hallaron que adquirir un TC a mitad del tratamiento ni mejora la cobertura ni la preservación de los OAR, respecto a un protocolo de IGRT con un CBCT diario. Veresezan et al. ${ }^{102}$ tras analizar las controversias en la literatura, estimaron como óptimo el realizar un nuevo TC entre las semanas 3 o 4 de tratamiento.

\subsubsection{Criterio de selección de pacientes potencialmente beneficiarios de ART}

Dada la disparidad de resultados en cuanto al momento idóneo para la replanificación tiene sentido plantear que esta necesidad es dependiente del paciente ${ }^{108}$ y que por tanto tiene interés definir a priori qué pacientes se beneficiarán de ART.

Brouwer et al. ${ }^{98}$ plantearon que, puesto que las variaciones dosimétricas mayores se dan en los OAR, era esperable que la adaptación del tratamiento produjera mayor beneficio monitorizando la dosis absorbida en estos volúmenes. Entre todos los factores estudiados, la mayor correlación hallada es entre la dosis absorbida media planificada inicial para la parótida y su pérdida de volumen. En un estudio posterior con 116 pacientes concluyeron que la dosis absorbida media planificada en la parótida (> 22.2 Gy) era el único parámetro significativo correlacionado con una variación relevante de dosis absorbida (> 3 Gy). ${ }^{109}$ Brown et al. ${ }^{110}$ categorizaron a los pacientes con arreglo a su probabilidad de requerir ART, encontrando que aquellos pacientes con estadios N2-3, peso mayor de $100 \mathrm{~kg}$ y GTVn de mayor tamaño tenían más del $80 \%$ de probabilidad de necesitar ART. Veresezan et al. ${ }^{102}$ propusieron un criterio para la selección de pacientes para ART: aquellos con una pérdida de peso mayor del 5\% o una reducción del diámetro del cuello mayor del $10 \%$ deberían ser sometidos a una nueva planificación.

\subsubsection{Estrategias ART simplificadas}

Vickress et al. ${ }^{111}$ estudiaron un método que permitía una adaptación online, proyectando los contornos 
a los CBCT diarios mediante registro deformado de los mismos con el TC de planificación, y volcando la dosis absorbida planificada en el CBCT mediante registro rígido. Encontraron que una disminución de D95\% del PTV o un aumento de la dosis absorbida media de las parótidas por encima de 26 Gy era un indicador adecuado de la necesidad de ART. Piron et al. ${ }^{112}$ establecieron niveles de acción basados en comparar las imágenes EPID sucesivas con las del primer día de tratamiento. En el estudio mencionado se evaluó el valor medio del índice gamma, $\langle\gamma\rangle$, su desviación estándar, y el 1\% de los valores mayores de $\gamma$, y se utilizaron para definir categorías y hallar los umbrales que indicaban desviaciones dosimétricas no aceptables. Encontraron que $\langle\gamma\rangle$ mayor de 0.42 era un buen indicador de qué desviaciones anatómicas iban a tener un impacto dosimétrico relevante. Zhang et al. ${ }^{106}$ desarrollaron un proceso automático que utilizaba los CBCT diarios para valorar diferencias anatómicas y geométricas eligiendo el CBCT de la primera sesión como referencia mediante registro rígido. Utilizaron un coeficiente de correlación tridimensional para evaluar las desviaciones geométricas (Pearson del CTV < 0.75) y un umbral de diferencia de dosis absorbida entre valores significativos del histograma dosis-volumen (Dif $>5 \%, D_{95 \%}, D_{90 \%}, D_{10 \%}, D_{5 \%}$ ) para determinar la indicación de ART.

\subsubsection{Beneficios dosimétricos de ART en cabeza y cuello}

A nuestro conocimiento la última revisión publicada sobre beneficios dosimétricos de ART en cabeza y cuello es la de Castelli et al. ${ }^{97}$ En general los resultados de las publicaciones posteriores están en concordancia con esta revisión aunque es difícil sintetizar dada la heterogeneidad de los estudios. Se puede afirmar que: la ganancia en la dosis absorbida a las parótidas es generalizada, alrededor de -4 Gy; para la médula espinal se describen reducciones desde 0.1 hasta 6 Gy; en los volúmenes de tratamiento se puede hablar de una mejora en la homogeneidad y de un incremento de D95\% del PTV de 2 Gy.

La conclusión más extendida para la mayoría de los autores es que son necesarios estudios prospectivos con un número suficiente de pacientes para poder establecer el uso en rutina de ART en pacientes con tumores de cabeza y cuello. ${ }^{97,98,102,110,113}$ Los estudios aleatorizados en fase III que están en marcha permitirán obtener conclusiones definitivas en cuanto a tolerabilidad, eficacia y supervivencia de la aplicación de ART en cabeza y cuello. ${ }^{114}$

\subsection{Cáncer de pulmón}

\subsubsection{Cambios anatómicos}

En el cáncer de pulmón, durante el tratamiento se producen una regresión del tumor, su desplazamiento y/o su deformación, la aparición o resolución de derrame pleural y atelectasia. En promedio, la regresión del volumen tumoral hacia la mitad del tratamiento se ha cuantificado en aproximadamente el $30 \%$, y en el $45 \%$ hacia el final del mismo, ${ }^{115}$ con un rango que varía entre $0.6 \%$ y $2.4 \%$ por día. ${ }^{11}$ La variación en las vías aéreas puede ocasionar movimientos relativos entre el tumor primario y los ganglios de $2.5 \mathrm{~mm}$ (tanto $\Sigma$ como $\left.\sigma^{\dagger}\right)^{11}$

\subsubsection{Aplicación de ART}

Kavanaugh et al. ${ }^{115}$ describieron estrategias de ART en cáncer de pulmón según el propósito de partida recogiendo algunos estudios que ya aportan resultados clínicos.

\subsubsection{ART para el mantenimiento de la dosis absorbida prescrita}

Este enfoque se implementa para paliar el efecto de la aparición de derrame pleural, modificación en la atelectasia o deformación del tumor. Tvilum et al. ${ }^{116}$ presentaron los resultados de ART aplicada a 54 pacientes guiados con CBCT diario en el que se evalúan, en la unidad de tratamiento, distintas referencias geométricas en tejido blando (tumor, ganglios, etc.), Al exceder 3 días consecutivos las tolerancias establecidas, se valoraba el beneficio de adquirir un nuevo TC y elaborar un nuevo plan con márgenes reducidos respecto al plan original, resultando 12 el número de pacientes con planes adaptados. Esta estrategia se comparaba con un grupo de control de 55 pacientes guiados por estructuras óseas y sin adaptar hallándose un incremento del control local sin aumento de la toxicidad. Møller et al. ${ }^{14}$ aplicaron la misma estrategia a 233 pacientes, realizando 79 adaptaciones y hallando que resulta una disminución de la dosis absorbida al pulmón. El criterio utilizado identificó correctamente el $98 \%$ de los pacientes que requerían ART con un $20 \%$ de falsos positivos.

\subsubsection{ART para mejorar la dosis absorbida en el tejido sano}

Esta estrategia trata de aprovechar la ventaja geométrica de la regresión del tumor para tratar un

\footnotetext{
$\Sigma$ : incertidumbres sistemáticas: $\sigma$ : incertidumbres aleatorias.
} 
volumen menor, reduciendo la dosis absorbida a los tejidos sanos. Ramella et al. ${ }^{15}$ presentaron los resultados del ensayo prospectivo LARTIA (217 pacientes) con el objetivo principal de reducir la toxicidad. Se realizaba un TC semanal evaluando si existía o no regresión y en caso afirmativo si esta era relevante o no; hallaron que 50 pacientes tuvieron que ser replanificados y obtuvieron en promedio un volumen de CTV replanificado de $90.7 \mathrm{~cm}^{3}$ frente a los $154.9 \mathrm{~cm}^{3}$ iniciales. Existe un interés creciente por el uso del PET también para adaptar, Xiao et al. ${ }^{117}$ valoraron el beneficio que supone el crear un plan adaptado obtenido a partir de un PET-TC hacia el final del tratamiento. Compararon los HDV de los OAR del plan original con el que se trataron los 17 pacientes (23 fracciones de 2 Gy), con los del plan adaptado elaborado sobre un PET-TC a los 40 Gy. Encontraron una reducción estadísticamente significativa del GTV cercana al $50 \%$ y una mejora en los HDV de todos los OAR. El valor de $V_{5 \%}$ de los pulmones pasaba de $59 \%$ a $49 \%$ y el de $V_{20 \%}$ de $28 \%$ a $23 \%$, la dosis absorbida media del corazón de 19 Gy a 15 Gy y la del esófago de 25 Gy a 23 Gy.

\subsubsection{ART para escalar la dosis absorbida}

Este enfoque es el más ambicioso, pretendiendo aumentar la dosis absorbida al tumor a un volumen reducido, manteniendo dosis absorbidas biológicamente equivalentes a los tejidos sanos. Se basa habitualmente en el uso de una o varias imágenes TC adquiridas durante el tratamiento. La adaptación del plan se lleva a cabo bien al observar un cambio anatómico notable, bien en un momento preestablecido, incluyendo una sobreimpresión simultánea o añadiendo fracciones al final del tratamiento. Kelsey et al. ${ }^{118}$, basándose en PET, compararon para 30 pacientes un plan basado en un TC a los 50 Gy en el que se planificaba una sobreimpresión de 10-14 Gy, administrados simultáneamente a la zona residual en la que capta en el PET, con el plan original simulado ( 60 Gy en 30 fracciones). Obtuvieron una mejora significativa en la dosis absorbida en los OAR: para los pulmones una reducción de la dosis absorbida media de 0.6 Gy y un $0.5 \%$ en $V_{20} \%$, la dosis absorbida media del corazón se redujo en 0.75 Gy y la del esófago disminuía en 0.8 Gy.

\subsubsection{ART en tratamiento con protones}

La elevada sensibilidad del alcance de los protones a las variaciones de densidad del tejido hace todavía más crítica la necesidad de adaptar los tratamientos, ya que los cambios anatómicos pueden conllevar grandes variaciones en la distribución de dosis absorbida. Hoffman et al. ${ }^{119}$ evaluaron la necesidad de adaptación con intensidad modulada de protones (Intensity-Modulated Proton Therapy, IMPT) calculando retrospectivamente mediante IMPT los planes de 23 pacientes tratados con ART e IMRT. Para ello utilizaron los dos 4D-TC adicionales de control intermedios de que disponían para cada paciente. Utilizando el criterio de mantener un cubrimiento del 95\% del volumen por el $95 \%$ de la dosis absorbida, encontraron que no era necesario adaptar para los planes de IMRT, frente a la necesidad de hacerlo en el $61 \%$ de los pacientes con IMPT. En el caso de Pencil Beam Scanning (PBS) IMPT puede darse además el efecto interplay (movimiento relativo entre el GTV y los haces puntuales), planteando retos adicionales en los tratamientos. El informe de Particle Therapy Co-Operative Group Thoracic and Lymphoma Subcommittee, ${ }^{120}$ recoge una serie de recomendaciones para llevar a cabo este tipo de tratamientos de la forma más precisa posible, indicando respecto a la ART la realización de un 4D-TC semanal para evaluar la necesidad de adaptar.

\subsubsection{Momento de la replanificación}

Dial et al. ${ }^{121}$ estudiaron la relación entre la frecuencia con que se adapta y la reducción de dosis absorbida a los tejidos sanos. Para 12 pacientes tratados con IMRT (63 Gy, 1.8 Gy por fracción), reprodujeron varios escenarios: no adaptación, una replanificación a la fracción 18, una replanificación semanal y una replanificación diaria, para lo que generaron imágenes sintéticas diarias, a partir de las imágenes adquiridas semanalmente, mediante registro deformable. Obtuvieron una reducción significativa de la dosis absorbida a los OAR con ART aplicada a mitad del tratamiento y observaron que al aumentar la frecuencia de ART se incrementaban los beneficios, pero la magnitud de la ganancia disminuía.

En general, parece que el beneficio dosimétrico mayor ocurre adaptando alrededor de la fracción 15. Sin embargo, esto es muy dependiente de cada paciente y se da en mayor medida en pacientes con un GTV inicial de gran volumen. Por ello algunos autores recomiendan adquirir una imagen tridimensional a la semana. ${ }^{115}$

En resumen, ART aplicado en el tratamiento del cáncer de pulmón localmente avanzado ofrece la posibilidad de mejorar los resultados clínicos, aunque hasta la fecha no existe consenso en cuál es la estrategia de ART que proporciona un mayor beneficio y se está a la espera de resultados de ensayos prospectivos con un mayor número de pacientes. 


\subsection{Próstata}

\subsubsection{Cambios anatómicos}

En el tratamiento del cáncer de próstata mediante radioterapia se producen cambios tanto en los volúmenes de tratamiento como en los OAR. ${ }^{122}$ Estos cambios pueden ser sistemáticos o aleatorios. ${ }^{123}$ Los márgenes a añadir al CTV pueden ser especialmente limitantes para la administración de fraccionamientos potencialmente más efectivos como RT hipofraccionada o radioterapia estereotáxica extracraneal (Stereotactic Body Radiation Therapy, SBRT). ${ }^{124}$

Mc Partlin et al. ${ }^{123}$ analizaron estos cambios en estudios basados en diferentes sistemas de guiado: $\mathrm{TC}, \mathrm{kV}, \mathrm{MV}, \mathrm{CBCT}, \mathrm{FM}^{\ddagger}, \mathrm{EM}^{\S}$, RM. Para el movimiento interfracción observaron que $\Sigma$ variaba entre 0.3 y $4.8 \mathrm{~mm}$, y $\sigma$ estaba entre 0.4 y $5.7 \mathrm{~mm}$, predominando las direcciones AP y SI. En los movimientos intrafracción que, aun siendo menores, pueden cobrar relevancia cuando los tiempos de tratamiento se alargan, se ha observado que $\Sigma$ y $\sigma$ alcanzan hasta 2.6 mm. ${ }^{123,125-127}$ Tong et al. ${ }^{128}$ hallaron, con Calypso 4D (Varian Medical Systems), que se producían desplazamientos de la próstata en cualquier dirección más de $2,3,5$, y $7 \mathrm{~mm}$, durante más de $30 \mathrm{~s}$, en un $56.8 \%$, $27.2 \%, 4.6 \%$, y $0.7 \%$ de las fracciones y del lecho prostático $68.7 \%, 35.6 \%, 10.1 \%$, y $1.8 \%$ respectivamente. Cuando el CTV incluye las vesículas seminales (vvss), varios estudios muestran que los movimientos tanto intra como interfracción son mayores que los de la próstata, no hallando correlación entre los desplazamientos de ambos órganos. ${ }^{123}$

Recientemente, Shibayama et al.,129 basándose en CBCT, han analizado las deformaciones sufridas para diferentes tipos de CTV (riesgo bajo, intermedio, alto y próstata+vvss) en los 6 grados de libertad principales concluyendo que no son despreciables, siendo mayores para los casos de riesgo intermedio y alto, donde $\Sigma$ está entre 1.4 y $3 \mathrm{~mm}$ en las 6 direcciones, en concordancia con publicaciones anteriores basadas en imagen RM. ${ }^{123}$

Las rotaciones interfracción aparecen predominantemente en el plano sagital $\left(\Sigma=4.8^{\circ}, \sigma=3.9^{\circ}\right)$ y correlacionadas con el llenado del recto. Las rotaciones intrafracción, menores, alcanzan más de $2^{\circ}$ para tiempos de tratamiento de 14 min. ${ }^{123}$

Oates et al. ${ }^{130}$ hallaron correlación entre el diámetro inicial del recto y el desplazamiento de la próstata en sentido antero-posterior y la rotación en el plano sagital, siendo un valor de diámetro de $3.5-4.5 \mathrm{~cm}$ un umbral predictivo a partir del cual el movimiento de la

FM: fiducial markers.

§ EM: electromagnetic transponder. próstata era significativo. Según McPartlin et al. ${ }^{123}$ no se ha evidenciado correlación entre el llenado de la vejiga y los movimientos prostáticos.

Respecto a los OAR, Pearson et al. ${ }^{131}$ encontraron, basándose en CBCT diario, que el volumen de la vejiga era menor en el $74.8 \%$ de las imágenes en tanto que el del recto era mayor en el $45.2 \%$.

\subsubsection{Cambios dosimétricos}

En la tabla 2 se recogen los efectos dosimétricos que se derivan de los cambios anatómicos producidos durante el tratamiento mediante radioterapia.

\subsubsection{Aplicación de ART}

Desde mediados de los años 90 ha sido mostrado el papel de ART en el tratamiento de próstata en cuanto a la posibilidad de reducir los márgenes y, por tanto, permitir una escalada de dosis. ${ }^{123}$

Thörnqvist et al. ${ }^{71}$ revisaron las estrategias de ART en el tratamiento de tumores pélvicos. En el caso del cáncer de próstata encontraron que se usaba la adaptación del MLC y obtención de un nuevo plan/ optimización o la librería de planes. En cuanto a los estudios implementados clínicamente, el $57 \%$ de pacientes incluidos habían sido tratados con ART offline mediante una nueva planificación/optimización. En esta se adaptaba el PTV con arreglo al movimiento de la próstata respecto a las estructuras óseas, a partir de las imágenes de TC o CBCT tomadas durante las primeras dos primeras semanas de tratamiento. El resto de pacientes se recogían en estudios que utilizaban marcadores de oro, bien para adaptar la forma del MLC online, bien para hacer una nueva planificación offline. Recogieron también la experiencia de un centro que utilizaba una LdP con 5 planes generados para diferentes desplazamientos de la próstata respecto a los ganglios.

\subsubsection{Beneficios dosimétricos de ART en próstata}

Según Thörnqvist et al. ${ }^{71}$, las ventajas dosimétricas al emplear ART serían: un incremento de $D_{99 \%}$ y $D_{95 \%}$ para el CTV de alrededor del 5\%-10\%, una disminución significativa de la dosis absorbida en el recto de entre 5 y $30 \%$ para diferentes índices $\left(V_{60-70 \%,} D_{30 \%}\right)$ y no se encontraron diferencias significativas al emplear ART para la vejiga. Kontaxis et al. ${ }^{137}$ simularon dos estrategias de ART online en términos de la cobertura del CTV y el posible beneficio en los OAR para 5 pacientes, con marcadores fiduciales de oro, tratados con IMRT. Analizaron 2 escenarios de replanificación 
Tabla 2. Variaciones dosimétricas durante la radioterapia externa.

\begin{tabular}{|c|c|c|c|c|}
\hline $\begin{array}{c}\text { Autores } \\
\text { (No pacientes) }\end{array}$ & $\begin{array}{l}\text { Imágenes } \\
\text { utilizadas }\left(\mathrm{N}^{0}\right)\end{array}$ & $\begin{array}{l}\text { Sistema comercial } \\
\text { de registro }\end{array}$ & $\begin{array}{l}\text { Técnica de } \\
\text { tratamiento }\end{array}$ & Resultados y conclusiones \\
\hline $\begin{array}{c}\text { Chen et al.132 } \\
\text { (19) }\end{array}$ & $\begin{array}{l}\text { CBCT } \\
(314)\end{array}$ & Raysearch & VMAT & $\begin{array}{l}\text { Un incremento del volumen de la vejiga } \\
\text { de un } 10 \% \text { implica una disminución de } \\
\text { dosis absorbida media acumulada de un } \\
5.6 \% \text {. }\end{array}$ \\
\hline $\begin{array}{c}\text { Chiesa et al. }{ }^{125} \\
(12)\end{array}$ & $\begin{array}{l}\text { CBCT } \\
(263)\end{array}$ & MIM & VMAT & $\begin{array}{l}\text { El impacto de los errores rotacionales } \\
\text { en V95\% de los PTV es relevante sobre } \\
\text { todo para las VVSS, en que disminuye } \\
\text { en un } 5 \% \text {. }\end{array}$ \\
\hline $\begin{array}{c}\text { Juneja et al. }{ }^{133} \\
\text { (18) }\end{array}$ & $\begin{array}{l}\mathrm{KIM}^{\mathrm{a}} \\
(294)\end{array}$ & Calypso (Varian) & VMAT & $\begin{array}{l}\text { Analizando retrospectivamente } 294 \text { frac- } \\
\text { ciones, adoptan un umbral de } 3 \mathrm{~mm} \\
\text { para el desplazamiento 3D como nivel } \\
\text { de acción, valor que supone una dismi- } \\
\text { nución del } 6.2 \% \text { en D95\% }\end{array}$ \\
\hline $\begin{array}{l}\text { Liu et al. }{ }^{134} \\
\quad(10)\end{array}$ & $\begin{array}{l}\text { TC diario } \\
\text { (102) }\end{array}$ & ABAS, Elekta & IMRT & $\begin{array}{l}\text { Las variaciones de volumen del CTV, el } \\
\text { recto y la vejiga corresponden a valores } \\
\text { de coeficiente de similutd (Dice Similari- } \\
\text { ty Coefficient, DSC) de } 86.6 \%, 77.3 \% \text { y } \\
75.4 \% \text { respectivamente y conllevan una } \\
\text { disminución del } 10-12 \% \text { en el valor de } \\
V_{100 \%} \text { del CTV y PTV, y un aumento del } \\
30 \% \text { y } 45 \% \text { para } V_{45} \text { Gy y } V_{60} \text { Gy, del recto } \\
\text { respectivamente. }\end{array}$ \\
\hline $\begin{array}{l}\text { Maeda et al. }{ }^{135} \\
\text { (10) }\end{array}$ & $\begin{array}{l}\text { TC diario } \\
\text { (263) }\end{array}$ & MIM & $\begin{array}{l}\text { Haces antero- } \\
\text { oblicuos } \\
\text { protones }\end{array}$ & $\begin{array}{l}\text { La variación de la longitud equivalente } \\
\text { en agua es de } 7-9 \mathrm{~mm} \text { y } 4-6 \mathrm{~mm} \text { en las } \\
\text { partes distal y proximal del PTV respec- } \\
\text { tivamente. }\end{array}$ \\
\hline $\begin{array}{l}\text { Moteabed et } \\
\text { al. }{ }^{136}(10)\end{array}$ & $\begin{array}{l}\text { TC semanal } \\
(90)\end{array}$ & MIM & $\begin{array}{l}\text { VMAT/Haces } \\
\text { antero-oblicuos } \\
\text { protones }\end{array}$ & $\begin{array}{l}\text { La disminución de } \text { D } 98 \% \text { para la prósta- } \text { ta (EQD2) depende de la técnica, y no } \\
\text { del fraccionamiento, siendo alrededor de } \\
0.15 \text { Gy para los planes de protones y } \\
\text { 0.6 Gy para VMAT. }\end{array}$ \\
\hline $\begin{array}{l}\text { Pearson et al. }{ }^{131} \\
\text { (6) }\end{array}$ & $\begin{array}{l}\text { CBCT } \\
\text { (168) }\end{array}$ & MIM & IMRT & $\begin{array}{l}\text { Al disminuir el volumen de la vejiga, el } \\
V_{70} \text { Gy aumenta de } 9.5 \% \text { a } 11 \% \text { y con- } \\
\text { trariamente, el aumentar el volumen del } \\
\text { recto el } V_{70} \text { Gy pasa de } 7.3 \% \text { a } 11.6 \% \text {. }\end{array}$ \\
\hline
\end{tabular}

online, compensando: (a) las rotaciones, añadiendo un movimiento de la mesa, (b) las rotaciones y las traslaciones. Se estudiaron diferentes márgenes de obtención del PTV (0-8 mm). La nueva planificación estaba disponible en dos minutos, obteniéndose valores de D99\% (CTV) similares a los planes originales, para todos los valores de margen y con ambas estrategias. El beneficio en la dosis absorbida integral al tejido sano, respecto a los planes clínicos, fue de hasta 32.9\% para un margen de $0 \mathrm{~mm}$. Saito et al. ${ }^{138}$ estudiaron los beneficios de ART para mitigar las variaciones intrafracción, retrospectivamente en 21 pacientes de
IMRT guiada con emisores electromagnéticos (Calypso 4D, Varían Medical Systems). Valoraron las variaciones porcentuales de $D_{95 \%}$ de la próstata y $V_{65}$ Gy de los OAR y extrayendo los coeficientes de correlación entre diferentes mediciones de movimiento (traslaciones en AP, SI, DI; distancia 3D al eje haz) y los cambios dosimétricos, concluyendo que las pendientes de las rectas resultantes podían ser de utilidad para inferir variaciones dosimétricas. Por último, McVicar et al..139 revisaron las publicaciones sobre ART en próstata recogiendo las principales barreras para su implementación en la clínica siendo estas el incremento de 
recursos necesarios, la necesidad de procedimientos de control de calidad y la falta de evidencia clínica.

\subsection{Vejiga}

\subsubsection{Cambios anatómicos}

La vejiga es un órgano hueco y móvil que puede cambiar de forma, tamaño y posición durante el tratamiento. Esto conlleva variaciones considerables de posición de la pared vesical y del tumor, haciendo necesario el uso de márgenes del orden de 20 a $30 \mathrm{~mm},{ }^{140}$ que implican la irradiación de un volumen considerable de tejido sano (entre 234 y $922 \mathrm{~cm}^{3}$, promedio: $\left.486 \mathrm{~cm}^{3}\right) .70$

Dees-Ribbers et al. ${ }^{141}$ estudian retrospectivamente, a partir de CBCT pre y post tratamiento, las variaciones inter e intrafracción para diferentes condiciones de llenado de la vejiga, obteniendo que no existen diferencias estadísticamente significativas entre las diferentes condiciones. Hallan movimientos intrafracción de la pared vesical discretamente menores para los pacientes tratados con la vejiga llena, en tanto que los cambios interfracción son solo ligeramente mayores, variando $\Sigma$ y $\sigma$ para estos últimos desde $1 \mathrm{~mm}$ en la parte caudal hasta $12 \mathrm{~mm}$ en la craneal-anterior. Nishioka et al.,142 evalúan los movimientos inter e intrafracción de la parte de la pared en la que está localizado el tumor mediante marcadores de oro en la pared vesical. Hallan, al igual que en Dees-Ribbers et al. ${ }^{141}$, que los mayores movimientos fueron en las direcciones cráneo-caudal (de $-13.6 \mathrm{~mm}$ a $10.8 \mathrm{~mm}$ ) y antero-posterior (de $-10.0 \mathrm{~mm}$ a $7.7 \mathrm{~mm}$ ) para el movimiento interfracción (cuantil 95\%), aunque los valores de $\Sigma$ y $\sigma$ hallados son menores, alrededor de $5 \mathrm{~mm}$. En Collins et al. ${ }^{70}$ se describe un aumento del volumen de la vejiga intrafracción de hasta $150 \mathrm{~cm}^{3}$.

\subsubsection{Aplicación de ART}

Encontramos varios artículos de revisión sobre la aplicación de ART en cáncer de vejiga: Thörnqvist et al. ${ }^{71}$, Kibrom et al. ${ }^{143}$, Kong et al. ${ }^{140}$ y Collins et al. ${ }^{70}$

\subsubsection{ART offline}

Se ha utilizado en aproximadamente el $20 \%$ de los pacientes, ${ }^{71} \mathrm{su}$ implementación tiene relativamente poco impacto puesto que solo corrige las incertidumbres sistemáticas, y su eficacia depende de que el volumen de la vejiga de las sesiones iniciales sea representativo de del resto de sesiones.

\subsubsection{ART online. Elección del plan del día}

Esta es la estrategia mayoritariamente descrita en la literatura; en cada sesión se elige el plan de la librería con el menor PTV que se ajuste la vejiga de ese día, basándose habitualmente en el CBCT pretratamiento. A continuación, se resumen los métodos empleados, pudiéndose encontrar los detalles de los distintos estudios en Kong et al. ${ }^{140}$

- Uso de una o varias imágenes TC. Se describen dos posibilidades:

a. Con un TC se crean varios planes generando el PTV, ya sea con márgenes anisótropos, ya sea añadiendo valores al margen de forma isótropa (hasta 6 planes con márgenes $5 \mathrm{~mm}$ y $30 \mathrm{~mm}$ ). La desventaja de este método es que el uso de una única imagen y márgenes poblacionales no caracteriza la variabilidad del llenado y de las deformaciones de cada paciente.

b. A partir de varios TC adquiridos con diferentes condiciones (con la vejiga llena, con la vejiga vacía y en algún caso un llenado intermedio), se generan varios ITV, bien añadiendo diferentes márgenes, bien mediante modelos de deformación, generándose una librería de entre 2 y 5 planes. Esta estrategia tiene en cuenta la variabilidad interpaciente, pero no las eventuales diferencias sistemáticas entre la planificación y el tratamiento. Ambas posibilidades presentan la ventaja de que desde la primera sesión se dispone de un plan adaptado. ${ }^{143}$

- Uso de imágenes CBCT. La LdP se elabora utilizando el TC de planificación y los CBCT de la primera semana de tratamiento, utilizando diferentes combinaciones y/o número de volúmenes.

Algunos aspectos prácticos del uso del plan del día se discuten en Collins et al..$^{70}$ la no existencia de plan adecuado en la librería, con el consiguiente impacto en el flujo de trabajo; el potencial incremento de la dosis absorbida integral debido al uso de imágenes adicionales; la variabilidad interobservador en la interpretación de las imágenes diarias; el incremento de recursos y tiempo necesarios.

\subsubsection{ART online. Optimización de un nuevo plan}

Es el método que potencialmente presenta un mejor balance ya que puede tener en cuenta las incertidumbres sistemáticas y aleatorias, pero su impacto en un servicio de radioterapia es muy considerable, por lo que son escasos todavía los pacientes tratados mediante esta estrategia. Vestergaard et al. ${ }^{144}$ estudiaron el potencial del uso de RM para realizar ART mediante imágenes adquiridas al inicio y al final de la 
sesión, para planes generados con márgenes isotrópicos, anisotrópicos o basados en datos poblacionales. Hallaron una reducción considerable de la irradiación del tejido sano (disminución de $304 \mathrm{~cm}^{3}$ del PTV) concluyendo que esta estrategia tenía un gran potencial para la realización de una optimización diaria.

\subsubsection{Beneficios dosimétricos de ART en la vejiga}

La mayoría de los estudios consideran únicamente la reducción del volumen del PTV como beneficio del uso de ART, sin especificar los beneficios dosimétricos en el volumen a tratar u OAR, 140 incluso algunos hallan que no existen diferencias significativas en términos de cobertura. ${ }^{70}$ En algunos estudios se describe, con ART offline, una disminución del volumen del PTV de entre $15 \%$ y $40 \%$, con la consiguiente reducción en la irradiación del tejido sano, manteniendo una adecuada cobertura del CTV. ${ }^{71,143}$ Las publicaciones sobre ART online con plan del día, ${ }^{71,140,143}$ refieren también reducciones considerables en el volumen irradiado (alrededor del 40\%), cuantificando solo algunos autores la disminución en los OAR: reducción del 29\% de $V_{45}$ Gy en tejido sano y reducción del $30 \%$ de $V_{30}$ Gy del recto. La mayoría presentan mejoras en la cobertura del CTV y PTV frente al tratamiento convencional, hallándose valores del $V_{95 \%}$ (CTV) alrededor de $95-99 \% .{ }^{70}$ Así, según Kibron et al. ${ }^{143}$ el método de LdP es el que mejor balance de preservación de tejido sano y cobertura presenta frente a ART offline y no ART. Usando una optimización diaria, se describe una disminución adicional significativa en el tejido sano irradiado frente al uso del plan del día. ${ }^{144}$

Apenas hay publicaciones comparando diferentes técnicas de ART. Kong et al. ${ }^{21}$ estudiaron, retrospectivamente, las diferencias dosimétricas entre tratamiento no adaptado, ART offline, plan del día y nueva optimización. Evaluaron el volumen que recibe el $95 \%$ de la dosis absorbida prescrita $V_{95}$ Acu basándose en la dosis absorbida acumulada calculada en las imágenes CBCT diarias. Hallaron que todas las estrategias de ART reducía notablemente $V_{95}$ _Acu, siendo la optimización de un nuevo plan la que proporciona una mayor reducción (-25\% frente a $-12 \%$ para plan del día y $-16 \%$ para ART offline).

\subsection{Tumores ginecológicos}

La mayoría de los estudios de tumores ginecológicos corresponden al cáncer de cérvix localmente avanzado cuyo tratamiento estándar consiste en una primera fase de radioterapia externa (External Beam RadioTherapy, EBRT) con quimioterapia concomitante seguida de Braquiterapia (BT). La regresión del tumor durante la radioterapia, añadida a los movimientos de los órganos involucrados, hacen idóneo el usar una estrategia adaptativa. Esta se ha llevado a cabo con éxito en el ensayo prospectivo EMBRACE I, ${ }^{145}$ con 1416 pacientes de braquiterapia ginecológica enroladas desde 2008. La mayoría de las publicaciones sobre ART en cáncer de cérvix refieren a la componente de BT (Image-guided adaptive brachytherapy, IGABT) de acuerdo con las recomendaciones GEC-ESTRO, siendo pocos los estudios sobre ART en EBRT. ${ }^{71}$

\subsubsection{Cambios anatómicos}

En el caso del cáncer de cérvix se producen cambios de forma interfracción debidos principalmente a variaciones en el llenado de la vejiga, con desplazamientos en el extremo del útero de hasta $50 \mathrm{~mm}$, siendo menor el movimiento del cérvix, variando $\Sigma$ entre 3.4 y $5.5 \mathrm{~mm}$ y $\sigma$ entre 2.2 y $4.5 \mathrm{~mm},{ }^{11}$ predominantemente en el sentido antero-posterior (1-16 mm). ${ }^{146}$ Los cambios intrafracción pueden ser del orden de 2-3 mm. ${ }^{147}$ Por otro lado se produce una regresión del tumor durante el tratamiento con EBRT que, alrededor de la tercera semana puede ser del 60\%-80\% Ilegando a ser del $80 \%-90 \%$ en el momento de la BT. ${ }^{148}$

\subsubsection{Aplicación de ART}

El flujo de ART en BT siguiendo las recomendaciones de GEC ESTRO consiste en:

a. La adquisición de imágenes en el momento de la BT para determinar la regresión del tumor tras la quimioterapia y la EBRT, preferiblemente mediante imagen RM.

b. La delimitación de volúmenes con la introducción de un concepto de volumen blanco adaptativo que refleja la regresión del tumor y la topografía de los OAR al final de la EBRT (45-50 Gy), que es la base de la sobreimpresión mediante BT con la prescripción de niveles de dosis absorbida específicos (completando hasta entre 60 y 90 Gy), adaptada a los diferentes niveles de riesgo, a volúmenes GTV y CTV definidos al momento del diagnóstico y al de la BT.

c. La planificación individualizada del tratamiento de BT eligiendo el aplicador adecuado, habitualmente con una componente intersticial añadida, y optimización 3D de la distribución de dosis absorbida teniendo en cuenta la tolerancia de los OAR. ${ }^{148}$ Esta estrategia se ha utilizado también por algún grupo para otro tipo de tumores como cáncer de vagina o endometrio. ${ }^{71}$ 
En 2018 se puso en marcha EMBRACE II con objeto de validar prospectivamente los resultados de los ensayos EMBRACE I y Retro-EMBRACE. Entre las indicaciones de este ensayo está la de usar IMRT o VMAT para la radioterapia externa, siendo más relevantes para estas técnicas las variaciones anatómicas diarias. Además se recomienda utilizar de forma sistemática el concepto de ITV para compensar los movimientos de los órganos, utilizando una estrategia offline a partir de las primeras imágenes pretratamiento o mediante LdP que contemple las diferentes condiciones de llenado de la vejiga y el recto. ${ }^{148}$

La mayoría de los principales trabajos de ART en la parte de EBRT son simulados, los cuales se encuentran recogidos por Cree et al. ${ }^{146}$ Existe algún estudio sobre ART offline de replanificación semanal basándose en TC, CBCT o RM, ${ }^{37}$ pero lo más extendido es el estudio de ART online utilizando una LdP. ${ }^{149}$ Esta se genera habitualmente a partir de varios TC de planificación (2 o 3) con diferente volumen de llenado de la vejiga, o utilizando herramientas de deformación y datos poblacionales. ${ }^{150}$ Para el guiado y elección del plan diario se usa mayoritariamente el CBCT pretratamiento. ${ }^{71}$

Aunque no existe evidencia clínica sobre la superioridad del guiado con imagen RM frente a CBCT, con la mayor disponibilidad de la imagen RM incluso en la unidad de tratamiento, es esperable que la calidad de imagen que esta proporciona facilite la elección del plan del día, y sobre todo posibilite la replanificación online. ${ }^{146}$

\subsubsection{Beneficios dosimétricos de ART en tumores ginecológicos}

Las primeras publicaciones sobre IGABT con comparaciones con la planificación estándar ya mostraban notables ventajas dosimétricas. Tanderup et al. ${ }^{151}$ hallaron que para los tumores pequeños, mediante IGABT, se reducían los casos en que se violaban las tolerancias de los OAR del $72 \%$ al $6 \%$, manteniendo la cobertura. Para los tumores grandes aumentaba el D90\% (HR-CTV) en 7 Gy, resultando una cobertura completa en el $72 \%$ de los pacientes (frente al $25 \%$ para el tratamiento estándar), reduciendo también el número de veces que se superan los límites de los OAR. El estudio EMBRACE I ha demostrado que el uso de IGBAT con aplicadores específicos y optimización de la dosis absorbida mejora notablemente el control local y reduce la tasa de complicaciones severas. ${ }^{148}$ Serban et al. ${ }^{152}$ evaluaron el volumen que englobaban las isodosis correspondientes a diferentes niveles de dosis absorbida significativos (85 Gy, 75 Gy y 60 Gy) para 1200 pacientes de EMBRACE I. Entre sus resultados relevantes destaca la fuerte correlación existente entre el volumen de la isodosis y el volumen del HR-CTV lo cual pone de manifiesto que la adaptación de la dosis absorbida se ha realizado para cada tamaño de tumor y respuesta concreta. Por otro lado, hallaron una reducción en $\mathrm{V}_{85}$ Gy EQD210 del 23\% en el $80 \%$ de las pacientes, comparando con el resultante de prescribir 85 Gy al punto A.

En cuanto a la EBRT, algunos estudios retrospectivos presentan resultados dosimétricos con series de pocos pacientes. Van de Schoot et al. ${ }^{153}$ hallaron una cobertura inadecuada del CTV en el 17\% de las fracciones, con la estrategia no adaptativa. Esta mejoraba significativamente al utilizar el plan del día, haciendo que el D98\% fuese mayor de 95\%, y disminuyendo además de forma significativa la dosis al recto e intestino valoradas con $V_{1.5}$ Gy,$V_{2}$ Gy,$D_{50 \%}$ y $D_{2 \%}$ (las diferencias de $V_{2}$ Gy para el recto e intestino fueron del $20 \%$ y $8.5 \%$ respectivamente). Visser et al. ${ }^{149}$ compararon, retrospectivamente, los resultados obtenidos mediante la LdP frente a una estrategia simulada de ART online guiada por imagen RM para 17 pacientes asumiendo tratamientos de 10 minutos de duración. La reducción promedio del volumen de la dosis de prescripción encontrada fue de $422 \mathrm{~cm}^{3}$. El número de pacientes en que no se cumplía $V_{40}$ Gy (cavidad abdominal) $<350 \mathrm{~cm}^{3}$ pasaba de 13 a 5 pacientes (con margen de PTV de $5 \mathrm{~mm}$ ). Van de Schoot et al. ${ }^{154}$ estudiaron la posible mejora en un tratamiento simulado con protones respecto a fotones al emplear LdP. Para ambas estrategias, se encuentra que $\mathrm{V}_{95 \%}>98 \%$ en cerca del 95\% de los planes, y con protones se obtiene una reducción estadísticamente significativa, en la mayoría de los índices dosimétricos de los OAR, en la dosis mediana al intestino, la vejiga y el recto.

Los estudios actuales se encaminan a hallar estrategias de ART tanto en BT como en EBRT para maximizar la ventana terapéutica en pacientes individuales. ${ }^{148}$

\subsection{Otras localizaciones anatómicas}

Hasta aquí, se ha descrito la aplicación de ART en los tumores pélvicos, que constituyen el mayor número de pacientes tratados mediante esta estrategia, y también en localizaciones en las que se da actualmente una gran actividad en ensayos clínicos como son cabeza y cuello, pulmón y cérvix. ${ }^{155}$ Recogemos a continuación de forma más somera la aplicación de ART en otras regiones anatómicas.

\subsubsection{Cáncer de mama}

En el tratamiento del cáncer de mama se puede producir una reducción del seroma y del volumen de sobreimpresión que pueden ser considerables, ${ }^{156}$ alrededor del $50 \%$ de ambos, así como variaciones en la posición relativa del corazón en los casos de mama izquierda, de varios milímetros. ${ }^{11}$ Sager et al. ${ }^{156}$ evaluaron el repetir un TC hacia el final de la irradiación 
de la mama para definir de forma más ajustada la sobreimpresión. Con esta estrategia, encontraron una reducción significativa del 3-4\% en las dosis medias en la mama ipsilateral, el pulmón y el corazón. Algún autor describe el uso de TC diario (in-room) para realizar ART online en un proceso de 10 minutos de duración, obteniendo mejoras del 35\% en la dosis mínima y del 15\% en el valor de $D_{95 \%}$ de la dosis en la zona de sobreimpresión. La imagen RM también se ve como potencialmente valiosa para llevar a cabo ART online, con la consideración del incremento de dosis absorbida en la superficie. Otros autores, se han planteado la valoración de la necesidad de ART offline en base al volumen del seroma, encontrando que está justificada en el $80 \%$ de los pacientes con seroma mayor de $30 \mathrm{~cm}^{3} .37$

\subsubsection{Tumores abdominales}

Las incertidumbres de la posición de los órganos se deben a la respiración (intrafracción) y a los movimientos fisiológicos (interfracción) en las localizaciones abdominales. Estos pueden ser considerables (20-30 mm), teniendo mayor impacto en los tratamientos de SBRT. Se encuentra algún estudio sobre ART online con TC diario combinado con gating respiratorio en cáncer de páncreas. Debido a la reducción de márgenes permitida por la aplicación de ART disminuye el volumen irradiado con la dosis prescrita, de $46 \%$ a $16 \% .{ }^{37}$

En esta región anatómica cobra interés el uso del guiado por imagen RM para ART online que se encuentra ya descrito en algunos estudios de tratamientos de SBRT (Stereotactic MR-guided Adaptive Radiation Therapy, SMART). Henke et al. ${ }^{67}$ publicaron los resultados de un ensayo en el que se utilizaba SMART. Se adaptaban los tratamientos cuando, con arreglo a la anatomía del día, no se cumplían los objetivos dosimétricos o existía opción de incrementar la dosis. Según este criterio, se procedió a adaptar el plan en 81 de las 97 fracciones consideradas, siendo la causa en el 61 de ellas el incumplimiento de los límites a los OAR. Obtuvieron, en promedio, una mejora en la cobertura respecto a no adaptar, concluyendo que SMART incrementaba la ventana terapéutica en SBRT abdominal.

\subsubsection{Sarcoma de partes blandas}

Durante la radioterapia preoperatoria de los sarcomas de partes blandas en extremidades se producen tanto una reducción como un aumento del volumen (entre $-57 \%$ y $+28 \%$ ). 11 Dickie et al. ${ }^{157}$ estudiaron las variaciones dosimétricas que implicaban estos cambios en 22 pacientes tratados con un fraccionamiento estándar, mediante CBCT diario, para IMRT y 3D. Concluyeron que la adquisición de un segundo
TC cuando se observa un cambio en cualquiera de las dimensiones del tumor en el CBCT de más de $1 \mathrm{~cm}$, era una estrategia de ART offline adecuada para asegurar una cobertura adecuada, independientemente de la técnica de tratamiento utilizada.

\subsubsection{Sistema nervioso central}

Peyraga et al. ${ }^{158}$ estudiaron nuevos trazadores PET y diferentes secuencias de imagen RM, en la delimitación de las áreas radioresistentes de los tumores cerebrales y su papel en la radioterapia, en particular en ART. La conclusión del estudio es que, siendo un campo prometedor, todavía son necesarios avances tecnológicos y un abordaje multidisciplinar, que permitan la incorporación de ART en rutina mediante ensayos clínicos.

\section{Algoritmos de registro deformable}

Un algoritmo de DIR consta de tres partes fundamentales: ${ }^{159,160}$ la función objetivo $\mathscr{E}$, el modelo de transformación $T$, y el optimizador que guiará al algoritmo para encontrar el mejor resultado de la métrica de similitud $\mathscr{M}$. Dados dos estudios de imagen, denominados imagen fija $B$ y móvil $A$, el objetivo del registro deformable es encontrar la mejor transformación que minimice las diferencias entre la imagen $B$ y la imagen transformada de $A\left(A^{\prime}\right)$. Por tanto, el proceso del DIR es un proceso iterativo que comienza con un valor inicial de la métrica de similitud, $\mathscr{M}_{i}$, entre la imagen fija y la móvil y el optimizador intenta maximizar o minimizar dicha métrica (según como esté definida) dando lugar a un campo vectorial de deformación que deforma la imagen móvil. Tras ello, se recalcula de nuevo la métrica de similitud entre la imagen móvil deformada y la imagen fija, de manera que el proceso continuará iterativamente hasta que se obtenga el valor de la métrica óptimo, que proporcionará la mejor correspondencia de ambas imágenes.

En los siguientes apartados se describe cada uno de los elementos de los que consta un algoritmo DIR.

\subsection{Función objetivo y regularización de la transformación}

Como ya se ha indicado, el objetivo de DIR es encontrar el mejor vector de deformación, $T\left(x^{\prime}\right)$ donde $x^{\prime}$ es el vector posición en la imagen móvil, que minimice las diferencias entre $B(x)$ y $A^{\prime}=A\left(T\left(x^{\prime}\right)\right)^{\text {ฯ }}$. Por tanto,

\footnotetext{
T El símbolo prima (') denotará la aplicación de la matriz de transformación, $T$, al estudio de imagen correspondiente. $A^{\prime}$ es el resultado de aplicar $T$ al estudio $A$.
} 
los algoritmos de DIR intentan optimizar una función objetivo del tipo: ${ }^{161,162}$

$$
\mathscr{E}=\mathscr{M}\left(B, A\left(T\left(x^{\prime}\right)\right)\right)+\mathscr{R}(T)
$$

- $\mathscr{M}$ : métrica de similitud que cuantifica el nivel de coincidencia entre la imagen fija $B$ y la imagen móvil $A$.

- $\mathscr{R}$ : término de regularización. Puesto que se trata de una transformación espacialmente variante con $3 N$ grados de libertad ( $N$ : número de vóxeles del estudio de imagen), no existe una solución única a la hora de encontrar el DVF. El término $\mathscr{R}$ impone restricciones específicas al modelo de deformación implementado en el algoritmo para asegurarse que se obtienen transformaciones anatómicas razonables. Por ejemplo, si se clasifica una región como hueso, se restringirá el grado de deformación en dicha región.

La regularización ayuda a evitar mínimos locales de la función objetivo y es necesaria en los casos de DIR que se basan en niveles de intensidad ya que hay que estimar las componentes de los vectores desplazamientos de cada vóxel, conociendo sólo el valor de píxel.

La regularización de la función objetivo se puede realizar de dos formas:

\subsubsection{Implícita}

Se introduce en el modelo de deformación cualquier conocimiento previo que se tenga sobre las propiedades físicas de la estructura anatómica subyacente; para ello, se parametriza el DVF con funciones continuas.

\subsubsection{Explícita}

El término de regularización impone restricciones a la transformación para que se preserven las siguientes propiedades:

- Consistencia inversa (Inverse Consistency, IC). En general, los algoritmos de registro de imagen son asimétricos, es decir, el resultado no es el mismo si se registra $A$ a $B \circ B$ a $A$. Los algoritmos de IC restringen las transformaciones en ambos sentidos para que sean correspondencias inversas entre sí. ${ }^{163}$ Para ello, se introducen términos que penalizan la diferencia entre las transformaciones en un sentido y en el contrario de las respectivas asignaciones inversas.
- Conservación de la topología. Los algoritmos que mantienen la topología realizan una correspondencia vóxel a vóxel entre las dos imágenes. Esto implica que el DVF es invertible y continuo. La transformación es inyectiva si el determinante Jacobiano de DVF es mayor que cero.

- Conservación del volumen. Esta restricción es importante cuando se sabe que una estructura es incompresible y que los cambios en la misma sólo pueden ser debidos al movimiento (ej. miocardio) o cambios debidos a la acción de agentes de contraste. Si el jacobiano es mayor que uno indica una expansión del volumen, valores entre 0 y 1 señalan una reducción, mientras que un valor de 1 denota que no hay cambios.

- Restricción de rigidez. Puesto que en las imágenes médicas existen estructuras rígidas, algunos algoritmos introducen explícitamente restricciones de rigidez. ${ }^{161,164}$

La función objetivo del algoritmo ANACONDA, ${ }^{165}$ implementado en el sistema de planificación RayStation, consta de una métrica de similitud y dos términos de regularización que aseguran un DVF suave e invertible y evitan deformaciones inaceptables de las estructuras.

\subsection{Métodos de optimización}

El objetivo de la optimización es encontrar la transformación que mejor alinee las dos imágenes de acuerdo con una función objetivo como la descrita en la ecuación (1), de manera que la calidad del resultado obtenido dependerá del tipo de optimización elegida.

Los métodos de optimización del tipo gradiente descendente o gradiente conjugado son métodos iterativos que persiguen la convergencia de la función objetivo, $\mathscr{E}$, a un mínimo local, de manera que la dirección de búsqueda está basada en la derivada de dicha función objetivo respecto a los parámetros de la transformación (DVF). Los métodos quasi-Newton y de Gauss-Newton emplean la función Hessiana de la función de coste. Una descripción detallada de los métodos de optimización está fuera del alcance del presente documento, pero el lector puede consultar los trabajos de Sotiras et al., ${ }^{161}$ Klein et al. ${ }^{166}$ y Yu et al. ${ }^{167}$

\subsection{Métricas de similitud empleadas en el proceso de optimización}

Las métricas de similitud se clasifican en tres grupos según la forma en la que aprovecha la información disponible en las imágenes para realizar el proceso de correspondencia: métricas geométricas o basadas en características (featured-based), métricas basadas en 
intensidad de vóxel o icónicas, y métricas híbridas que combinan las dos anteriores.

\subsubsection{Métricas geométricas o featured-based}

En los métodos geométricos se establece una correspondencia entre puntos de referencia (marcas anatómicas, fiduciales o superficies de órganos) situados en regiones anatómicas de interés. ${ }^{168}$ El registro geométrico es robusto respecto a las condiciones iniciales y a la existencia de grandes deformaciones. Sin embargo, localizar puntos de referencia fiables es difícil e introduce una dependencia inter e intraobservador si son definidos manualmente; por otro lado, sólo se establecen correspondencias directas para el reducido conjunto de puntos de referencia seleccionados, lo que da lugar al empleo de interpolaciones para estimar la deformación de puntos situados fuera del conjunto de referencia, disminuyendo la exactitud cuando aumenta la distancia a los puntos de referencia.

Puesto que los puntos de referencia no dependen del valor de píxel (intensidad de la imagen), las métricas geométricas son muy útiles para registros multimodalidad.

- Basadas en puntos. La métrica se define como la suma del cuadrado de las distancias entre los puntos correspondientes:

$$
\mathscr{M}=\Sigma\left(p_{A^{\prime}}-p_{B}\right)^{2} / N
$$

siendo $p_{A^{\prime}}, p_{B}$ las coordenadas de los puntos de referencia en los estudios de imagen $A$ y $B$, respectivamente y $N$ el número total de puntos. La suma se realiza sobre el número de puntos, o puntos superficiales, sobre los que se ha establecido la correspondencia. Se divide por $N$ para normalizar la métrica.

Para determinar rotaciones y traslaciones se necesitan un mínimo de tres puntos; para transformaciones afines $^{* *}$ son necesarios, al menos, cuatro puntos no coplanares.

- Basadas en contornos. Las métricas geométricas basadas en superficies no requieren una correspondencia punto a punto, sino que intentan maximizar los solapamientos entre las superficies extraídas de ambos conjuntos de imágenes. Las

\footnotetext{
Transformación afín: transformación que consiste en una aplicación lineal seguida de una traslación, preservando las relaciones de colinealidad y coplanaridad entre puntos y las razones de distancia a lo largo de una línea. Además de producirse rotaciones y traslaciones, con conservación de distancias y ángulos, pueden tener lugar otro tipo de transformaciones como escalados, reflexiones o cizalladuras.
}

superficies de la imagen $B$ se representan como un volumen binario o una superficie poligonal, $S_{B}$, y las de la imagen $A$ se caracterizan como un conjunto de puntos $\left(p_{A^{\prime}}\right)$ muestreados de la superficie, de forma que la métrica se define como:

$\mathscr{M}=\Sigma \operatorname{dist}\left(p_{A^{\prime}}-S_{B}\right)^{2} / N$

siendo $\left(p_{A^{\prime}}-S_{B}\right)$ la distancia mínima entre el punto $p_{A^{\prime}}$ y la superficie $S_{B}$. La suma se realiza sobre el número de puntos, $N$, en el estudio $A$.

\subsubsection{Métricas basadas en intensidad de píxel/vóxel o icónicos}

Estas métricas utilizan la información de los niveles de grises o valores de píxel para medir cuán bien están registrados dos estudios de imagen, determinando la similitud entre las distribuciones de los valores de vóxel correspondientes de la imagen $B$ y la versión transformada de la imagen $A\left(A^{\prime}\right)$.

Para el caso de registro monomodalidad (el mismo dispositivo de imagen se utiliza para capturar el mismo tipo de información en ambos volúmenes) las métricas empleadas son:

\section{- Suma de diferencias cuadráticas (Sum of Squared Differences, SSD)}

$$
S S D=\sum_{X^{\prime} \in \Omega}\left(I_{A^{\prime}}-I_{B}\right)^{2} / N
$$

siendo:

- $\Omega$, área de solapamiento de la imagen fija $B$ y la imagen móvil deformada $A^{\prime}$.

- $I_{A^{\prime}}, I_{B}$ : valor de píxel de la imagen transformada $A^{\prime}$ y $B$, respectivamente.

- $N$, número de vóxeles evaluados en $\Omega$.

Es una métrica que funciona bien para imágenes poco ruidosas que tengan esencialmente idénticas intensidades para la anatomía que se desea registrar, como por ejemplo las series de un 4D-TC.

También se puede utilizar la suma de diferencias absolutas (Sum of Absolute Differences, SAD), pero es más restrictiva ya que considera que las regiones de interés (Region Of Interest, ROI) tienen las mismas intensidades en las dos imágenes.

$$
S A D=\sum_{x^{\prime} \in \Omega}\left|I_{A^{\prime}}-I_{B}\right| / N
$$


- Correlación cruzada (C). En esta métrica en lugar de minimizar las diferencias de intensidad, durante el registro se maximiza el producto de las intensidades:

$$
C=\sum_{x} B(x) \cdot T(A(x))
$$

La limitación de esta métrica es que es sensible a cambios en el valor de vóxel, por ejemplo, debido a la presencia de ruido, por lo que un aumento del valor de vóxel aumentaría el valor de C, sin que realmente haya una mejora en el registro de las imágenes.

- Coeficiente de correlación (CC). Soluciona el problema de la métrica de correlación cruzada, al asumir que existe una relación lineal entre los valores de intensidad en cada imagen y, por tanto, la métrica puede aplicarse a imágenes con diferentes valores de contraste y brillo. Se define como:

$$
C C=\frac{\sum_{x}(A(x)-\bar{A})(T(B(x))-\bar{B})}{\sqrt{\sum_{x}(A(x)-\bar{A})^{2} \sum_{x}(T(B(x))-\bar{B})^{2}}}
$$

Para el registro de imágenes de diferentes modalidades, tales como TC o RM, en los que los valores de píxel de las distintas estructuras son inherentemente diferentes, las métricas basadas en diferencias o productos de intensidades no son efectivas. En estos casos, se deben emplear métricas basadas en estadística de valores de intensidad, ya que, de este modo, la métrica no depende del valor absoluto de píxel. Un ejemplo de este tipo de métricas es la métrica de información mutua (IM), en la que el registro de imagen se considera como un proceso en el que se maximiza la cantidad de información compartida entre las dos imágenes.

- Información mutua (IM): ${ }^{169}$ la métrica IM intenta alinear los vóxeles cuyos valores tienen una probabilidad común de estar presentes en ambos estudios de imagen y se define como:

$$
\begin{aligned}
I M\left(I_{A^{\prime}}, I_{B}\right)= & \sum_{B} \sum_{A^{\prime}} P\left(I_{A^{\prime}}, I_{B}\right) . \\
& \cdot \log \frac{p\left(I_{A^{\prime}}, I_{B}\right)}{p\left(I_{A^{\prime}}\right) p\left(I_{B}\right)}
\end{aligned}
$$

siendo $p\left(I_{A^{\prime}}\right), p\left(I_{B}\right)$ las funciones de distribución de probabilidad de las intensidades $I_{A^{\prime}}$ e $I_{B}$, respectivamente y $p\left(I_{A^{\prime}}, I_{B}\right)$ la función de la distribución de probabilidad conjunta.
Una propiedad importante de la métrica de IM es su generalidad, es decir, no asume ninguna relación entre las intensidades de las imágenes; sin embargo, no es invariante al solapamiento que pueda existir entre ellas, es decir, el tamaño de la región que se solapa en las imágenes influye en el valor de IM (a mayor solapamiento, mayor número de muestras, lo que aumenta el poder estadístico de estimación de la distribución de probabilidad). Para solucionar este problema se emplea una versión normalizada de la IM.

En general, los métodos de registro basados en intensidad proporcionan mayor exactitud que los métodos geométricos ya que establecen una correspondencia densa (mayor número de puntos). No obstante, tienen un alto coste computacional y, al considerar todos los puntos de la imagen de la misma manera, pueden fallar en asignar la importancia que merecen los puntos anatómicos de interés. Además, como se ha indicado previamente, la solución a la que llegan depende de las condiciones iniciales, tales como el solapamiento inicial que exista entre ambas imágenes, de manera que la presencia de grandes deformaciones puede deteriorar la solución. Esto puede suponer un problema en regiones donde existe una gran variabilidad de los órganos como en la región abdominal o para la creación de modelos deformables de órganos de tejido blando basados en análisis poblacionales.

\subsubsection{Métricas híbridas}

Estas métricas intentan incorporar lo mejor de las dos opciones anteriores. Se distinguen dos tipos en función de cómo se emplee la información geométrica:

- La información adicional se utiliza independientemente. Se realiza un registro geométrico, a partir de marcas de referencia o superficies, que pre-alinea las dos imágenes para después realizar un registro basado en niveles de intensidad.

- La información adicional se utiliza como restricción. Utilizar un tipo de información independientemente de la otra para iniciar el siguiente paso, suele dar lugar a un aumento de robustez en el procedimiento de registro, pero no hay garantía de que las correspondencias que se establecieron en el paso previo se conserven. Para superar esta limitación, se usan las correspondencias que se estimaron durante el primer paso como una restricción para la estimación de las correspondencias durante el siguiente paso.

Weistrand y Svensson ${ }^{165}$ emplean el CC como métrica de similitud y permiten al usuario definir ROI o puntos de interés (Point Of Interest, POI) que guíen 
al algoritmo de deformación, de manera que la función objetivo incluye un término de penalización que consiste en la distancia euclídea entre las ROI o los POI correspondientes. EI DIR implementado en VoxAlign Deformation Engine ${ }^{\circledR}$ (MIM software $)^{170}$ es una combinación de DIR basado en contornos y niveles de intensidad, de manera que, trata de minimizar la métrica basada tanto en diferencias de intensidad entre las dos imágenes como diferencias cuadráticas entre las funciones distancia que representan las superficies de los contornos definidas en ambas imágenes.

\subsection{Modelos de deformación o de registro deformable}

Las correspondencias de POI o ROI entre dos imágenes se actualizan basadas en un modelo de transformación que optimiza la métrica de similitud. Dicho modelo define cómo hallar el vector deformación, $u$, del vector posición $x^{\prime}$ en la imagen móvil $A$, y que transforma $x^{\prime}$ en $x$ en la imagen fija $B$.

Independientemente del modelo de deformación empleado, Castadot et al. ${ }^{171}$ indican que la técnica multirresolución, la cual se describirá a continuación, se ha convertido en un estándar en el registro deformable ya que resuelve los inconvenientes de los algoritmos monorresolución en los casos de grandes deformaciones. En las estrategias multirresolución se construye una pirámide de imágenes en la que la base es la imagen original. Cada nivel de la pirámide consiste en una imagen submuestreada de la imagen del nivel inferior por un factor 2 . Por ejemplo, si la imagen original tiene un tamaño de $256 \times 256 \times 256$ vóxeles y la pirámide tiene 4 niveles, cada nivel tiene unas dimensiones, desde la base hasta el vértice, $(256 \times$ $256 \times 256),(128 \times 128 \times 128),(64 \times 64 \times 64)$ y $(32$ $\times 32 \times 32$ ), respectivamente. El algoritmo comienza en la resolución más gruesa, permitiendo que encuentre rápidamente una aproximación grosera de grandes desplazamientos, para después utilizar las imágenes de mayor resolución con el objetivo de refinar localmente el DVF. Sin embargo, los algoritmos monorresolución sólo son capaces de identificar pequeñas deformaciones (desplazamientos de pocos vóxeles) y si la magnitud de la deformación es muy grande, se necesitan muchas iteraciones para recuperar la deformación, pudiendo quedar estancado en una solución local, además de exigir una alta demanda computacional.

Los modelos de registro deformable pueden clasificarse en tres categorías dependiendo de si la transformación se basa en modelos físicos, en la teoría de la interpolación o en modelos biofísicos y/o biomecánicos.

\subsubsection{Transformación geométrica derivada de modelos físicos}

\subsubsection{Modelos de cuerpo elástico}

La imagen a deformar se considera como un cuerpo elástico, donde la deformación se describe mediante la ley de elasticidad de Hooke, de manera que, si un vóxel/ píxel es deformado en la imagen móvil, dicha deformación introduce una fuerza y el resto de vóxeles son deformados hasta que las fuerzas alcanzan el equilibrio.

La ley de Hooke describe modelos elásticos lineales, los cuales no son capaces de manejar grandes deformaciones y no garantizan la IC, por lo que es más adecuado emplear modelos elásticos no lineales que además conservan la topología.

\subsubsection{Modelos de fluido viscoso}

En este caso la imagen a deformar se modela como un fluido viscoso donde la fuerza, $F$, que deforma la imagen móvil es proporcional a la velocidad de la deformación según la ecuación de Navier-Stokes:

$$
\mu_{f} \nabla^{2} v+\left(\mu_{f}+\lambda_{f}\right) \nabla(\nabla \cdot v)+F=0
$$

siendo $\mu_{f}$ y $\lambda_{f}$ los coeficientes de viscosidad.

$v\left(x^{\prime}, t\right)$ : campo de velocidad de la deformación en el instante de tiempo $t$ y en la posición $x^{\prime}$ de la imagen móvil. Se relaciona con el vector desplazamiento como $v\left(x^{\prime}, t\right)=\partial_{t} u\left(x^{\prime} ; t\right)+\left(\nabla\left(u\left(x^{\prime} ; t\right) v\left(x^{\prime} ; t\right)\right)\right.$.

Estos modelos permiten que la ROI en la imagen móvil sea proyectada a la ROI en la imagen fija conservando la topología de las estructuras deformadas, incluso para grandes deformaciones no lineales. Las deformaciones de fluido viscoso son continuas, diferenciables y mantienen una correspondencia punto a punto.

\subsubsection{Modelos de difusión (Demons)}

La mayoría de los modelos de difusión implementados se basan en el algoritmo de "Demons" de Thirion. ${ }^{172}$ La idea principal es considerar el contorno de un objeto en la imagen fija como una membrana semipermeable sobre la que se sitúan Demons o ejecutores, de manera que, al actuar sobre la imagen móvil, modelada como una rejilla deformable, esta se difunde a través de dicha membrana.

Se trata de un algoritmo basado en intensidad en el que la imagen móvil $(A)$ se deforma de acuerdo a las diferencias de intensidad local entre dicha imagen y la imagen fija $(B)$, utilizando un modelo de fuerza basado en flujo óptico, de manera que el DVF en una posición de la imagen móvil se expresa como: 


$$
u\left(x^{\prime}\right)=\frac{\left(I_{A^{\prime}}\left(x^{\prime}\right)-I_{B}(x)\right) \cdot \nabla I_{B}(x)}{\left|\nabla I_{B}(x)\right|^{2}+\left(I_{A^{\prime}}\left(x^{\prime}\right)-I_{B}(x)\right)^{2}}
$$

Por definición, el algoritmo Demons realiza el registro minimizando las diferencias de intensidad entre los estudios de imagen a registrar, por lo que presenta una capacidad limitada para registro monomodalidad o multimodalidad de estudios de imágenes que presenten mucho ruido o artefactos localizados como en el caso del CBCT. ${ }^{173}$

\subsubsection{Transformación geométrica derivada de la teoría de interpolación}

En contraposición a los modelos descritos hasta ahora, en los que el vector de transformación se calcula en todos los puntos, estos modelos obtienen un DVF interpolado, expresado como combinación lineal de funciones base y determinado a partir de un número finito de puntos de control seleccionados por el usuario, por lo que también se los conoce como modelos paramétricos.

Una de las ventajas de estos métodos es que el cambio local de un punto se puede realizar por puntos cercanos que se encuentran a cierta distancia, por lo que reducen de manera notable el tiempo de cálculo y recursos de memoria del procesador.

\subsubsection{Funciones de base radial (Thin-plate splines ${ }^{\dagger \dagger}$ )}

Los thin-plate splines se representan de manera natural por funciones base radiales que determinan la correspondencia espacial entre cualquier posición $x$ en el espacio y su nueva posición $f(x)$, en función de la distancia de $\mathrm{x}$ a una muestra conocida de puntos de control $p\left\{p_{i}, i=1,2, \ldots, k\right\}$. En el campo de DIR, los puntos de control están representados por áreas de fuerza y la fuerza representa los desplazamientos desde los puntos de control en la imagen móvil y sus puntos de control en la imagen fija. La selección de los puntos de control en ambas imágenes se puede hacer de manera automática o manual. El vector deformación de un píxel en la imagen móvil se puede expresar como:

$$
u\left(x^{\prime}\right)=C \cdot x^{\prime}+D+\sum_{i=1}^{2} w_{i} \varphi\left(\left\|x-p_{i}\right\|\right)
$$

$\|\cdot\|$ : distancia euclídea.

Las matrices de coeficientes $C$ y $D$, y el factor de peso $w_{i}$, son calculados a partir de los $n$ pares de puntos de control emparejados. $\varphi$ es la función base que mide la distancia desde $x^{\prime}$ al $i$ ésimo punto de control

$\dagger^{\dagger}$ Spline: curva diferenciable definida en porciones mediante polinomios. $p_{i}$ en la imagen móvil. Shusharina y Sharp ${ }^{174}$ proponen el uso de una función de base radial gaussiana, $\varphi(r)=$ $e^{-\|r\|^{2} / \sigma^{2}}$, para crear campos vectoriales que interpolen de manera exacta las correspondencias de los fiduciales en la imagen fija y en la móvil.

La ventaja de este tipo de algoritmos es que son capaces de interpolar un campo de deformación a partir de valores conocidos distribuidos irregularmente. Sin embargo, su uso está limitado a problemas de registro global, ya que el desplazamiento de una sola marca de referencia puede distorsionar la deformación en toda la imagen. Para solucionar este problema, es necesario definir suficientes fiduciales en la región de interés, o introducir un término de regularización, como proponen Shusharina y Sharp, ${ }^{174}$ que además soluciona los problemas de IC que presentan este tipo de algoritmos.

\subsubsection{Deformaciones de forma libre (Free Form Deformations, FFD)}

FFD es uno de los algoritmos más utilizados debido a su habilidad para estimar DVF continuos y regulares. La idea de este modelo es deformar un objeto manipulando una máscara subyacente de puntos de control, es decir, una imagen móvil de tamaño $N_{x} \times N_{y} \times N_{z}$. Se deforma interpolando el vector desplazamiento $(d)$ de los puntos de control sobre una rejilla rectangular de tamaño $K_{x} \times K_{y} \times K_{z}\left(K_{i} \ll N_{i}\right)$ que se superpone a la imagen, de manera que el DVF se calcula como:

$$
u\left(x^{\prime}\right)=\sum_{l=0}^{3} \sum_{m=0}^{3} \sum_{n=0}^{3} B_{l}\left(u_{x}\right) B_{m}\left(u_{y}\right) B_{n}\left(u_{z}\right) \cdot d_{i+l, j+m, k+n}
$$

donde $u_{x}, u_{y}$, y $u_{z}$ son las distancias desde $x^{\prime}$ a los puntos de control más cercanos, $(i, j, k)$, respectivamente. $B_{l}$ representa la función base $l$ ésima de $B$-spline.

El número de puntos de control $B$-spline utilizados durante el registro determina la cantidad de deformación permitida durante el registro y la aproximación multirresolución se consigue modificando el espaciado de la rejilla de los puntos de control. A pesar de ser un algoritmo que proporciona transformaciones continuas, la conservación de la topología no está garantizada.

El algoritmo VoxAlign Deformation Engine $($ implementado por MIM para registro deformable de imágenes de la misma modalidad, consiste en un algoritmo restringido, basado en intensidad FFD. ${ }^{33}$ La deformación comienza con un registro rígido para a continuación realizar el registro deformable, en el que se emplea una aproximación multirresolución para definir una rejilla de los puntos de control sobre la imagen fija. La función de coste combina criterios de similitud y suavidad. Broggi et al. ${ }^{175}$ validaron este algoritmo y su uso para la proyección de contornos de las parótidas en imágenes de resonancia de pacientes tratados con radioterapia. El error de proyección promedio con respecto a los 
contornos de referencia fue menor que la diagonal del vóxel (2 mm), y el DSC fue de 0.8.

\subsubsection{Transformación geométrica basada en modelos biofísicos/biomecánicos}

Los modelos biofísicos/biomecánicos también se basan en modelos físicos, pero a diferencia de los descritos en el apartado 4.4.1, están íntimamente relacionados con la anatomía y fisiología de los tejidos u órganos que se van a deformar. Habitualmente, emplean métodos de elementos finitos (Finite Element Methods,
FEM) para modelar las propiedades de los tejidos en consideración.

La razón principal para emplear este tipo de modelos radica en la hipótesis de que, cuanta más información se conozca a priori de las propiedades biomecánicas del tejido, más fiable será la estimación de DVF complejos empleando pocos grados de libertad. Además, se asume que la plausibilidad de la deformación estimada mejorará con la creación de modelos de órganos deformables coherentes con sus propiedades físicas y el algoritmo será capaz de manejar mejor grandes deformaciones y/o deformaciones atípicas. Estos modelos son más apropiados para registro de imágenes de un

Tabla 3. Resumen de los tipos de algoritmos, métrica de similitud, modelo de transformación y método de optimización implementados en las distintas soluciones comerciales para los algoritmos de registro deformable.

\begin{tabular}{|c|c|c|c|c|c|c|}
\hline $\begin{array}{c}\text { Casa } \\
\text { comercial }\end{array}$ & Algoritmo & $\begin{array}{l}\text { Métrica de } \\
\text { similitud }\end{array}$ & $\begin{array}{l}\text { Modelo de } \\
\text { transformación }\end{array}$ & $\begin{array}{l}\text { Método de } \\
\text { optimización }\end{array}$ & Uso & Notas \\
\hline \multirow{3}{*}{ MIM } & $\begin{array}{l}\text { Intensity- } \\
\text { Based }\end{array}$ & SSD & $\begin{array}{l}\text { Constrained, } \\
\text { intensity based, } \\
\text { free form }\end{array}$ & $\begin{array}{l}\text { Gradiente } \\
\text { descendiente } \\
\text { modificado }\end{array}$ & $\begin{array}{c}\text { TC-TC } \\
\text { CBCT-CBCT }\end{array}$ & $\begin{array}{l}\text { Reg Reveal: } \\
\text { herramienta de control } \\
\text { de calidad para evaluar } \\
\text { DIR }\end{array}$ \\
\hline & Hybrid-based & $\begin{array}{l}\text { Intensidades } \\
\text { entre } \\
\text { imágenes + } \\
\text { diferencias } \\
\text { contornos }\end{array}$ & Free form & $\begin{array}{l}\text { Gradiente } \\
\text { descendiente } \\
\text { modificado }\end{array}$ & $\begin{array}{c}\text { TC-TC } \\
\text { TC-СВCT } \\
\text { СВСТ-СВСТ }\end{array}$ & Reg Refine $^{a}$ \\
\hline & Multi-Modality & $\begin{array}{l}\text { Diferencias } \\
\text { de vóxeles } \\
\text { vecinos }\end{array}$ & Free form & Gauss-Newton & $\begin{array}{l}\text { RM-TC } \\
\text { RM-RM } \\
\text { TC-CBCT } \\
\text { TC-TC }\end{array}$ & \\
\hline \multirow[t]{2}{*}{ RayStation } & ANACONDA & $\begin{array}{c}\text { Híbrida: CC + } \\
\text { ROI y/o POI }\end{array}$ & Free form & & $\begin{array}{c}\text { TC, } \text { CBCT y } \\
\text { RM }\end{array}$ & $\begin{array}{l}\text { La función objetivo } \\
\text { incluye dos términos de } \\
\text { regularización (rejilla y } \\
\text { forma) }\end{array}$ \\
\hline & MORFEUS & & Biomecánico & & $\begin{array}{l}\text { Cualquier } \\
\text { modalidad de } \\
\text { imagen }\end{array}$ & \\
\hline \multirow[b]{2}{*}{ Varian } & \multirow[b]{2}{*}{ Velocity ${ }^{T M}$} & $\mathrm{Ml}$ & $\begin{array}{c}\text { Elástico } \\
\text { (B-esplines) }\end{array}$ & & & \\
\hline & & $\mathrm{Ml}$ & $\begin{array}{l}\text { Híbrido: Elástico } \\
\text { (B-esplines) + } \\
\text { ROI }\end{array}$ & & $\begin{array}{l}\text { RM-TC } \\
\text { RM-RM } \\
\text { TC-CBCT } \\
\text { TC-TC }\end{array}$ & \\
\hline Accuray & & NCC & $\begin{array}{l}\text { No paramétrica } \\
\text { Multirresolución }\end{array}$ & & $\begin{array}{l}\text { TC-MVCT } \\
\text { TC-TC } \\
\text { TC-RM }\end{array}$ & $\begin{array}{l}\text { Regularización } \\
\text { mediante suavizado } \\
\text { Reg Reveal }\end{array}$ \\
\hline Pinnacle & & & $\begin{array}{c}\text { Demons } \\
\text { multirresolución }\end{array}$ & & $\begin{array}{c}\text { TC-TC } \\
\text { TC-CBCT }\end{array}$ & $\begin{array}{l}\text { Regularización } \\
\text { mediante filtro } \\
\text { suavizado gausiano }\end{array}$ \\
\hline
\end{tabular}

a Los algoritmos Intensity-based y Multi-Modality disponen de una herramienta adicional denominada Reg Refine que permite al usuario definir alineamientos locales rígidos que proporcionen información adicional para ayudar al algoritmo en la proximidad de esas áreas. Puede ser utilizado de manera iterativa para ejecutar el DIR, para evaluar la exactitud local del DIR y sugiere alineamientos locales para mejorar el resultado del DIR hasta conseguir la alineación óptima buscada. 
mismo paciente, ya que el modelo biofísico no suele ser válido para registro de imágenes interpaciente.

Entre los inconvenientes que presentan, cabe destacar que los modelos necesitan una definición exacta de las propiedades del material y de la geometría (segmentación precisa de la estructura anatómica y adecuada transformación en una malla del dominio de imagen) así como de las condiciones de contorno (especificadas como restricciones de desplazamientos para las superficies de los órganos segmentados). La incertidumbre en la especificación de estos parámetros y el hecho de que se empleen valores genéricos (no definidos para cada caso particular) puede dar lugar a sesgos no deseables.

DIR basado en modelos biomecánicos se ha empleado en localizaciones como cabeza y cuello, ${ }^{176,177}$ pulmón, ${ }^{178-182}$ mama, ${ }^{183}$ y próstata ${ }^{184-186}$.

Morfeus es el nombre comercial que ha dado RaySearch Laboratories a su algoritmo de registro deformable biomecánico. ${ }^{187}$ Este algoritmo genera modelos de malla tetraédrica de uno o múltiples órganos a partir de las ROI delimitadas en la imagen de referencia a las que asigna propiedades de material elástico lineal. Para un subconjunto de tejidos de la imagen objetivo también se crean mallas triangulares a partir de los contornos que existen en dicho estudio de imagen. Estas ROI con mallas en ambas imágenes, denominadas "ROI de control", sufren deformaciones individuales para alinear las superficies y servir como condiciones de contorno. Las ROI englobadas dentro de la ROI "contorno externo", como por ejemplo los pulmones, pueden interaccionar con elementos del contorno externo con un método fijo o deslizante. Los desplazamientos internos del modelo tetraédrico son resueltos mediante análisis de elementos finitos, incluso para aquellas ROI que no sufrieron deformaciones de la superficie individual y, por lo tanto, se deforman implícitamente.

Velec et al. ${ }^{188}$ determinaron que la exactitud del algoritmo Morfeus, evaluado para las localizaciones de tórax, abdomen y pelvis, fue similar a la resolución de vóxel de la imagen en promedio en múltiples modalidades de imagen.

\subsection{Algoritmos implementados en softwares comerciales}

De acuerdo con la recomendación del TG 132, ${ }^{10}$ el fabricante debe proporcionar información detallada sobre su algoritmo para que el usuario pueda realizar un uso adecuado del mismo. En la tabla 3 se resumen las características más relevantes de los algoritmos DIR disponibles actualmente:

\section{Validación de los algoritmos de registro deformable de imagen}

\subsection{Registro deformable de imágenes}

Mediante la relación que establece el DIR podemos proyectar los contornos y dosis de una imagen a otra. Proyectar las ROI de una imagen a otra, permite a los técnicos de imagen y a los oncólogos radioterápicos, disminuir el tiempo dedicado a la delimitación de las estructuras anatómicas de los pacientes. Cuando se proyectan los contornos es recomendable revisar si estos coinciden con la estructura anatómica y si no fuera el caso, habría que modificarlos.

Al igual que se proyectan las ROI utilizando los vectores de deformación, también podemos proyectar las dosis. Esta es la base de la ART offline, ya que para tomar la decisión de adaptar un plan debemos conocer la dosis acumulada, que es la dosis proyectada desde diferentes imágenes de IGRT hasta el pTC.

El mayor problema para implementar clínicamente la ART en los centros es que, además del aumento de la carga de trabajo y la falta de equipamiento avanzado, no existe un método estándar para determinar la incertidumbre que introduce el DIR cuando relaciona las dos imágenes. Eso implica que cuando el algoritmo no relaciona correctamente dos imágenes mediante el vector de deformación de campo, obtendremos como resultado una incorrecta proyección de contornos y de dosis de una imagen a otra. Si el DIR se utiliza únicamente para proyectar contornos, estos se pueden modificar para que coincidan con la estructura anatómica, por lo que no aumenta la incertidumbre del proceso radioterápico. En cambio, cuando se utiliza el DIR para proyectar la dosis de una imagen a otra, el algoritmo puede estar relacionando incorrectamente las dos imágenes, lo que implicaría observar que las estructuras están recibiendo una dosis que no es la realmente administrada. Por este motivo, debemos tener especial cuidado a la hora de valorar y tomar decisiones clínicas si lo que estamos observando son dosis proyectadas.

En el TG- $132^{10}$ se realizan importantes recomendaciones sobre la utilización del registro de imágenes y la fusión en radioterapia. A continuación, se resumen los puntos más destacados de este informe sobre la validación de los algoritmos de registro deformable:

- El proceso de registro de imágenes conlleva incertidumbres que se deben evaluar y considerar.

- Se debe comprobar todo el sistema (end-to-end test) mediante un maniquí físico.

- Para la puesta en marcha de un sistema de registro de imágenes se requiere una validación cuantitativa; sin embargo, en la práctica clínica habitual, se 
debe realizar una verificación cualitativa del registro de imágenes para garantizar la aceptabilidad del registro.

- Entre los métodos cuantitativos para determinar la exactitud del algoritmo se encuentran:

- Distancia entre puntos.

- Solapamiento de estructuras.

- Determinante del jacobiano.

- Consistencia inversa.

- Maniquíes físicos.

- Los algoritmos de DIR deben poder exportar un DVF en formato DICOM.

- La incertidumbre del registro debe tenerse en cuenta, por ejemplo, en los márgenes de tratamiento (PTV).

- Para cada localización se debe desarrollar un protocolo escrito que proporcione una descripción de los aspectos más importantes del registro.

En el informe de la AAPM no se aborda la problemática de la utilización de los algoritmos de registro deformable para acumular dosis y este es uno de los puntos más delicados a la hora de utilizar algoritmos de registro deformable. Cuando comparamos la dosis calculada del plan de tratamiento original en el pTC con la dosis proyectada desde otra imagen a este PTC, no podemos discriminar si las diferencias que se muestran en el HDV se deben a un error del algoritmo de DIR en la relación de los vóxeles de las imágenes o a que el paciente ha cambiado anatómicamente.

En la siguiente sección se van a detallar los diferentes métodos para validar un algoritmo de registro deformable de imágenes, incluyendo los propuestos en el informe de la AAPM sobre registro y fusión de imágenes en radioterapia.

\subsection{Métodos de validación del DIR}

Existen diferentes métodos para validar los algoritmos DIR:

- La utilización de marcas, puntos de referencia y/o contornos de las dos imágenes de adquisición. ${ }^{189-197}$

- El uso de la consistencia inversa. ${ }^{168,198-200}$

- El empleo de maniquíes deformables. ${ }^{201-206}$

- La utilización de aplicaciones de software específicas. ${ }^{163,207-215}$

El método de utilización de puntos de referencia (Target Registration Error, TRE) o ROI se basa en que, si dos imágenes están perfectamente relacionadas mediante los vectores de deformación del campo y colocamos el punto o el contorno igual en las dos imágenes, al proyectarlos de una imagen a otra, este debe coincidir perfectamente en la misma área de la otra imagen.

La metodología para la utilización de POI para definir el TRE sería la siguiente: Colocamos un punto en la imagen $A$ en una zona determinada y en la imagen $B$ colocamos otro punto en la misma zona. Si deformamos el punto desde la imagen $A$ hasta la imagen $B$, este punto debe coincidir en el espacio. Esto únicamente se cumple si la imagen $A$ y la $B$ están perfectamente relacionadas con los vectores de campo y se han colocado perfectamente los puntos. Con las distancias entre los dos puntos podemos determinar la exactitud del algoritmo de DIR.

En el caso de los contornos, la metodología sería similar, con la diferencia de que aquí se delimitaría la misma estructura en las dos imágenes. Si queremos validar un algoritmo DIR con contornos para imágenes de CBCT, el proceso sería el siguiente: primero se debería delimitar la misma estructura en imagen de TC y en la de CBCT. Después, se proyectaría la estructura del CBCT al TC mediante el algoritmo a evaluar, por lo que tendríamos en el estudio TC dos estructuras, la que se delimitó originalmente y la proyectada desde el CBCT. Si el algoritmo hubiera relacionado perfectamente las dos estructuras y estas hubieran sido perfectamente delimitadas en las dos imágenes, la estructura original y la proyectada deberían coincidir. Comparando las dos estructuras podemos determinar la exactitud del DIR con índices de similitud y/o de solapamiento. Las dos métricas más conocidas son la distancia media y el DSC.

La IC se ha definido en la sección 4.1.2. de algoritmos de registro deformable. Un algoritmo que cumpla la propiedad de IC nos permitiría proyectar la dosis, $\mathrm{ROI}$ o POI entre exactamente las mismas zonas anatómicas de las dos imágenes, independientemente de cual fuera la imagen de referencia y cual la imagen deformada.

Tanto para la métrica de IC como para las distancias entre contornos o puntos, la tolerancia según el informe de la AAPM es como máximo 2-3 mm. La tolerancia del índice de similitud de contornos está entre 0.8 y 0.9 .

Los maniquíes deformables se pueden separar en dos grupos, los dosimétricos y los que están basados en marcas. Todos ellos son maniquíes deformables, ya que lo que interesa es determinar la exactitud del algoritmo de DIR cuando relaciona el maniquí deformado y sin deformar. En los maniquís deformables dosimétricos, como por ejemplo los de tipo gel, se irradia y se toma una imagen del TC del maniquí sin deformar y se determina la dosis, luego se realiza la misma operación, pero deformado. Con este método, podemos conocer cuál es la dosis deformada real y la dosis deformada calculada por el algoritmo. En el caso de los maniquís deformables con marcas, el 
proceso es similar, se toma una imagen de TC con el maniquí deformado y otra imagen sin deformar. Como el maniquí tiene unas marcas internas que podemos identificar, podemos determinar en distancias la exactitud del DIR.

Las aplicaciones específicas de software permiten introducir deformaciones conocidas en la imagen que se pueden comparar con las deformaciones identificadas por nuestro algoritmo. Así, podemos comparar la deformación que nos ofrece nuestro algoritmo con la deformación real conocida. Este es el método elegido por el grupo de la AAPM para realizar el control de calidad de los registros de imágenes. Para poder realizar estas pruebas, se necesita que el software sea capaz de trabajar con DVF en formato DICOM. Según la revisión bibliográfica realizada, las tolerancias para el registro deformable de dosis es que el 95\% de vóxeles este dentro de $2 \mathrm{~mm}$ y que el error máximo sea inferior a $5 \mathrm{~mm}$.

Ya existen diferentes publicaciones donde se validan los algoritmos de DIR siguiendo el informe de la AAPM. ${ }^{216,217}$

Todos los métodos tienen limitaciones específicas. Por ejemplo, las deformaciones introducidas mediante software no tienen en cuenta la adquisición de imágenes y debido a que realizan unas deformaciones artificiales, estas pueden no ser representativas de las que se producen en los órganos. Respecto a los maniquís, la mayoría de los hospitales no tienen acceso a ellos y, al igual que ocurre en el software, es muy complicado en los maniquís físicos reproducir las deformaciones (y los tejidos) de los órganos humanos. El problema cuando se utilizan contornos o POI es que la selección de puntos, o la creación de estructuras, tienen una incertidumbre asociada al observador. Además, se estudian pocos vóxeles y es muy difícil valorar las zonas con poco contraste, ya que no es trivial delimitar o colocar puntos en estas zonas. ${ }^{205}$ Una de las limitaciones generales de estos métodos es que todos ellos, a excepción de los maniquíes deformables dosimétricos, suelen ofrecer los resultados en términos de distancias o índices, mientras que la magnitud de mayor interés en la radioterapia es la dosis absorbida. La incertidumbre geométrica puede implicar una diferencia en dosis absorbida diferente en función de si se encuentra en una zona de gran gradiente de dosis, como es la zona entre el PTV y un OAR, o puede implicar una mínima diferencia en dosis absorbida si se trata una zona homogénea del PTV o lejos de la zona de tratamiento. ${ }^{213}$

Por último, queremos señalar el error inherente de estos algoritmos al proyectar la dosis absorbida de una imagen a otra, ya que la dosis absorbida se define como energía depositada por unidad de masa, y la masa del vóxel puede variar de la imagen original a la imagen a la que se le proyecta la dosis absorbida. Este variación de la masa puede producir errores superiores al $5 \% .{ }^{214}$

\subsubsection{Validación con puntos de los algoritmos de registro deformable}

Uno de los métodos más sencillos, aunque laborioso, para determinar la exactitud de un algoritmo de registro deformable es la utilización de POI. Por este motivo desde el grupo de trabajo hemos utilizado los pacientes de la publicación de García-Mollá et al. ${ }^{168}$ para comparar los resultados en distancias de gran parte de los programas de registro deformable que actualmente están disponibles en el mercado.

En la comparación se utilizaron cinco pacientes con cáncer de cabeza y cuello. Para cada paciente se utilizaron una imagen PTC y tres imágenes CBCT para determinar la precisión del algoritmo de DIR. Las imágenes de CBCT se adquirieron utilizando un sistema ELEKTA XVI CBCT con un espesor de corte y tamaño de píxel de $1 \mathrm{~mm}$.

Se colocaron $10 \mathrm{POI}$ en diez zonas anatómicamente reconocibles en la imagen de pTC, en los cinco pacientes. Posteriormente se seleccionaron nuevamente en las mismas áreas en los tres $\mathrm{CBCT}$. El procedimiento consistió en proyectar los POI al pTC utilizando el DVF. La diferencia en las distancias entre cada POI proyectado desde el CBCT y su POI de referencia correspondiente, determinó la exactitud en distancia del DIR.

No se utilizaron estructuras ni puntos para guiar a los algoritmos, únicamente los valores de píxel de las imágenes.

En la tabla 4 se muestran los resultados para el algoritmo ANACONDA de RayStation, el elástico de Velocity ${ }^{\top \mathrm{M}}$, Intensity-Based de MIM maestro® y el Demons de Pinnacle.

De los resultados se puede concluir que no existe una gran diferencia en la exactitud entre los algoritmos para pacientes de cabeza y cuello. Es en el tejido blan-

Tabla 4. Distancias promedio con su desviación típica (factor de cobertura $k=1$ ) entre los puntos de referencia del PTC y los puntos proyectados desde los CBCT al PTC mediante los vectores de deformación.

\begin{tabular}{c|c|c|c}
\multirow{2}{*}{} & \multicolumn{3}{|c}{ TRE (cm) } \\
\cline { 2 - 4 } & Promedio & Zona rígida & Zona blanda \\
\hline RayStation & $0.19 \pm 0.07$ & $0.16 \pm 0.06$ & $0.22 \pm 0.06$ \\
\hline Velocity ${ }^{\mathrm{TM}}$ & $0.21 \pm 0.11$ & $0.18 \pm 0.07$ & $0.24 \pm 0.12$ \\
\hline Pinnacle & $0.27 \pm 0.14$ & $0.20 \pm 0.10$ & $0.34 \pm 0.14$ \\
\hline MIM maestro® & $0.20 \pm 0.06$ & $0.18 \pm 0.07$ & $0.23 \pm 0.11$
\end{tabular}


do donde el algoritmo de Pinnacle tiene una exactitud menor que el resto de los algoritmos. Este resultado está en concordancia con lo publicación de Pukala et al. ${ }^{190}$ donde este algoritmo muestra una exactitud menor en algunos órganos con poco contraste. En este estudio MIM maestro® obtiene sistemáticamente valores de TRE menores que el resto de los algoritmos, resultado que nosotros no hemos obtenido en nuestra evaluación. Esto puede ser debido a que no hemos utilizado la misma metodología y a que las versiones de los algoritmos son diferentes.

A excepción del valor de Pinnacle para tejidos blandos, el resto está dentro de las tolerancias ( 2-3 mm) recomendadas por el informe de la AAPM. ${ }^{10}$

Hay que tener en cuenta que estos resultados se han realizado sobre pacientes de cabeza y cuello, por lo que no son extrapolables a zonas con órganos con importantes deformaciones y/o traslaciones, como por ejemplo la zona de la pelvis.

Entre las limitaciones del trabajo están las que son inherentes al método TRE, como que únicamente se validan pocas zonas y que están suelen tener contraste. Habría que añadir la incertidumbre de colocación de los puntos, pero esta limitación teórica no lo es en este estudio porque varios observadores colocaron los puntos y se demostró que el valor de la incertidumbre era mucho menor que la del algoritmo. Otra limitación viene dada debida a que Pinnacle no exporta puntos mediante el DVF, por lo que se crearon unas estructuras con forma de cruz invertida. Estas estructuras se pueden proyectar y se obtiene el TRE entre el centro de la estructura original y el proyectado.

\section{Recomendaciones}

En este apartado se resumen las recomendaciones de este grupo de la SEFM a la hora de implementar la radioterapia adaptativa en la práctica clínica. Dado que la ART es una técnica relativamente joven, en constante desarrollo y con distintas dificultades técnicas que dependen de la estrategia utilizada, estas recomendaciones deben ser tomadas como una guía para poder implementarla en los centros y no como unas normas a cumplir. El citado informe del TG 132,10 proporciona una serie de recomendaciones para la utilización del registro y fusión de imágenes, pero aquí se detallarán solo los aspectos relacionados con los algoritmos de registro deformable y ART.

Siguiendo la estructura del documento las recomendaciones se han clasificado con arreglo a la estrategia, offline y online.

\subsection{Recomendaciones ART offline}

\subsubsection{Puesta en marcha}

- Conocer el funcionamiento teórico y las limitaciones de la tecnología a utilizar, especialmente de los algoritmos de DIR. Para ello, las casas comerciales deben facilitar la documentación necesaria.

- Estimar los recursos necesarios para su uso clínico, tanto tecnológicos como humanos.

- Establecer un flujo de trabajo con procesos y responsables:

- Estrategia a seguir (modelos anatómicos, Triggered Adaption, Adaptación Programada).

- Determinar incertidumbres de los diferentes procesos:

- Cálculo de la dosis en las imágenes de IGRT (Tabla TC-ED, tamaño FOV, artefactos...).

- Registro rígido.

- Registro deformable.

- Comprobación de todo el sistema (end-to-end) mediante un maniquí físico.

- Incluir el proceso en la metodología de matrices de riesgo. ${ }^{218,219}$

\subsubsection{Uso clínico}

- Comenzar por localizaciones sin grandes deformaciones como cabeza y cuello.

- Establecer medidas para minimizar el aumento de la incertidumbre con la utilización de la ART:

- Debe utilizarse el mismo protocolo de adquisición de imágenes de IGRT para el plan del paciente.

- Un único profesional debe delimitar las estructuras en un mismo paciente a lo largo de la ART.

- En caso de replanificación el protocolo de adquisición, los inmovilizadores, la posición y las estructuras delimitadas deben ser lo más parecidos posibles a los del pTC inicial.

- Evaluar el plan de tratamiento:

- Debe evaluarse el plan suma, que es el plan original más el plan adaptado.

- Debe evaluarse el plan adaptado. Este puede tener sub o sobredosificaciones importantes que pueden ser no admisibles radiobiológicamente. 


\subsection{Recomendaciones ART online}

\subsubsection{Puesta en marcha}

- Conocer el funcionamiento teórico y las limitaciones de la tecnología a utilizar. Para ello, las casas comerciales deben facilitar la documentación necesaria.

- Estimar los recursos necesarios para su uso clínico, tanto tecnológicos como humanos.

- Establecer un flujo de trabajo con procesos y responsables:

- Minimizar los tiempos de cada proceso.

- Establecer un control de calidad robusto y eficiente a todo el proceso.

- Tipo de planificación.

» Replanificación basada en la anatomía del día.

» Plan del día.

- Decidir el criterio de adaptación.

- Establecer el método de verificación del tratamiento.

- Determinar las incertidumbres de los diferentes procesos:

- Registro TC-RM.

- Nueva delimitación de estructuras.

- Cálculo de dosis psTC.

- Movimiento del paciente.

- Comprobación de todo el sistema (end-to-end) mediante un maniquí físico.

- Incluir el proceso en la metodología de matrices de riesgo. ${ }^{218,219}$

\subsubsection{Uso clínico}

- Establecer medidas para minimizar el aumento de la incertidumbre con la utilización de la ART:

- Preferentemente el mismo profesional debe delimitar las estructuras en un mismo paciente a lo largo de la ART.

- Movimiento del paciente:

- Colocación del paciente en una posición cómoda y estable.

- Control del movimiento intrafracción.

\section{Conclusiones}

El concepto de ART no es nuevo, ya que siempre se ha intentado compensar, en la medida de lo posible, los diversos factores (cambios anatómicos, ${ }^{11}$ errores sistemáticos y aleatorios de posicionamiento ${ }^{220}$ ) que impiden que la dosis real administrada durante el tratamiento radioterápico sea igual a la dosis planificada.
Este tipo de adaptación, consistente, básicamente, en realizar un nuevo plan a partir de un nuevo estudio TC utilizando los mismos criterios clínicos que para el plan original, no ofrece ninguna ganancia sobre el conocimiento de la dosis real administrada, las tasas de toxicidad y el beneficio que supone la adaptación en términos de mejora de control local y reducción de la toxicidad; es más, si la adaptación no se realiza en el momento oportuno se puede perder la oportunidad de mejorar la ventana terapéutica.

Sin embargo, con la llegada de los avances tecnológicos la ART también se ha sofisticado. ${ }^{221}$ La disponibilidad de imagen volumétrica en la propia unidad de tratamiento, junto con herramientas de autosegmentación, planificación inversa y la implementación de algoritmos de DIR en softwares comerciales han permitido que la decisión de adaptar el tratamiento se base en consideraciones dosimétricas y no solo geométricas, siendo el DIR el instrumento clave para tomar una decisión basada en la dosis acumulada durante el tratamiento y no en "capturas de imagen" en un instante determinado, lo que permitirá establecer, de una manera más precisa, las relaciones dosis - efecto volumen o la respuesta tras la radioterapia.222

Esta evolución de la ART conlleva cambios en los flujos de trabajo de radioterapia actuales: ${ }^{4}$ offline (modelos anatómicos programados, triggered adaptation, y adaptación programada), online (librería de planes, replanificación online) y la ART en tiempo real, ${ }^{223}$ en la que el plan se adapta continuamente a la anatomía del paciente permitiendo tener en cuenta los cambios intrafracción. Todas las aproximaciones siguen mostrando un punto débil: encontrar un criterio fiable para identificar los pacientes que realmente se benefician de la adaptación del tratamiento, además de, en el caso de la ART offline, cómo establecer un criterio para decidir en qué momento se debe realizar la adaptación del plan. Estos dos problemas han quedado patentes a lo largo del apartado 3 donde se ha mostrado la heterogeneidad a la hora de implementar la ART para las distintas localizaciones anatómicas: para cabeza y cuello parece adecuado realizar ART offline entre la $3^{\mathrm{a}}$ y $4^{\mathrm{a}}$ semana para aquellos pacientes que presenten una variación relevante de la dosis media en la parótida; para cáncer de pulmón, la ART a realizar depende del objetivo perseguido (mantenimiento de la dosis prescrita, mejora de la tolerancia en tejido sano, o escalar la dosis), siendo la fracción 15 la idónea para obtener mayor beneficio, si bien es muy dependiente de cada paciente; para próstata se baraja tanto el uso de ART offline tras las dos primeras semanas de tratamiento o ART online, ambas con el fin de reducir márgenes al PTV y realizar una escalada de dosis; para vejiga la estrategia más empleada es la ART online (plan del día u optimización de un nuevo plan); para tumores ginecológicos, en el que el uso 
más extendido de ART es para cáncer de cérvix donde IGABT consiste en una adaptación individualizada para cada fracción del tratamiento.

Como se ha indicado en el apartado 4, es fundamental comprender cómo funcionan los algoritmos de registro deformable para hacer un uso propicio de los mismos; así es esencial conocer cómo es la función objetivo y en qué consisten sus términos de regularización, que en algunos casos puede requerir la definición de POI o ROI por parte del usuario para guiar al algoritmo y así conseguir que proporcionen deformaciones aceptables. Por otro lado, el usuario debe conocer cuál es la métrica de similitud empleada por el DIR, ya que las métricas geométricas serán más adecuadas para registros multimodalidad, mientras que las basadas en intensidad se deberán emplear para registros monomodalidad proporcionando mayor exactitud que los primeros al emplear un mayor número de puntos. Además, es imprescindible determinar la incertidumbre que introduce el DIR al relacionar dos imágenes, tal y como se ha mostrado en el apartado 5. Como se ha explicado en dicho apartado, su evaluación no es sencilla, ya que no existe una metodología libre de inconvenientes: las aplicaciones específicas de software pueden evaluar deformaciones que no sean muy representativas de la práctica clínica, mientras que los maniquíes dosimétricos sólo permiten evaluar deformaciones en las que se conserva la masa y densidad de la estructura deformada. Por tanto, a pesar de poder realizarse una estimación de la incertidumbre de los algoritmos de deformación de dosis, la deformación calculada, basada en la correspondencia que se establece entre los vóxeles de los estudios de imagen que se pretenden deformar, se encuentra limitada cuando existe regresión de un tumor sólido o de volumen de un órgano de riesgo y por ende no se preserva el volumen/ masa de la estructura que se quiere proyectar de un estudio a otro.

Finalmente, señalaremos que la implementación a la práctica clínica de la ART supone un gran uso de recursos humanos y materiales. No obstante, la llegada de la inteligencia artificial, ${ }^{224-226}$ en forma de redes neuronales convolucionales profundas (neuronal convolutional networks, CNN), ${ }^{224-227}$ que consiguen que el proceso de autosegmentación sea más rápido y exacto, y machine learning,,228-234 supondrá un beneficio para todas las etapas de ART (delimitación de estructuras, registro de imágenes, planificación, control de calidad y toma de decisiones), lo que permitirá que esta técnica se convierta en una práctica rutinaria de tratamiento en los próximos años.

\section{Agradecimientos}

Este grupo de trabajo quiere mostrar su agradecimiento a determinadas personas y grupos por su contribución y ayuda a la elaboración de este documento:

- A la Junta Directiva de la SEFM y a su Comisión Científica por el apoyo prestado.

- A los integrantes de los Servicios o unidades de Radiofísica, donde los autores realizan su trabajo, por su comprensión y colaboración.

- A Aurora Vicedo González, de la sección de Radiofísica del Servicio de Oncología Radioterápica ERESA, en el Consorcio Hospital General Universitario de Valencia por su ayuda en el estudio de la incertidumbre del registro deformable mediante el uso del software comercial MIM.

- A Miguel Rodríguez, de Varian Medical Systems (España), por su colaboración en el estudio de la incertidumbre del registro deformable mediante el uso del software comercial Velocity ${ }^{\mathrm{TM}}$.

- Al Dr. José Pérez-Calatayud por la ayuda y asesoramiento en los comienzos de este Grupo de Trabajo.

\section{Listado de abreviaturas}

ART Radioterapia adaptativa

C Correlación cruzada

CBCT Tomografía computarizada de haz cónico

CC Coeficiente de correlación

CTV Volumen blanco clínico

DSC Coeficiente de similitud Dice

DIR Registro deformable de imágenes

DMLC Colimador multilámina dinámico

DVF Campo vectorial de deformación

EBRT Radioterapia externa

EQD2 Dosis equivalente en fracciones de 2 Gy externa

FOV Campo de visión

GTV Volumen tumoral macroscópico

HDV Histograma dosis-volumen

IC Consistencia inversa

ICRU Comisión Internacional de Unidades y Medidas de la Radiación

IGABT Braquiterapia adaptativa guiada por la imagen

IGRT Radioterapia guiada por la imagen

IM Información mutua

IMRT Radioterapia de intensidad modulada

LdP Librería de planes

LINAC Acelerador lineal de electrones

MLC Colimador multilámina 


\begin{tabular}{|c|c|}
\hline \multirow{2}{*}{$\begin{array}{l}\text { MVCBCT } \\
\text { MVCT }\end{array}$} & Tomografía computarizada de haz cónico \\
\hline & $\begin{array}{l}\text { Tomografía computarizada de haz de } \\
\text { abanico }\end{array}$ \\
\hline OAR & Órganos de riesgo \\
\hline $\mathrm{POI}$ & Punto de interés \\
\hline PRV & $\begin{array}{l}\text { Volumen de planificación del órgano de } \\
\text { riesgo }\end{array}$ \\
\hline psTC & Pseudo TC \\
\hline pTC & TC de planificación \\
\hline PTV & Volumen blanco de planificación \\
\hline RM & Resonancia magnética \\
\hline RM-IGRT & $\begin{array}{l}\text { Radioterapia guiada por imagen por } \\
\text { resonancia magnética }\end{array}$ \\
\hline $\mathrm{ROI}$ & Región de interés \\
\hline $\mathrm{RR}$ & Registro rígido \\
\hline SMLC & Multilámina estático \\
\hline SSD & Suma de diferencias cuadráticas \\
\hline $\mathrm{TC}$ & Tomografía computarizada \\
\hline TC-ED & $\begin{array}{l}\text { Tomografía computarizada-densidad } \\
\text { electrónica }\end{array}$ \\
\hline VMAT & Arcoterapia de modulación volumétrica \\
\hline VVSS & Vesículas seminales \\
\hline 4D-TC & $\begin{array}{l}\text { Tomografía computarizada de cuatro } \\
\text { dimensiones }\end{array}$ \\
\hline
\end{tabular}

\section{Referencias}

1. Gregoire V, Mackie TR, De Neve W, Gospodarowicz M, van Herk M, Niemierko A. ICRU Report 83. J ICRU. 2010. doi:10.1093/jicru/ndq013

2. Yan D, Vicini F, Wong J, Martinez A. Adaptive radiation therapy. Phys Med Biol. 1997;42(1):123-132. doi:10.1088/00319155/42/1/008

3. Yan D. Adaptive Radiotherapy: Merging Principle Into Clinical Practice. Semin Radiat Oncol. 2010;20(2):79-83. doi:https://doi.org/10.1016/j.semradonc.2009.11.001

4. Green OL, Henke LE, Hugo GD. Practical Clinical Workflows for Online and Offline Adaptive Radiation Therapy. Semin Radiat Oncol. 2019;29(3):219-227. doi:https://doi.org/10.1016/j. semradonc.2019.02.004

5. van Herk M. Errors and margins in radiotherapy. Semin Radiat Oncol. 2004;14(1):52-64. doi:https://doi.org/10.1053/j.sem radonc.2003.10.003

6. van Herk M, Remeijer P, Rasch C, Lebesque JV. The probability of correct target dosage: dose-population histograms for deriving treatment margins in radiotherapy. Int J Radiat Oncol. 2000;47(4):1121-1135. doi:https://doi.org/10.1016/ S0360-3016(00)00518-6

7. Litzenberg DW, Balter JM, Lam KL, Sandler HM, Ten Haken RK. Retrospective analysis of prostate cancer patients with implanted gold markers using off-line and adaptive therapy protocols. Int J Radiat Oncol. 2005;63(1):123-133. doi:https://doi.org/10.1016/j.ijrobp.2005.02.013

8. Seet KYT, Barghi A, Yartsev S, Van Dyk J. The effects of fieldof-view and patient size on CT numbers from cone-beam computed tomography. Phys Med Biol. 2009;54(20):62516262. doi:10.1088/0031-9155/54/20/014

9. Posiewnik M, Piotrowski T. A review of cone-beam CT applications for adaptive radiotherapy of prostate cancer. Phys Medica. 2019;59:13-21. doi:https://doi.org/10.1016/j. ejmp.2019.02.014

10. Brock KK, Mutic S, McNutt TR, Li H, Kessler ML. Use of image registration and fusion algorithms and techniques in radiotherapy: Report of the AAPM Radiation Therapy Committee Task Group No. 132. Med Phys. 2017;44(7):e43-e76. http://doi.wiley.com/10.1002/mp.12256. Accessed April 9, 2018

11. Sonke JJ, Aznar M, Rasch C. Adaptive Radiotherapy for Anatomical Changes. Semin Radiat Oncol. 2019;29(3):245257. doi:10.1016/j.semradonc.2019.02.007

12. Nuver TT, Hoogeman MS, Remeijer P, van Herk M, Lebesque J V. An Adaptive Off-Line Procedure for Radiotherapy of Prostate Cancer. Int J Radiat Oncol Biol Phys. 2007; 67(5):1559-1567. doi:10.1016/j.ijrobp.2006.12.010

13. Van Kranen S, Mencarelli A, Van Beek S, Rasch C, Van Herk $\mathrm{M}$, Sonke JJ. Adaptive radiotherapy with an average anatomy model: Evaluation and quantification of residual deformations in head and neck cancer patients. Radiother Oncol. 2013;109(3):463-468. doi:10.1016/j.radonc.2013.08.007

14. Møller DS, Holt MI, Alber M, et al. Adaptive radiotherapy for advanced lung cancer ensures target coverage and decreases lung dose. Radiother Oncol. 2016;121(1):32-38. doi:10.1016/j.radonc.2016.08.019

15. Ramella S, Fiore M, Silipigni S, et al. Local Control and Toxicity of Adaptive Radiotherapy Using Weekly CT Imaging: Results from the LARTIA Trial in Stage III NSCLC. J Thorac Oncol. 2017;12(7):1122-1130. doi:10.1016/j.jtho. 2017.03.025

16. Qin A, Gersten D, Liang J, et al. A clinical 3D/4D CBCTbased treatment dose monitoring system. J Appl Clin Med Phys. 2018;19(6):166-176. doi:10.1002/acm2.12474

17. Schwartz DL, Garden AS, Thomas J, et al. Adaptive Radiotherapy for Head-and-Neck Cancer: Initial Clinical Outcomes From a Prospective Trial. Int J Radiat Oncol Biol Phys. 2012;83(3):986-993. doi:10.1016/j.jjrobp.2011. 08.017

18. Zhang B, Lee S-W, Chen S, et al. Action Levels on Dose and Anatomic Variation for Adaptive Radiation Therapy Using Daily Offline Plan Evaluation: Preliminary Results. Pract Radiat Oncol. 2019;9(1):49-54. doi:10.1016/j.prro. 2018.08.006

19. Paelinck L, Lievens Y, Gulyban A, et al. Adaptive radiotherapy for locally advanced non-small cell lung cancer, can we predict when and for whom? AU - Berkovic, Patrick. Acta Oncol (Madr). 2015;54(9):1438-1444. doi:10.3109/02841 86X.2015.1061209

20. Huang $H$, Lu $H$, Feng $G$, et al. Determining appropriate timing of adaptive radiation therapy for nasopharyngeal carcinoma during intensity-modulated radiation therapy. Radiat Oncol. 2015;10:192:1-9. doi:10.1186/s13014-015-0498-1

21. Kong VC, Taylor A, Chung P, Craig T, Rosewall T. Comparison of 3 image-guided adaptive strategies for bladder locoregional radiotherapy. Med Dosim. 2019;44(2):111-116. doi:10.1016/j.meddos.2018.03.004 
22. ZouW, Dong L, Kevin Teo B-K. CurrentState of Image Guidance in Radiation Oncology: Implications for PTV Margin Expansion and Adaptive Therapy. Semin Radiat Oncol. 2018;28(3):238247. doi:https://doi.org/10.1016/j.semradonc.2018.02.008

23. Chen J, Morin O, Aubin M, Bucci MK, Chuang CF, Pouliot J. Dose-guided radiation therapy with megavoltage cone-beam CT. Br J Radiol. 2006;79(SPEC. ISS.):S87-S98. doi:10.1259/ bjr/60612178

24. De Marco P, Abdi Osman I, Castellini F, et al. Image quality and dose evaluation of MVCT TomoTherapy acquisitions: A phantom study. Phys Medica. 2019;57:200-206. doi:10.1016/j.ejmp.2019.01.009

25. Held M, Cremers F, Sneed PK, et al. Assessment of image quality and dose calculation accuracy on kV CBCT, MV CBCT, and MV CT images for urgent palliative radiotherapy treatments. J Appl Clin Med Phys. 2016;17(2):279-290. doi:10.1120/jacmp.v17i2.6040

26. Guan H, Dong H. Dose calculation accuracy using conebeam CT (CBCT) for pelvic adaptive radiotherapy. Phys Med Biol. 2009;54(20):6239-6250. doi:10.1088/0031-9155/54/ 20/013

27. Seet KYT, Barghi A, Yartsev S, Van Dyk J. The effects of fieldof-view and patient size on CT numbers from cone-beam computed tomography. Phys Med Biol. 2009;54(20):62516262. doi:10.1088/0031-9155/54/20/014

28. Hatton J, McCurdy B, Greer PB. Cone beam computerized tomography: the effect of calibration of the Hounsfield unit number to electron density on dose calculation accuracy for adaptive radiation therapy. Phys Med Biol. 2009; 54(15):N329-46. doi:10.1088/0031-9155/54/15/N01

29. Zhen X, Yan H, Zhou L, Jia X, Jiang SB. Deformable image registration of $\mathrm{CT}$ and truncated cone-beam $\mathrm{CT}$ for adaptive radiation therapy. Phys Med Biol. 2013;58(22):7979-7993. doi:10.1088/0031-9155/58/22/7979

30. Raysearch Laboratories. RayStation 7 Manual de Usuario. 2017:1-1114.

31. Fox T, Andl G, Bose S. Velocity and Deformable Image Registration. White Pap Veloc Software, Varian Med Syst. 2018:1-7.

32. Jordan P, Myronenko A, Gorczowski K, Foskey M, Holloway $\mathrm{R}$, Maurer CR. Accuray deformable image registration: description and evaluation. white paper. White paper I Accuray PrecisionTM software. White Pap Accuray Software, Accuray Precis. 2017:1-8.

33. Piper J, Nelson A, Harper J. Deformable Image Registration in MIM Maestro TM Evaluation and Description [White Paper]. 2013:1-5.

34. Radiation Oncology P. Pinnacle3 16.0 Dynamic Planning. White Pap Pinnacle Softw. 2018:1-51.

35. Court LE, Dong L, Lee AK, et al. An automatic CT-guided adaptive radiation therapy technique by online modification of multileaf collimator leaf positions for prostate cancer. Int J Radiat Oncol Biol Phys. 2005;62(1):154-163. doi:10.1016/j.ijrobp.2004.09.045

36. Mohan R, Zhang X, Wang $\mathrm{H}$, et al. Use of deformed intensity distributions for on-line modification of image-guided IMRT to account for interfractional anatomic changes. Int J Radiat Oncol Biol Phys. 2005;61(4):1258-1266. doi:10.1016/j. ijrobp.2004.11.033
37. Lim-Reinders S, Keller BM, Al-Ward S, Sahgal A, Kim A. Online Adaptive Radiation Therapy. Int J Radiat Oncol Biol Phys. 2017;99(4):994-1003. doi:10.1016/j.ijrobp.2017. 04.023

38. Badey A, Barateau A, Delaby N, et al. Overview of adaptive radiotherapy in 2019: From implementation to clinical use. Cancer Radiother. 2019;23(6-7):581-591. doi:10.1016/j. canrad.2019.07.142

39. X. AL, E. A. Online Adaptive Correction Strategies for Interfraction Variations. In: Press C, ed. Adaptive Radiation Therapy. 1st Edition; 2011:426.

40. Hunt A, Hansen VN, Oelfke U, Nill S, Hafeez S. Adaptive Radiotherapy Enabled by MRI Guidance. Clin Oncol. 2018; 30(11):711-719. doi:10.1016/j.clon.2018.08.001

41. Noel C, Parikh P, Spencer C, et al. Comparison of onboard low-field magnetic resonance imaging versus onboard computed tomography for anatomy visualization in radiotherapy. Acta Oncol. 2015;54:1-9. doi:10.3109/0284186X.2015. 1062541

42. Chilla GS, Tan CH, Xu C, Poh CL. Diffusion weighted magnetic resonance imaging and its recent trend-a survey. Quant Imaging Med Surg. 2015;5(3):407-422. doi:10.3978/j. issn.2223-4292.2015.03.01

43. Johnstone E, Wyatt JJ, Henry AM, et al. Systematic Review of Synthetic Computed Tomography Generation Methodologies for Use in Magnetic Resonance Imaging-Only Radiation Therapy. Int J Radiat Oncol Biol Phys. 2018;100(1):199217. doi:10.1016/j.ijrobp.2017.08.043

44. Prabhakar R, Julka PK, Ganesh T, Munshi A, Joshi RC, Rath GK. Feasibility of using MRI alone for 3D Radiation Treatment Planning in Brain Tumors. Jpn J Clin Oncol. 2007; 37(6):405-411. doi:10.1093/jjco/hym050

45. Karotki A, Mah K, Meijer G, Meltsner M. Comparison of bulk electron density and voxel-based electron density treatment planning. J Appl Clin Med Phys. 2011;12(4):97-104. doi:10.1120/jacmp.v12i4.3522

46. Korsholm ME, Waring LW, Edmund JM. A criterion for the reliable use of MRI-only radiotherapy. Radiat Oncol. 2014; 9(1):16. doi:10.1186/1748-717X-9-16

47. Lambert J, Greer PB, Menk F, et al. MRI-guided prostate radiation therapy planning: Investigation of dosimetric accuracy of MRI-based dose planning. Radiother Oncol. 2011;98(3):330-334. doi:https://doi.org/10.1016/j. radonc. 2011.01 .012

48. Chin AL, Lin A, Anamalayil S, Teo B-KK. Feasibility and limitations of bulk density assignment in MRI for head and neck IMRT treatment planning. J Appl Clin Med Phys. 2014;15(5):100-111. doi:10.1120/jacmp.v15i5.4851

49. Dowling JA, Sun J, Pichler P, et al. Automatic Substitute Computed Tomography Generation and Contouring for Magnetic Resonance Imaging (MRI)-Alone External Beam Radiation Therapy From Standard MRISequences. Int J Radiat Oncol. 2015;93(5):1144-1153. doi:https://doi.org/10.1016/ j.ijrobp.2015.08.045

50. Dowling JA, Lambert J, Parker J, et al. An Atlas-Based Electron Density Mapping Method for Magnetic Resonance Imaging (MRI)-Alone Treatment Planning and Adaptive MRIBased Prostate Radiation Therapy. Int J Radiat Oncol. 2012; 83(1):e5-e11. doi:https://doi.org/10.1016/j.ijrobp.2011.11. 056 
51. Edmund JM, Andreasen D, Mahmood F, Van Leemput K. Cone beam computed tomography guided treatment delivery and planning verification for magnetic resonance imaging only radiotherapy of the brain. Acta Oncol (Madr). 2015;54(9):1496-1500. doi:10.3109/028418 6X.2015.1062546

52. Kim J, Glide-Hurst C, Doemer A, Wen N, Movsas B, Chetty IJ. Implementation of a Novel Algorithm For Generating Synthetic CT Images From Magnetic Resonance Imaging Data Sets for Prostate Cancer Radiation Therapy. Int J Radiat Oncol. 2015;91(1):39-47. doi:https://doi.org/10.1016/j.ijrobp.2014.09.015

53. Koivula L, Wee L, Korhonen J. Feasibility of MRI-only treatment planning for proton therapy in brain and prostate cancers: Dose calculation accuracy in substitute CT images. Med Phys. 2016;43(8):4634-4642. doi:10.1118/1.4958677

54. Raaijmakers A, Raaymakers BW, Lagendijk J. Integrating a MRI scanner with a $6 \mathrm{MV}$ radiotherapy accelerator: Dose increase at tissue-air interfaces in a lateral magnetic field due to returning electrons. Phys Med Biol. 2005;50:13631376. doi:10.1088/0031-9155/50/7/002

55. Klüter S. Technical design and concept of a $0.35 \mathrm{~T}$ MR-Linac. Clin Transl Radiat Oncol. 2019;18:98-101. doi:10.1016/j.ctro.2019.04.007

56. Mutic S, Dempsey JF. The ViewRay System: Magnetic Resonance-Guided and Controlled Radiotherapy. Semin Radiat Oncol. 2014;24(3):196-199. doi:10.1016/j.semradonc.2014.02.008

57. Fischer-Valuck BW, Henke L, Green O, et al. Two-anda-half year clinical experience with the world's first magnetic resonance image-guided radiation therapy system. Adv Radiat Oncol. 2017;2(3):485-493. doi:10.1016/j. adro.2017.05.006

58. Acharya S, Fischer-Valuck BW, Kashani R, et al. Online Magnetic Resonance Image Guided Adaptive Radiation Therapy: First Clinical Applications. Int J Radiat Oncol Biol Phys. 2016;94(2):394-403. doi:10.1016/j.ijrobp.2015.10.015

59. Lagendijk JJW, Raaymakers BW, van Vulpen M. The magnetic resonance imaging-linac system. Semin Radiat Oncol. 2014;24(3):207-209. doi:10.1016/j.semradonc.2014.02.009

60. Tijssen RHN, Philippens MEP, Paulson ES, et al. MRI commissioning of 1.5T MR-linac systems - a multi-institutional study. Radiother Oncol. 2019;132:114-120. doi:10.1016/j. radonc.2018.12.011

61. Stemkens B, Glitzner M, Kontaxis C, et al. Effect of intrafraction motion on the accumulated dose for free-breathing MR-guided stereotactic body radiation therapy of renalcell carcinoma. Phys Med Biol. 2017;62(18):7407-7424. doi:10.1088/1361-6560/aa83f7

62. Kontaxis C, Bol GH, Lagendijk JJW, Raaymakers BW. Towards adaptive IMRT sequencing for the MR-linac. Phys Med Biol. 2015;60(6):2493-2509. doi:10.1088/00319155/60/6/2493

63. Bol GH, Hissoiny S, Lagendijk JJW, Raaymakers BW. Fast online Monte Carlo-based IMRT planning for the MRI linear accelerator. Phys Med Biol. 2012;57(5):1375-1385. doi:10.1088/0031-9155/57/5/1375

64. Raaymakers B, Jürgenliemk-Schulz I, Bol G, et al. First patients treated with a $1.5 \mathrm{~T}$ MRI-Linac: Clinical proof of concept of a high-precision, high-field MRI guided radiotherapy treatment. Phys Med Biol. 2017;62:L41-L50. doi:10.1088/1361-6560/aa9517

65. Lamb J, Cao M, Kishan A, et al. Online Adaptive Radiation Therapy: Implementation of a New Process of Care. Cureus. 2017;9(8):e1618. doi:10.7759/cureus.1618

66. Ethos_Brochure_RAD10737_Mar2020.

67. Henke L, Kashani R, Robinson C, et al. Phase I trial of stereotactic MR-guided online adaptive radiation therapy (SMART) for the treatment of oligometastatic or unresectable primary malignancies of the abdomen. Radiother Oncol. 2018;126(3):519-526. doi:10.1016/j.radonc.2017.11.032

68. Noel CE, Santanam L, Parikh PJ, Mutic S. Processbased quality management for clinical implementation of adaptive radiotherapy. Med Phys. 2014;41(8):081717. doi:10.1118/1.4890589

69. Winkel D, Bol G, Kroon P, et al. Adaptive radiotherapy: The Elekta Unity MR-linac concept. Clin Transl Radiat Oncol. 2019;18:54-59. doi:10.1016/j.ctro.2019.04.001

70. Collins SD, Leech MM. A review of plan library approaches in adaptive radiotherapy of bladder cancer. Acta Oncol (Madr). 2018;57(5):566-573. doi:10.1080/028418 6X.2017.1420908

71. Thörnqvist S, Hysing LB, Tuomikoski L, et al. Adaptive radiotherapy strategies for pelvic tumors - a systematic review of clinical implementations. Acta Oncol (Madr). 2016;55(8):943-958. doi:10.3109/028418 6X.2016.1156738

72. Meijer GJ, Van Der Toorn PP, Bal M, Schuring D, Weterings $J$, De Wildt M. High precision bladder cancer irradiation by integrating a library planning procedure of 6 prospectively generated SIB IMRT plans with image guidance using lipiodol markers. Radiother Oncol. 2012;105(2):174-179. doi:10.1016/j.radonc.2012.08.011

73. Lalondrelle S, Huddart R, Warren-Oseni K, et al. Adaptivepredictive organ localization using cone-beam computed tomography for improved accuracy in external beam radiotherapy for bladder cancer. Int J Radiat Oncol Biol Phys. 2011;79(3):705-712. doi:10.1016/j.ijrobp.2009.12.003

74. Tuomikoski L, Korhonen J, Collan J, et al. Implementation of adaptive radiation therapy for urinary bladder carcinoma: Imaging, planning and image guidance. Acta Oncol (Madr). 2013;52(7):1451-1457. doi:10.3109/02841 86X.2013.813639

75. Foroudi F, Pham D, Rolfo A, et al. The outcome of a multicentre feasibility study of online adaptive radiotherapy for muscle-invasive bladder cancer TROG 10.01 BOLART. Radiother Oncol. 2014;111(2):316-320. doi:10.1016/j. radonc.2014.02.015

76. Vestergaard A, Muren LP, Lindberg $\mathrm{H}$, et al. Normal tissue sparing in a phase $\|$ trial on daily adaptive plan selection in radiotherapy for urinary bladder cancer. Acta Oncol. 2014;53(8):997-1004. doi:10.3109/028418 6X.2014.928419

77. Ahunbay EE, Peng C, Holmes S, Godley A, Lawton C, Li XA. Online adaptive replanning method for prostate radiotherapy. Int J Radiat Oncol Biol Phys. 2010;77(5):1561-1572. doi:10.1016/j.ijrobp.2009.10.013

78. Ahunbay EE, Peng C, Chen GP, et al. An on-line replanning scheme for interfractional variations. Med Phys. 2008;35(8):3607-3615. doi:10.1118/1.2952443

79. Bol GH, Lagendijk JJW, Raaymakers BW. Virtual couch shift (VCS): Accounting for patient translation and rotation by onli- 
ne IMRT re-optimization. Phys Med Biol. 2013;58(9):29893000. doi:10.1088/0031-9155/58/9/2989

80. Tol JP, Dahele M, Delaney AR, Slotman BJ, Verbakel WFAR. Can knowledge-based DVH predictions be used for automated, individualized quality assurance of radiotherapy treatment plans? Radiat Oncol. 2015;10(1):1-14. doi:10.1186/s13014-015-0542-1

81. Zhang X, Li X, Quan EM, Pan X, Li Y. A methodology for automatic intensity-modulated radiation treatment planning for lung cancer. Phys Med Biol. 2011;56(13):3873-3893. doi:10.1088/0031-9155/56/13/009

82. Li X, Quan EM, Li Y, et al. A fully automated method for ct-on-rails-guided online adaptive planning for prostate cancer intensity modulated radiation therapy. Int J Radiat Oncol Biol Phys. 2013;86(5):835-841. doi:10.1016/j.ijrobp.2013.04.014

83. Mestrovic A, Milette M-P, Nichol A, Clark BG, Otto K. Direct aperture optimization for online adaptive radiation therapy. Med Phys. 2007;34(5):1631-1646. doi:10.1118/1.2719364

84. Ziegenhein P Kamerling C P and Oelfke U PS. Fast cpubased Monte Carlo simulation for radiotherapy dose calculation. Phys Med Biol. 2015;60(15):6097-6111. http://stacks. iop.org/0031-9155/60/i=15/a=6097.

85. Gu X, Choi D, Men C, Pan H, Majumdar A, Jiang SB. GPUbased ultra-fast dose calculation using a finite size pencil beam model. Phys Med Biol. 2009;54(20):6287-6297. doi:10.1088/0031-9155/54/20/017

86. Pratx G, Xing L. GPU computing in medical physics: a review. Med Phys. 2011;38(5):2685-2697. doi:10.1118/1.3578605

87. Men C, Jia X, Jiang SB. GPU-based ultra-fast direct aperture optimization for online adaptive radiation therapy. Phys Med Biol. 2010;55(15):4309-4319. doi:10.1088/00319155/55/15/008

88. Cai B, Green OL, Kashani R, Rodriguez VL, Mutic S, Yang D. A practical implementation of physics quality assurance for photon adaptive radiotherapy. Z Med Phys. 2018;28(3):211-223. doi:10.1016/j.zemedi.2018.02.002

89. Peng C, Chen G, Ahunbay E, Wang D, Lawton C, Li XA. Validation of an online replanning technique for prostate adaptive radiotherapy. Phys Med Biol. 2011;56(12):36593668. doi:10.1088/0031-9155/56/12/013

90. Fontenot JD. Evaluation of a novel secondary check tool for intensity-modulated radiotherapy treatment planning. J Appl Clin Med Phys. 2014;15(5):4990. doi:10.1120/jacmp. v15i5.4990

91. Le AH, Stojadinovic S, Timmerman R, et al. Real-Time Whole-Brain Radiation Therapy: A Single-Institution Experience. Int J Radiat Oncol. 2018;100(5):1280-1288. doi:https://doi.org/10.1016/j.ijrobp.2017.12.282

92. Mata Colodro F, Serna Berna A, Puchades Puchades V. Dosimetric validation of a redundant independent calculation software for VMAT fields. Phys Med. 2013;29(4):341349. doi:10.1016/j.ejmp.2012.05.003

93. Pawlicki T, Yoo S, Court LE, et al. Moving from IMRT QA measurements toward independent computer calculations using control charts. Radiother Oncol. 2008;89(3):330-337. doi:10.1016/j.radonc.2008.07.002

94. Tuazon B, Narayanasamy G, Papanikolaou N, Kirby $\mathrm{N}$, Mavroidis P, Stathakis S. Evaluation and compari- son of second-check monitor unit calculation software with Pinnacle3treatment planning system. Phys Medica. 2018;45(December 2017):186-191. doi:10.1016/j. ejmp.2017.12.004

95. Thoelking J, Fleckenstein J, Sekar Y, et al. Patient-specific online dose verification based on transmission detector measurements. Radiother Oncol. 2016;119(2):351-356. doi:https://doi.org/10.1016/j.radonc.2016.04.003

96. Olch AJ, O'Meara K, Wong KK. First Report of the Clinical Use of a Commercial Automated System for Daily Patient QA Using EPID Exit Images. Adv Radiat Oncol. 2019;4(4):722728. doi:https://doi.org/10.1016/j.adro.2019.04.001

97. Castelli J, Simon A, Rigaud B, et al. Adaptive radiotherapy in head and neck cancer is required to avoid tumor underdose. Acta Oncol (Madr). 2018;57(9):1267-1270. doi:10.1 080/0284186X.2018.1468086

98. Brouwer CL, Steenbakkers RJHM, Langendijk JA, Sijtsema NM. Identifying patients who may benefit from adaptive radiotherapy: Does the literature on anatomic and dosimetric changes in head and neck organs at risk during radiotherapy provide information to help? Radiother Oncol. 2015;115(3):285-294. doi:10.1016/j.radonc.2015.05.018

99. Chuter RW, Pollitt A, Whitehurst P, Mackay RI, Van Herk M, McWilliam A. Assessing MR-linac radiotherapy robustness for anatomical changes in head and neck cancer. Phys Med Biol. 2018;63(12):125020. doi:10.1088/1361-6560/ aac749

100. Noble DJ, Yeap PL, Seah SYK, et al. Anatomical change during radiotherapy for head and neck cancer, and its effect on delivered dose to the spinal cord. Radiother Oncol. 2019;130:32-38. doi:10.1016/j.radonc.2018.07.009

101. Castadot P, Lee JA, Geets X, Grégoire V. Adaptive Radiotherapy of Head and Neck Cancer. Semin Radiat Oncol. 2010;20(2):84-93. doi:https://doi.org/10.1016/j. semradonc.2009.11.002

102. Veresezan O, Troussier I, Lacout A, et al. Adaptive radiation therapy in head and neck cancer for clinical practice: state of the art and practical challenges. Jpn J Radiol. 2017;35(2):43-52. doi:10.1007/s11604-016-0604-9

103. Gros SAA, Xu W, Roeske JC, Choi M, Emami B, Surucu M. A novel surrogate to identify anatomical changes during radiotherapy of head and neck cancer patients. Med Phys. 2017;44(3):924-934. doi:10.1002/mp.12067

104. Mendez LC, Moraes FY, Poon I, Marta GN. The management of head and neck tumors with high technology radiation therapy. Expert Rev Anticancer Ther. 2016;16(1):99110. doi:10.1586/14737140.2016.1121111

105. Brown E, Owen R, Harden F, et al. Head and neck adaptive radiotherapy: Predicting the time to replan. Asia Pac J Clin Oncol. 2016;12(4):460-467. doi:10.1111/ajco.12516

106. Zhang P, Simon A, Rigaud B, et al. Optimal adaptive IMRT strategy to spare the parotid glands in oropharyngeal cancer. Radiother Oncol. 2016;120(1):41-47. doi:10.1016/j. radonc.2016.05.028

107. Hvid CA, Elstrøm U V., Jensen K, Grau C. Cone-beam computed tomography (CBCT) for adaptive image guided head and neck radiation therapy. Acta Oncol (Madr). 2018;57(4):552556. doi:10.1080/0284186X.2017.1398414

108. Mazzola R, Fiorentino A, Ricchetti F, Gregucci F, Corradini S, Alongi $F$. An update on radiation therapy in head and neck 
cancers. Expert Rev Anticancer Ther. 2018;18(4):359-364. doi:10.1080/14737140.2018.1446832

109. Brouwer CL, Steenbakkers RJHM, van der Schaaf A, et al. Selection of head and neck cancer patients for adaptive radiotherapy to decrease xerostomia. Radiother Oncol. 2016;120(1):36-40. doi:10.1016/j.radonc.2016.05.025

110. Brown E, Owen R, Harden F, et al. Predicting the need for adaptive radiotherapy in head and neck cancer. Radiother Oncol. 2015;116(1):57-63. doi:10.1016/j. radonc.2015.06.025

111. Vickress JR, Battista J, Barnett R, Yartsev S. Online daily assessment of dose change in head and neck radiotherapy without dose-recalculation. J Appl Clin Med Phys. 2018;19(5):659-665. doi:10.1002/acm2.12432

112. Piron O, Varfalvy N, Archambault L. Establishing action threshold for change in patient anatomy using EPID gamma analysis and PTV coverage for head and neck radiotherapy treatment. Med Phys. 2018;45(8):3534-3545. doi:10.1002/ mp. 13045

113. Surucu M, Shah KK, Roeske JC, Choi M, Small W, Emami B. Adaptive Radiotherapy for Head and Neck Cancer: Implications for Clinical and Dosimetry Outcomes. Technol Cancer Res Treat. 2017;16(2):218-223. doi:10.1177/1533034616662165

114. Kataria T, Gupta D, Goyal S, et al. Clinical outcomes of adaptive radiotherapy in head and neck cancers. $\mathrm{Br} J$ Radiol. 2016;89(1062):20160085. doi:10.1259/bjr.20160085

115. Kavanaugh J, Hugo G, Robinson CG, Roach MC. Anatomical Adaptation-Early Clinical Evidence of Benefit and Future Needs in Lung Cancer. Semin Radiat Oncol. 2019;29(3):274283. doi:10.1016/j.semradonc.2019.02.009

116. Tvilum M, Khalil AA, Møller DS, Hoffmann L, Knap MM. Clinical outcome of image-guided adaptive radiotherapy in the treatment of lung cancer patients. Acta Oncol (Madr). 2015;54(9):1430-1437. doi:10.3109/028418 6X.2015.1062544

117. Xiao L, Liu N, Zhang G, et al. Late-course adaptive adjustment based on metabolic tumor volume changes during radiotherapy may reduce radiation toxicity in patients with non-small cell lung cancer. PLoS One. 2017;12(1):111. doi:10.1371/journal.pone.0170901

118. Kelsey CR, Christensen JD, Chino JP, Adamson J, Ready $\mathrm{NE}$, Perez BA. Adaptive planning using positron emission tomography for locally advanced lung cancer: A feasibility study. Pract Radiat Oncol. 2016;6(2):96-104. doi:10.1016/j. prro.2015.10.009

119. Hoffmann L, Alber M, Jensen MF, Holt MI, Møller DS. Adaptation is mandatory for intensity modulated proton therapy of advanced lung cancer to ensure target coverage. Radiother Oncol. 2017;122(3):400-405. doi:10.1016/j. radonc.2016.12.018

120. Chang JY, Zhang X, Knopf A, et al. Consensus Guidelines for Implementing Pencil-Beam Scanning Proton Therapy for Thoracic Malignancies on Behalf of the PTCOG Thoracic and Lymphoma Subcommittee. Int J Radiat Oncol Biol Phys. 2017;99(1):41-50. doi:10.1016/j.ijrobp.2017.05.014

121. Dial C, Weiss E, Siebers J V, Hugo GD, Dial C, Weiss E. Benefits of adaptive radiation therapy in lung cancer as a function of replanning frequency Benefits of adaptive radia- tion therapy in lung cancer as a function of replanning frequency. 2016;43(4):1787-1794. doi:10.1118/1.4943564

122. Li XA, Wu Q. Online adaptive planning for prostate cancer radiotherapy is necessary and ready now. Med Phys. 2014;41(8):080601-1-080601-080603. doi:10.1118/1.4883875

123. McPartlin AJ, Li XA, Kershaw LE, et al. MRI-guided prostate adaptive radiotherapy - A systematic reviewMRI-linac and prostate motion review. Radiother Oncol. 2016;119(3):371380. doi:10.1016/j.radonc.2016.04.014

124. Fernández Letón P, Baños Capilla C, Bea Gilabert J, et al. Recomendaciones de la Sociedad Española de Física Médica (SEFM) sobre implementación y uso clínico de radioterapia estereotáxica extracraneal (SBRT) Recommendations of the Spanish Society Of Medical Physics (SEFM) on Implementation and clinical use. Rev Física Médica. 2017;18(2):77-142.

125. Chiesa S, Placidi L, Azario L, et al. Adaptive optimization by 6 DOF robotic couch in prostate volumetric IMRT treatment: Rototranslational shift and dosimetric consequences. J Appl Clin Med Phys. 2015;16(5):35-45. doi:10.1120/jacmp. v16i5.5525

126. Wust P, Barelkowski T, Böhmer D, et al. Dosimetric implications of inter- and intrafractional prostate positioning errors during tomotherapyDosimetrische Veränderungen durch inter- und intrafraktionelle Prostataverschiebungen bei der Tomotherapie. Strahlentherapie und Onkol. 2017;193(9):700-706. doi:10.1007/s00066-017-1141-x

127. Huang CY, Tehrani JN, Ng JA, Booth J, Keall P. Six degreesof-freedom prostate and lung tumor motion measurements using kilovoltage intrafraction monitoring. Int J Radiat Oncol Biol Phys. 2015;91(2):368-375. doi:10.1016/j.ijrobp.2014.09.040

128. Tong X, Chen X, Li J, et al. Intrafractional prostate motion during external beam radiotherapy monitored by a realtime target localization system. J Appl Clin Med Phys. 2015;16(2):51-61. doi:10.1120/jacmp.v16i2.5013

129. Shibayama Y, Arimura H, Hirose TA, et al. Investigation of interfractional shape variations based on statistical point distribution model for prostate cancer radiation therapy. Med Phys. 2017;44(5):1837-1845. doi:10.1002/mp.12217

130. Oates R, Brown A, Tan A, et al. Real-time Imageguided Adaptive-predictive Prostate Radiotherapy using Rectal Diameter as a Predictor of Motion. Clin Oncol. 2017;29(3):180-187. doi:10.1016/j.clon.2016.09.019

131. Pearson D, Gill SK, Campbell N, Reddy K. Dosimetric and volumetric changes in the rectum and bladder in patients receiving CBCT-guided prostate IMRT: Analysis based on daily CBCT dose calculation. J Appl Clin Med Phys. 2016;17(6):107-117. doi:10.1120/jacmp.v17i6.6207

132. Chen Z, Yang Z, Wang J, Hu W. Dosimetric impact of different bladder and rectum filling during prostate cancer radiotherapy. Radiat Oncol. 2016;11(1):1-8. doi:10.1186/ s13014-016-0681-Z

133. Juneja P, Colvill E, Kneebone A, et al. Quantification of intrafraction prostate motion and its dosimetric effect on VMAT. Australas Phys Eng Sci Med. 2017;40(2):317-324. doi:10.1007/s13246-017-0536-4

134. Liu F, Ahunbay E, Lawton C and LX. Assessment and management of interfractional variations in daily diagnostic-qua- 
lity-CT guided prostate-bed irradiation after prostatectomy. Med Phys. 2014;41(3):9-12. doi:10.1118/1.4866222 LK

135. Maeda $Y$, Saito M, Saga $Y$, et al. Effects of organ motion on proton prostate treatments, as determined from analysis of daily CT imaging for patient positioning. Med Phys. 2018;45(5):1844-1856. doi:10.1002/mp.12869

136. Moteabbed M, Trofimov A, Khan FH, et al. Impact of interfractional motion on hypofractionated pencil beam scanning proton therapy and VMAT delivery for prostate cancer. Med Phys. 2018;45(9):4011-4019. doi:10.1002/mp.13091

137. Kontaxis C, Bol GH, Kerkmeijer LGW, Lagendijk JJW, Raaymakers BW. Fast online replanning for interfraction rotation correction in prostate radiotherapy. Med Phys. 2017;44(10):5034-5042. doi:10.1002/mp.12467

138. Saito N, Schmitt D, Bangert M. Correlation between intrafractional motion and dosimetric changes for prostate IMRT: Comparison of different adaptive strategies. J Appl Clin Med Phys. 2018;19(4):87-97. doi:10.1002/acm2.12359

139. McVicar N, Popescu IA, Heath E. Techniques for adaptive prostate radiotherapy. Phys Medica. 2016;32(3):492-498. doi:10.1016/j.ejmp.2016.03.010

140. Kong VC, Taylor A, Rosewall T. Adaptive Radiotherapy for Bladder Cancer-A Systematic Review. J Med Imaging Radiat Sci. 2017;48(2):199-206. doi:10.1016/j. jmir.2016.10.014

141. Dees-Ribbers HM, Betgen A, Pos FJ, Witteveen T, Remeijer $\mathrm{P}$, Van Herk M. Inter- and intra-fractional bladder motion during radiotherapy for bladder cancer: A comparison of full and empty bladders. Radiother Oncol. 2014;113(2):254259. doi:10.1016/j.radonc.2014.08.019

142. Nishioka K, Shimizu S, Shinohara N, et al. Analysis of interand intra fractional partial bladder wall movement using implanted fiducial markers. Radiat Oncol. 2017;12(1):44. doi:10.1186/s13014-017-0778-z

143. Kibrom AZ, Knight KA. Adaptive radiation therapy for bladder cancer: A review of adaptive techniques used in clinical practice. J Med Radiat Sci. 2015;62(4):277-285. doi:10.1002/jmrs.129

144. Vestergaard A, Hafeez S, Muren LP, et al. The potential of MRI-guided online adaptive re-optimisation in radiotherapy of urinary bladder cancer. Radiother Oncol. 2016;118(1):154-159. doi:10.1016/j.radonc.2015.11.003

145. Tanderup K, Lindegaard JC, Kirisits C, et al. Image Guided Adaptive Brachytherapy in cervix cancer: A new paradigm changing clinical practice and outcome. Radiother Oncol. 2016;120(3):365-369. doi:10.1016/j.radonc.2016.08.007

146. Cree A, Livsey J, Barraclough L, et al. The Potential Value of MRI in External-Beam Radiotherapy for Cervical Cancer. Clin Oncol. 2018;30(11):737-750. doi:10.1016/j. clon.2018.08.002

147. Heijkoop ST, Langerak TR, Quint S, et al. Quantification of intra-fraction changes during radiotherapy of cervical cancer assessed with pre- and post-fraction Cone Beam CT scans. Radiother Oncol. 2015;117(3):536-541. doi:10.1016/j.radonc.2015.08.034

148. Tan MBBS, MRCP, FRCR, MD LT, Tanderup PhD K, Kirisits PhD C, et al. Image-guided Adaptive Radiotherapy in Cervical Cancer. Semin Radiat Oncol. 2019;29(3):284-298. doi:10.1016/j.semradonc.2019.02.010
149. Visser J, Boer P De, Crama KF, et al. Dosimetric comparison of library of plans and online MRI-guided radiotherapy of cervical cancer in the presence of intrafraction anatomical changes. Radiat Oncol. 2019;14(1):126.

150. Rigaud B, Simon A, Gobeli M, et al. Statistical Shape Model to Generate a Planning Library for Cervical Adaptive Radiotherapy. IEEE Trans Med Imaging. 2019;38(2):406416. doi:10.1109/TMI.2018.2865547

151. Tanderup K, Nielsen SK, Nyvang GB, et al. From point A to the sculpted pear: MR image guidance significantly improves tumour dose and sparing of organs at risk in brachytherapy of cervical cancer. Radiother Oncol. 2010;94(2):173180. doi:10.1016/j.radonc.2010.01.001

152. Serban M, Kirisits C, Pötter R, et al. Isodose surface volumes in cervix cancer brachytherapy: Change of practice from standard (Point A) to individualized image guided adaptive (EMBRACE I) brachytherapy. Radiother Oncol. 2018;129(3):567-574. doi:10.1016/j.radonc.2018.09.002

153. van de Schoot AJAJ, de Boer P, Visser J, Stalpers LJA, Rasch CRN, Bel A. Dosimetric advantages of a clinical daily adaptive plan selection strategy compared with a nonadaptive strategy in cervical cancer radiation therapy. Acta Oncol (Madr). 2017;56(5):667-674. doi:10.1080/028418 6X.2017.1287949

154. van de Schoot AJAJ, de Boer P, Crama KF, et al. Dosimetric advantages of proton therapy compared with photon therapy using an adaptive strategy in cervical cancer. Acta Oncol (Madr). 2016;55(7):892-899. doi:10.3109/028418 6X.2016.1139179

155. Brock KK. Adaptive Radiotherapy: Moving Into the Future. Semin Radiat Oncol. 2019;29(3):181-184. doi:10.1016/j. semradonc.2019.02.011

156. Sager O, Dincoglan F, Uysal B, et al. Evaluation of adaptive radiotherapy (ART) by use of replanning the tumor bed boost with repeated computed tomography (CT) simulation after whole breast irradiation (WBI) for breast cancer patients having clinically evident seroma. Jpn J Radiol. 2018;36(6):401-406. doi:10.1007/s11604-018-0735-2

157. Dickie C, Parent A, Griffin AM, et al. The value of adaptive preoperative radiotherapy in management of soft tissue sarcoma. Radiother Oncol. 2017;122(3):458-463. doi:https:// doi.org/10.1016/j.radonc.2016.12.028

158. Peyraga G, Robaine N, Khalifa J, Cohen-JonathanMoyal E, Payoux P, Laprie A. Molecular pet imaging in adaptive radiotherapy: Brain. Q J Nucl Med Mol Imaging. 2018;62(4):337-348. doi:10.23736/S18244785.18.03116-3

159. Oh S, Kim S. Deformable image registration in radiation therapy. Radiat Oncol J. 2017;35(2):101-111. doi:10.3857/ roj.2017.00325

160. Chetty IJ, Rosu-Bubulac M. Deformable Registration for Dose Accumulation. Semin Radiat Oncol. 2019;29(3):198208. doi:10.1016/j.semradonc.2019.02.002

161. Sotiras A, Davatzikos C, Paragios N. Deformable medical image registration: A survey. IEEE Trans Med Imaging. 2013;32(7):1153-1190. doi:10.1109/TMI.2013.2265603

162. Glocker B, Sotiras A, Komodakis N, Paragios N. Deformable Medical Image Registration: Setting the State of the Art with Discrete Methods. Annu Rev Biomed Eng. 2011;13(1):219244. doi:10.1146/annurev-bioeng-071910-124649

163. Yang D, Li H, Low DA, Deasy JO, Naqa I El. A fast inverse consistent deformable image registration method 
based on symmetric optical flow computation. Phys Med Biol. 2008;53(21):6143-6165. doi:10.1088/00319155/53/21/017

164. Staring M, Klein S, Pluim JPW. A rigidity penalty term for nonrigid registration. Med Phys. 2007;34(11):4098-4108. doi:10.1118/1.2776236

165. Weistrand O, Svensson S. The ANACONDA algorithm for deformable image registration in radiotherapy. Med Phys. 2014;42(1):40-53. doi:10.1118/1.4894702

166. Klein S, Staring M, Pluim JPW. Evaluation of optimization methods for nonrigid medical image registration using mutual information and B-splines. IEEE Trans Image Process. 2007;16(12):2879-2890. doi:10.1109/ TIP.2007.909412

167. Yu G, Liang Y, Yang G, et al. Accelerated gradient-based free form deformable registration for online adaptive radiotherapy. Phys Med Biol. 2015;60(7):2765-2783. doi:10.1088/ 0031-9155/60/7/2765

168. García-Mollá R, Marco-Blancas N de, Bonaque J, Vidueira L, López-Tarjuelo J, Perez-Calatayud J. Validation of a deformable image registration produced by a commercial treatment planning system in head and neck. Phys Medica. 2015;31(3):219-223. doi:10.1016/j.ejmp.2015.01.007

169. Pluim, JP AMJ and VM. Mutual-Information-Based Registration of Medical Images: A Survey. IEEE Trans Med Imaging. 2003;22(8):986-1004. doi:10.1109/ TMI.2003.815867

170. Piper JW, Richmond JH, Nelson AS. VoxAlign Deformation Engine ${ }^{\circledR}$ Deformable Algorithms. 2018. www.mimsoftware. com.

171. Castadot P, Lee JA, Parraga A, Geets X, Macq B, Grégoire V. Comparison of 12 deformable registration strategies in adaptive radiation therapy for the treatment of head and neck tumors. Radiother Oncol. 2008;89(1):1-12. doi:10.1016/j. radonc.2008.04.010

172. JP T. Image matching as a diffusion process: an analogy with Maxwell's demons. Med Image Anal. 1998;2(3):243260. doi:10.1016/S1361-8415(98)80022-4

173. Singhrao K, Kirby N, Pouliot J. A three-dimensional headand-neck phantom for validation of multimodality deformable image registration for adaptive radiotherapy. Med Phys. 2014;41(12):121709-1-121709-7. doi:10.1118/1.4901523

174. Shusharina N, Sharp G. Analytic regularization for landmarkbased image registration. Phys Med Biol. 2012;57(6):14771498. doi:10.1088/0031-9155/57/6/1477

175. Broggi S, Scalco E, Belli ML, et al. A Comparative Evaluation of 3 Different Free-Form Deformable Image Registration and Contour Propagation Methods for Head and Neck MRI: The Case of Parotid Changes During Radiotherapy. Technol Cancer Res Treat. 2017;16(3):373-381. doi:10.1177/ 1533034617691408

176. Al-Mayah A, Moseley J, Hunter S, et al. Biomechanicalbased image registration for head and neck radiation treatment. Phys Med Biol. 2010;55(21):6491-6500. doi:10.1088/0031-9155/55/21/010

177. Kim J, Saitou K, Matuszak MM, Balter JM. A finite element head an neck model as a supportive tool for deformable image registration. Int J Comput Assit Radiol
Surg. 2016;11(7):1311-1317. doi:10.1088/00319155/58/18/6481

178. Al-Mayah A, Moseley J, Brock KK. Contact surface and material nonlinearity modeling of human lungs. Phys Med Biol. 2008;53(1):305-317. doi:10.1088/0031-9155/53/1/022

179. Werner R, Ehrhardt J, Schmidt R, Handels H. Patientspecific finite element modeling of respiratory lung motion using 4D CT image data. Med Phys. 2009;36(5):15001511. doi:10.1118/1.3101820

180. Eom J, Xu XG, De S, Shi C. Predictive modeling of lung motion over the entire respiratory cycle using measured pressure-volume data, 4DCT images, and finiteelement analysis. Med Phys. 2010;37(8):4389-4400. doi:10.1118/1.3455276

181. Manescu P, Ladjal H, Azencot J, Beuve M, Testa E, Shariat B. Four-dimensional radiotherapeutic dose calculation using biomechanical respiratory motion description. Int J Comput Assist Radiol Surg. 2014;9(3):449-457. doi:10.1007/s11548-013-0935-2

182. Al-mayah A, Moseley J, Velec M, Brock K. Towards efficient biomechanical based DIR lung for IGRT. Phys Med Biol. 2012;56(15):4701-4713. doi:10.1088/00319155/56/15/005

183. Han L, Hipwell JH, Tanner C, et al. Development of patient-specific biomechanical models for predicting large breast deformation. Phys Med Biol. 2012;57(2):455-472. doi:10.1088/0031-9155/57/2/455

184. Hensel JM, Ménard C, Chung PWM, et al. Development of Multiorgan Finite Element-Based Prostate Deformation Model Enabling Registration of Endorectal Coil Magnetic Resonance Imaging for Radiotherapy Planning. Int J Radiat Oncol Biol Phys. 2007;68(5):1522-1528. doi:10.1016/j. ijrobp.2007.04.004

185. Zhong H, Wen N, Gordon JJ, Elshaikh MA, Movsas B, Chetty IJ. An adaptive MR-CT registration method for MRI-guided prostate cancer radiotherapy. Phys Med Biol. 2015;60(7):2837-2851. doi:10.1088/00319155/60/7/2837

186. Bharatha A, Hirose M, Hata N, et al. Evaluation of threedimensional finite element-based deformable registration of pre- and intraoperative prostate imaging. Med Phys. 2001;28(12):2551-2560. doi:10.1118/1.1414009

187. Brock KK, Sharpe MB, Dawson LA, Kim SM, Jaffray DA. Accuracy of finite element model-based multi-organ deformable image registration. In: Medical Physics. Vol 32. ; 2005:1647-1659. doi:10.1118/1.1915012

188. Velec M, Moseley JL, Svensson S, et al. Evaluation of Biomechanical Deformable Image Registration (DIR) in a Commercial Radiation Therapy Planning System. Int J Radiat Oncol. 2015;93(3):S215-S216. doi:10.1016/j.ijrobp.2015.07.519

189. Hoffmann C, Krause S, Stoiber EM, et al. Accuracy quantification of a deformable image registration tool applied in a clinical setting. J Appl Clin Med Phys. 2014;15(1):4564. doi:10.1120/JACMP.V15I1.4564

190. Pukala J, Johnson PB, Shah AP, et al. Benchmarking of five commercial deformable image registration algorithms for head and neck patients. J Appl Clin Med Phys. 2016;17(3):5735. doi:10.1120/JACMP.V1713.5735

191. Mencarelli A, Van Kranen SR, Hamming-Vrieze O, et al. Deformable image registration for adaptive radiation therapy of head and neck cancer: Accuracy and precision in the 
presence of tumor changes. Int J Radiat Oncol Biol Phys. 2014;90(3):680-687. doi:10.1016/j.jirobp.2014.06.045

192. Hou J, Guerrero M, Chen W, D'Souza WD. Deformable planning CT to cone-beam CT image registration in head-and-neck cancer. Med Phys. 2011;38(4):2088. doi:10.1118/1.3554647

193. Robertson S, Weiss E, Hugo GD. Deformable mesh registration for the validation of automatic target localization algorithms. Med Phys. 2013;40(7):071721. doi:10.1118/1.4811105

194. Thor M, Andersen ES, Petersen JBB, et al. Evaluation of an application for intensity-based deformable image registration and dose accumulation in radiotherapy. Acta Oncol (Madr). 2014;53(10):1329-1336. doi:10.3109/0284 186X.2014.928742

195. Wang H, Dong L, Lii MF, et al. Implementation and validation of a three-dimensional deformable registration algorithm for targeted prostate cancer radiotherapy. Int J Radiat Oncol Biol Phys. 2005;61(3):725-735. doi:10.1016/j.ijrobp.2004.07.677

196. Sarrut D, Boldea V, Miguet S, Ginestet C. Simulation of four-dimensional CT images from deformable registration between inhale and exhale breath-hold CT scans. Med Phys. 2006;33(3):605-617. doi:10.1118/1.2161409

197. Wognum S, Heethuis SE, Rosario T, Hoogeman MS, Bel A. Validation of deformable image registration algorithms on CT images of ex vivo porcine bladders with fiducial markers. Med Phys. 2014;41(7):071916. doi:10.1118/1.4883839

198. Jamema S V., Phurailatpam R, Paul SN, Joshi K, Deshpande DD. Commissioning and validation of commercial deformable image registration software for adaptive contouring. Phys Medica. 2018. doi:10.1016/j.ejmp.2018.01.013

199. Vickress J, Battista J, Barnett R, Yartsev S. Representing the dosimetric impact of deformable image registration errors. Phys Med Biol. 2017;62(17):N391-N403. doi:10.1088/1361-6560/aa8133

200. Bender ET, Tomé WA. The utilization of consistency metrics for error analysis in deformable image registration. Phys Med Biol. 2009;54(18):5561-5577. doi:10.1088/00319155/54/18/014

201. Kirby N, Chuang C, Ueda U, Pouliot J. The need for application-based adaptation of deformable image registration. Med Phys. 2012;40(1):011702. doi:10.1118/1.4769114

202. Kashani R, Hub M, Kessler ML, Balter JM. Technical note: A physical phantom for assessment of accuracy of deformable alignment algorithms. Med Phys. 2007;34(7):2785. doi:10.1118/1.2739812

203. Yeo UJ, Taylor ML, Supple JR, et al. Is it sensible to "deform" dose? 3D experimental validation of dose-warping. Med Phys. 2012;39(8):5065-5072. doi:10.1118/1.4736534

204. Yeo UJ, Taylor ML, Dunn L, Kron T, Smith RL, Franich RD. A novel methodology for 3D deformable dosimetry. Med Phys. 2012;39(4):2203-2213. doi:10.1118/1.3694107

205. Yeo UJ, Supple JR, Taylor ML, Smith R, Kron T, Franich RD. Performance of 12 DIR algorithms in low-contrast regions for mass and density conserving deformation. Med Phys. 2013;40(10):101701. doi:10.1118/1.4819945

206. Moteabbed M, Sharp GC, Wang Y, Trofimov A, Efstathiou $\mathrm{JA}$, Lu H-M. Validation of a deformable image registration technique for cone beam CT-based dose verification. Med Phys. 2014;42(1):196-205. doi:10.1118/1.4903292

207. Varadhan R, Karangelis G, Krishnan K, et al. A framework for deformable image registration validation and clinical applications. J Appl Clin Med Phys. 2013;14(1):4066.

208. Niu CJ, Foltz WD, Velec M, Moseley JL, Al-Mayah A, Brock KK. A novel technique to enable experimental validation of deformable dose accumulation. Med Phys. 2012;39(2):765-776. doi:10.1118/1.3676185

209. Hub M, Thieke C, Kessler ML, Karger CP. A stochastic approach to estimate the uncertainty of dose mapping caused by uncertainties in b-spline registration. Med Phys. 2012;39(4):2186-2192. doi:10.1118/1.3697524

210. Wang H, Dong L, O'Daniel J, et al. Validation of an accelerated 'demons' algorithm for deformable image registration in radiation therapy. Phys Med Biol. 2005;50(12):2887-2905. doi:10.1088/0031-9155/50/12/011

211. Zhong H, Kim J, Chetty IJ. Analysis of deformable image registration accuracy using computational modeling. Med Phys. 2010;37(3):970-979. doi:10.1118/1.3302141

212. Nie K, Chuang C, Kirby N, Braunstein S, Pouliot J. Sitespecific deformable imaging registration algorithm selection using patient-based simulated deformations. Med Phys. 2013;40(4):041911. doi:10.1118/1.4793723

213. Saleh-Sayah NK, Weiss E, Salguero FJ, Siebers J V. A distance to dose difference tool for estimating the required spatial accuracy of a displacement vector field. Med Phys. 2011;38(5):2318-2323. doi:10.1118/1.3572228

214. Zhong H, Siebers J V. Monte Carlo dose mapping on deforming anatomy. Phys Med Biol. 2009;54(19):5815-5830. doi:10.1088/0031-9155/54/19/010

215. Murphy MJ, Salguero FJ, Siebers J V., Staub D, Vaman C. A method to estimate the effect of deformable image registration uncertainties on daily dose mapping. Med Phys. 2012;39(2):573-580. doi:10.1118/1.3673772

216. Latifi K, Caudell J, Zhang G, Hunt D, Moros EG, Feygelman $V$. Practical quantification of image registration accuracy following the AAPM TG-132 report framework. J Appl Clin Med Phys. 2018;19(4):125-133. doi:10.1002/acm2.12348

217. Guy CL, Weiss E, Che S, Jan N, Zhao S, Rosu-Bubulac M. Evaluation of Image Registration Accuracy for Tumor and Organs at Risk in the Thorax for Compliance With TG 132 Recommendations. Adv Radiat Oncol. 2019;4(1):177-185. doi:10.1016/j.adro.2018.08.023

218. IAEA-TECDOC-1685/S. Aplicación Del Método de La Matriz de Riesgo a La Radioterapia. Vol 4131. (IAEA, ed.).; 2012.

219. Guía para la aplicación de la metodología de matrices de riesgo en radioterapia externa. 2017.

220. Yan D, Wong J, Vicini F, et al. Adaptive modification of treatment planning to minimize the deleterious effects of treatment setup errors. Int J Radiat Oncol Biol Phys. 1997;38(1):197-206. doi:10.1016/S0360-3016(97)002290

221. Brock KK. Adaptive Radiotherapy: Moving Into the Future. Semin Radiat Oncol. 2019;29(3):181-184. doi:10.1016/j. semradonc.2019.02.011

222. Jaffray DA, Lindsay PE, Brock KK, Deasy JO, Tomé WA. Accurate Accumulation of Dose for Improved Understanding of Radiation Effects in Normal Tissue. Int J Radiat Oncol 
Biol Phys. 2010;76(3 SUPPL.):135-139. doi:10.1016/j. ijrobp.2009.06.093

223. Keall P, Poulsen P, Booth JT. See, Think, and Act: Real-Time Adaptive Radiotherapy. Semin RadiatOncol.2019;29(3):228235. doi:10.1016/j.semradonc.2019.02.005

224. Men K, Zhang T, Chen X, et al. Fully automatic and robust segmentation of the clinical target volume for radiotherapy of breast cancer using big data and deep learning. Phys Medica. 2018;50:13-19. doi:10.1016/j.ejmp.2018.05.006

225. Kisling K, Zhang L, Simonds $\mathrm{H}$, et al. Fully Automatic Treatment Planning for External-Beam Radiation Therapy of Locally Advanced Cervical Cancer: A Tool for LowResource Clinics. J Glob Oncol. 2019;5:1-9. doi:10.1200/ jgo.18.00107

226. Liang S, Tang F, Huang X, et al. Deep-learning-based detection and segmentation of organs at risk in nasopharyngeal carcinoma computed tomographic images for radiotherapy planning. Eur Radiol. 2019;29(4):1961-1967. doi:10.1007/ s00330-018-5748-9

227. Zhu W, Huang Y, Zeng L, et al. AnatomyNet: Deep learning for fast and fully automated whole-volume segmentation of head and neck anatomy. Med Phys. 2019;46(2):576-589. doi:10.1002/mp.13300

228. Zhu X, Ge Y, Li T, Thongphiew D, Yin FF, Wu QJ. A planning quality evaluation tool for prostate adaptive IMRT based on machine learning. Med Phys. 2011;38(2):719-726. doi:10.1118/1.3539749

229. Guidi G, Maffei N, Meduri B, et al. A machine learning tool for re-planning and adaptive RT: A multicenter cohort investigation. Phys Medica. 2016;32(12):1659-1666. doi:10.1016/j.ejmp.2016.10.005

230. Guidi G, Maffei N, Vecchi C, et al. A support vector machine tool for adaptive tomotherapy treatments: Prediction of head and neck patients criticalities. Phys Medica. 2015;31(5):442-451. doi:10.1016/j.ejmp.2015.04.009

231. Meyer P, Noblet V, Mazzara C, Lallement A. Survey on deep learning for radiotherapy. Comput Biol Med. 2018;98:126146. doi:10.1016/j.compbiomed.2018.05.018

232. Tseng H-H, Luo Y, Ten Haken RK, El Naqa I. The Role of Machine Learning in Knowledge-Based Response-Adapted Radiotherapy. Front Oncol. 2018;8:1-22. doi:10.3389/ fonc.2018.00266

233. Giraud P, Giraud P, Gasnier A, et al. Radiomics and machine learning for radiotherapy in head and neck cancers. Front Oncol. 2019;9:1-13. doi:10.3389/fonc.2019.00174

234. Elmahdy MS, Jagt T, Zinkstok RT, et al. Robust contour propagation using deep learning and image registration for online adaptive proton therapy of prostate cancer. Med Phys. 2019;46(8):3329-3343. doi:10.1002/mp.13620 


\section{(C) HyperArc"}

Aproveche toda su capacidad para administrar tratamientos de SRS de alta precisión

La tecnología de radioterapia de alta definición HyperArc ${ }^{\mathrm{TM}}$ se ha diseñado para simplificar los tratamientos más complejos, como los tratamientos de SRS no coplanares. Utiliza funciones de última generación que le permitirán tratar varias metástasis simultáneamente, así como mejorar su capacidad para tratar a más pacientes, reducir la duración de los tratamientos, aumentar el rendimiento y maximizar la eficacia.

Más información: Varian.com/HyperArc

Información de seguridad: La radiación puede provocar efectos secundarios y no ser adecuada para todos los tipos de cáncer.

(c) 2018 Varian Medical Systems, Inc. Varian y Varian Medical Systems son marcas comerciales registradas e HyperArc es una marca comercial de Varian Medical Systems, Inc. 